\title{
Physiology and Evolution of Voltage-Gated Calcium Channels in Early Diverging Animal Phyla: Cnidaria, Placozoa, Porifera and Ctenophora
}

\author{
Adriano Senatore *, Hamad Raiss and Phuong Le \\ Department of Biology, University of Toronto Mississauga, Mississauga, ON, Canada
}

\section{OPEN ACCESS}

Edited by:

Christoph Fahlke

Forschungszentrum Jülich, Germany

Reviewed by:

Maria Isabel Bahamonde Santos, Institute of Traumatology Barcelona,

Spain

Ute Ingrid Scholl,

University of Düsseldorf, Germany

Alan Neely,

Valparaiso University, Chile

*Correspondence:

Adriano Senatore

adriano.senatore@utoronto.ca

Specialty section:

This article was submitted to Membrane Physiology and Membrane

Biophysics,

a section of the journa

Frontiers in Physiology

Received: 29 August 2016 Accepted: 07 October 2016 Published: 04 November 2016

Citation:

Senatore A, Raiss H and Le P (2016)

Physiology and Evolution of Voltage-Gated Calcium Channels in Early Diverging Animal Phyla: Cnidaria Placozoa, Porifera and Ctenophora.

Front. Physiol. 7:481

doi: 10.3389/fphys.2016.00481
Voltage-gated calcium $\left(\mathrm{Ca}_{\mathrm{v}}\right)$ channels serve dual roles in the cell, where they can both depolarize the membrane potential for electrical excitability, and activate transient cytoplasmic $\mathrm{Ca}^{2+}$ signals. In animals, $\mathrm{Ca}_{v}$ channels play crucial roles including driving muscle contraction (excitation-contraction coupling), gene expression (excitation-transcription coupling), pre-synaptic and neuroendocrine exocytosis (excitation-secretion coupling), regulation of flagellar/ciliary beating, and regulation of cellular excitability, either directly or through modulation of other $\mathrm{Ca}^{2+}$-sensitive ion channels. In recent years, genome sequencing has provided significant insights into the molecular evolution of $\mathrm{Ca}_{v}$ channels. Furthermore, expanded gene datasets have permitted improved inference of the species phylogeny at the base of Metazoa, providing clearer insights into the evolution of complex animal traits which involve $\mathrm{Ca}_{v}$ channels, including the nervous system. For the various types of metazoan $\mathrm{Ca}_{v}$ channels, key properties that determine their cellular contribution include: Ion selectivity, pore gating, and, importantly, cytoplasmic protein-protein interactions that direct sub-cellular localization and functional complexing. It is unclear when these defining features, many of which are essential for nervous system function, evolved. In this review, we highlight some experimental observations that implicate $\mathrm{Ca}_{v}$ channels in the physiology and behavior of the most early-diverging animals from the phyla Cnidaria, Placozoa, Porifera, and Ctenophora. Given our limited understanding of the molecular biology of $\mathrm{Ca}_{\mathrm{v}}$ channels in these basal animal lineages, we infer insights from better-studied vertebrate and invertebrate animals. We also highlight some apparently conserved cellular functions of $\mathrm{Ca}_{v}$ channels, which might have emerged very early on during metazoan evolution, or perhaps predated it.

Keywords: calcium channel evolution, pre-synaptic exocytosis, excitation-contracting coupling, regulation of ciliary beating, synaptic scaffolding, early-diverging animals, evolution of the nervous system, synapse evolution 


\section{INTRODUCTION}

The coupling of fast electrical impulses, driven by voltagegated potassium $\left(\mathrm{K}_{\mathrm{v}}\right)$ and sodium $\left(\mathrm{Na}_{\mathrm{v}}\right)$ channels, with calciumdependent synaptic signaling, allows the nervous system to coordinate cellular activities rapidly and over long distances. In the pre-synaptic terminal of neurons, electrical impulses trigger secretion of neurotransmitters via the action of voltagegated $\mathrm{Ca}^{2+}\left(\mathrm{Ca}_{\mathrm{v}}\right)$ channels, positioned within nanometers of the $\mathrm{Ca}^{2+}$-sensitive exocytotic machinery. This proximity serves to overcome the strong sequestration and extrusion of $\mathrm{Ca}^{2+}$ from the cytosol in response to the ion's intracellular toxicity (Clapham, 2007; Stanley, 2016). The $\mathrm{Ca}^{2+}$ ion distinguishes itself from the more abundant $\mathrm{K}^{+}$and $\mathrm{Na}^{+}$by its ability to strongly bind oxygen-bearing proteins, altering their conformation. $\mathrm{Ca}_{\mathrm{V}}$ channels are thus able to convert electrical signals carried by $\mathrm{K}_{\mathrm{v}}$ and $\mathrm{Na}_{\mathrm{v}}$ channels into cytoplasmic $\mathrm{Ca}^{2+}$ signals, which can be "local", situated in close proximity to the channel pore, or "global," relayed by soluble $\mathrm{Ca}^{2+}$-activated second messengers such as calmodulin (Ikeda, 2001; Clapham, 2007). Local processes controlled by $\mathrm{Ca}_{\mathrm{v}}$ channels and directly by $\mathrm{Ca}^{2+}$ include exocytosis, modulation/activation of other ion channels [e.g., ryanodine receptors (Lanner et al., 2010), BK and SK potassium channels (Vergara et al., 1998; Stocker, 2004), chloride channels (Berg et al., 2012)], regulation of ciliary/flagellar beating (Tamm, 1994, 2014a; Fujiu et al., 2009), and contraction of various muscle cell types (Bers, 2002). Global effects mediated by $\mathrm{Ca}_{\mathrm{v}}$ channels include changes in gene expression associated with learning and memory (Dolmetsch, 2003), control of cell proliferation (Lory et al., 2006; Taylor et al., 2008; Monteith et al., 2012; Borowiec et al., 2014), and control of neurite outgrowth (Lory et al., 2006).

Extensive research has been carried out to understand $\mathrm{Ca}_{\mathrm{v}}$ channel physiology and pathology (Perez-Reyes, 2003; Catterall, 2011; Dolphin, 2013; Simms and Zamponi, 2014), relying largely on genetic association studies in human disease and select experimental model species including mouse, rat, Drosophila, C.elegans, and a few others. Beyond vertebrate and invertebrate animal model systems, however, we have a limited understanding of the roles that specific $\mathrm{Ca}_{\mathrm{v}}$ channels play, especially in the most early diverging lineages. Although numerous endogenous voltage-gated calcium channel currents have been recorded from tissue/cellular preparations derived from these basal animals, little is known about the underlying molecular biology and its homology to better understood systems. Below, we review what is known about voltagegated calcium channel physiology in the basal animal phyla of Cnidaria, Placozoa, Porifera, and Ctenophora, in light of a clearer genomic identity of their $\mathrm{Ca}_{\mathrm{v}}$ channels. We also attempt to link experimental observations of voltage-gated $\mathrm{Ca}^{2+}$ channel activity and localization in these animals with inferred distinguishing features of the different $\mathrm{Ca}_{\mathrm{v}}$ channel types as defined in wellstudied animal systems. By extension, we discuss seemingly conserved aspects of $\mathrm{Ca}_{\mathrm{v}}$ channel function that might have emerged very early on during evolution of the nervous system, or perhaps predated it.

\section{PHYLOGENETIC RELATIONSHIPS OF EARLY-DIVERGING ANIMALS}

Comparative physiology of metazoan $\mathrm{Ca}_{\mathrm{v}}$ channels requires a clearly-resolved species phylogeny, which despite an emerging consensus, is still a subject of debate. Metazoans are divided into four major groups based on body symmetry (Figure 1): (1) Animals with bilateral body symmetry (bilaterians), proposed to make up over 99\% of all animal species (Finnerty et al., 2004; Ryan and Chiodin, 2015), further subdivided into Deuterostomia (e.g., phyla Chordata, Hemichordata, and Echinodermata) and Protostomia (e.g., Arthropoda, Nematoda, Mollusca, and Annelida) (Wray, 2015); (2) Animals with radial body symmetry, from the phylum Cnidaria (e.g., jellyfish, corals, sea anemones, and hydra); (3) Animals that lack body symmetry, from the phyla Porifera (sponges) and Placozoa (Trichoplax sp.); and (4) Animals with bi-radial body symmetry, from the phylum Ctenophora (i.e., comb-jellies), which have a combination of bilateral and radial symmetry (Tamm, 2014a).

Until relatively recently, Porifera were broadly thought to sit at the base of Metazoa, due to their morphological simplicity, lack of nervous systems and musculature, and their bearing choanocytes, flagellated cells with a striking resemblance to single-celled choanoflagellates (Kent, 1880; Leadbeater and Kelly, 2001; King, 2004; King et al., 2008). Placozoans, amoeba-like benthic sea creatures (Eitel et al., 2013) which like sponges lack body symmetry, neurons, synapses and muscle, were also ascribed to this basal position (Schulze, 1892; Schierwater, 2005; Schierwater et al., 2009). A phylogenetic analysis of mitochondrial genomes

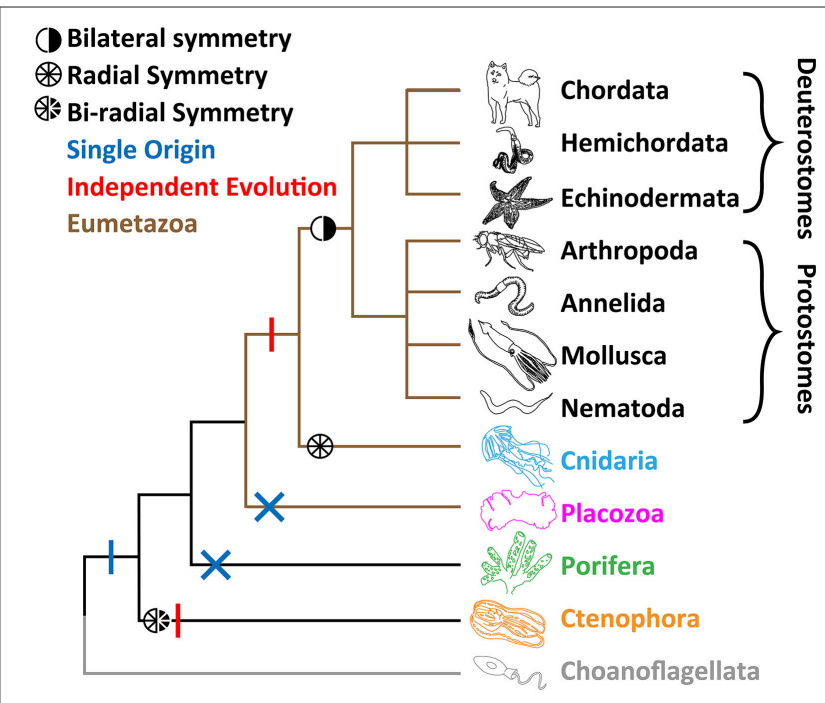

FIGURE 1 | Leading phylogeny of early-diverging animal phyla. The two alternate hypotheses for nervous system are depicted. The single origin hypothesis involves emergence at the stem of Metazoa (blue vertical bar), and losses in both Porifera (sponges) and Placozoa (Trichoplax; blue crosses), whereas the independent origins hypotheses involves separate emergence in Ctenophora (comb jellies) vs. Cnidaria (jellyfish, sea anemones, corals) and Bilateria (animals with bilateral symmetry; red vertical bars). 
supported Trichoplax as the basal metazoan (Dellaporta et al., 2006), however, subsequent expansive phylogenetic efforts, using nuclear encoded genes in the sequenced genomes of both Trichoplax and the sponge Amphimedon queenslandica, pointed to Porifera as the sister group to all animals, and Placozoa as a sister group to Cnidaria and Bilateria, forming the clade Eumetazoa or "true" animals (Srivastava et al., 2008, 2010) (Figure 1). The apparent resolution was not long lasting however, beginning in 2008 with a large-scale phylogenetic analysis, using expansive expressed sequence tag (EST) data, suggesting ctenophores are the most early-diverging animals (Dunn et al., 2008). This notion incited a debate about the origin of the nervous system (Marlow and Arendt, 2014; Halanych, 2015; Jékely et al., 2015; Ryan and Chiodin, 2015; Moroz and Kohn, 2016). Under the "ctenophore first" phylogeny, the absence of nervous systems in Porifera and Placozoa would suggest that the last common ancestor of all animals had a nervous system, and that these two phyla lost it. Alternatively, and more controversially, ctenophores independently evolved synapses and the nervous system (Figure 1). Instead, if sponges are the basal extant metazoan, the nervous system might have evolved only once, and was lost in placozoans. More recently, the genomes of two ctenophore species, Mnemiopsis leidyi and Pleurobranchia bachia, were published, both providing phylogenetic support for ctenophores as the most-early diverging group (Ryan et al., 2013; Moroz et al., 2014). These findings were corroborated in an expanded effort, where the authors sought to curtail potential systematic errors in phylogenetic inference (Whelan et al., 2015). However, an alternate analysis suggests that errors remain, and that sponges should reclaim the esteemed basal position (Pisani et al., 2015). Clearly, more work needs to be done to resolve the issue. However, it can be said with more and more certainty that either Ctenophora or Porifera are the most early-diverging extant animals, and that ctenophores possess the most divergent nervous systems in the animal Kingdom.

\section{CAv CHANNEL STRUCTURE AND MOLECULAR PHYLOGENY}

Our foray into understanding $\mathrm{Ca}_{\mathrm{v}}$ channel molecular identity, structure and function began with intracellular voltageclamp recording of various vertebrate and invertebrate tissue preparations, providing distinctions in observed $\mathrm{Ca}^{2+}$ currents such as voltages of activation, ion selectivity, and kinetics for activation and inactivation. One major distinction is the presence of separate low voltage activated (LVA) and high voltage activated (HVA) $\mathrm{Ca}^{2+}$ currents, with major implications for function since LVA channels are activated below action potential threshold, and hence serve to regulate excitability, while HVA channels are activated after action potential initiation, and hence serve as major effectors for transient $\mathrm{Ca}^{2+}$ signaling (Hagiwara et al., 1975; Carbone and Lux, 1984; Fedulova et al., 1985). Pharmacology with selective blockers, capable of distinguishing between different $\mathrm{Ca}^{2+}$ currents in recorded preparations, provided further evidence for the existence of multiple $\mathrm{Ca}_{\mathrm{v}}$ channel types (Catterall et al., 2005; Dolphin, 2006). Ultimately, biochemical protein isolation, protein and gene sequencing, and phylogenetics revealed the existence of three distinct subtypes of $\mathrm{Ca}_{\mathrm{v}}$ channels in animals (Ertel et al., 2000): $\mathrm{Ca}_{\mathrm{v}} 1$ and $\mathrm{Ca}_{\mathrm{v}} 2$, which conduct $\mathrm{HVA} \mathrm{Ca}{ }^{2+}$ currents, and $\mathrm{Ca}_{\mathrm{v}} 3$, which conduct LVA $\mathrm{Ca}^{2+}$ currents. As discussed below, distinct voltage-gated $\mathrm{Ca}^{2+}$ currents have also been recorded in preparations from early diverging animals, however, the specific ion channels involved are largely uncharacterized at the molecular level.

$\mathrm{Ca}_{\mathrm{v}}$ channels belong to a large family of cationic P-loop channels, so named because of their characteristic extracellular pore-loops that project into the narrowest part of the ionconduction pathway to select for either $\mathrm{Na}^{+}, \mathrm{K}^{+}$, or $\mathrm{Ca}^{2+}$ ions (Mackinnon, 1995). The $\mathrm{Ca}_{\mathrm{v}}$ channel structure consists of four homologous repeat domains (domains I to IV, Figure 2), each bearing 6 transmembrane alpha helices dubbed segments 1 to 6 (S1-S6). S1 to S4 helices make up the voltage sensors, with S4 helices bearing positively-charged lysine $(\mathrm{K})$ and/or arginine (R) residues for sensing charge gradients across the membrane (Figure 3A) (Wu et al., 2016). Depolarization causes S4 helices to slide upwards out of the membrane to open the channel pore (Catterall, 2012). The four P-loops of metazoan $\mathrm{Ca}_{\mathrm{v}}$ channels, situated between pore-forming S5 and S6 helices, contain key glutamate (E) or aspartate (D) amino acids with carboxyl oxygen atoms that form high affinity binding sites for $\mathrm{Ca}^{2+}$ ions, in so-called "selectivity filter" motifs, crucial for selectivity of $\mathrm{Ca}^{2+}$ over $\mathrm{Na}^{+}$and $\mathrm{K}^{+}$(Figure 2). Structurally, HVA and LVA channels bear three major differences: (1) $\mathrm{Ca}_{\mathrm{v}} 1$ and $\mathrm{Ca}_{\mathrm{v}} 2$ channel selectivity filters are comprised of four glutamate residues (i.e., selectivity filter motifs of EEEE), whereas $\mathrm{Ca}_{\mathrm{v}} 3$ channel filters are comprised of two glutamates and two aspartates (EEDD) (Figures 2, 3B); (2) the intracellular cytoplasmic linker between Domains $\mathrm{I}$ and II of $\mathrm{Ca}_{\mathrm{v}} 1$ and $\mathrm{Ca}_{\mathrm{v}} 2$ channels bear a rigid alpha helix, termed the alpha-interaction domain (AID), where accessory cytoplasmic subunit $\mathrm{Ca}_{\mathrm{V}} \beta$ binds to and regulates the channels (Figure 2A) (Wu et al., 2016), while in this equivalent position, $\mathrm{Ca}_{\mathrm{v}} 3$ channels bear a conserved helix-loop-helix motif, dubbed the gating brake (Perez-Reyes, 2010), which plays an important role in low voltage gating (Figure 2B); and (3) $\mathrm{Ca}_{\mathrm{v}} 1$ and $\mathrm{Ca}_{\mathrm{v}} 2$ channels bear conserved isoleucine-glutamine (IQ) motifs in their C-termini, absent in $\mathrm{Ca}_{\mathrm{v}} 3$ channels, which mediate physical coupling with the cytoplasmic $\mathrm{Ca}^{2+}$ sensor calmodulin (Figures 2A, 3C). Activation of calmodulin by channel opening and elevated cytoplasmic $\left[\mathrm{Ca}^{2+}\right]$ imposes conformational changes in the channel structure leading to more rapid transition to non-conducting inactivated states, limiting the amount of $\mathrm{Ca}^{2+}$ that enters the cell upon membrane depolarization (Simms and Zamponi, 2014).

Genomics has greatly improved our understanding of $\mathrm{Ca}_{\mathrm{v}}$ channel molecular evolution. In vertebrates, gene duplications expanded the $\mathrm{Ca}_{\mathrm{v}}$ channel repertoire to four $\mathrm{Ca}_{\mathrm{v}} 1$ channels (i.e., $\mathrm{Ca}_{\mathrm{v}} 1.1$ to $\mathrm{Ca}_{\mathrm{v}} 1.4$, collectively dubbed L-type channels), three $\mathrm{Ca}_{\mathrm{v}} 2$ channels $\left(\mathrm{Ca}_{\mathrm{v}} 2.1\right.$ or P-/Q-type, $\mathrm{Ca}_{\mathrm{v}} 2.2$ or $\mathrm{N}$-type, and $\mathrm{Ca}_{\mathrm{v}} 2.3$ or R-type channels) and three $\mathrm{Ca}_{\mathrm{v}} 3$ channels $\left(\mathrm{Ca}_{\mathrm{v}} 3.1\right.$ to $\mathrm{Ca}_{\mathrm{v}} 3.3$ or T-type channels) (Perez-Reyes, 2003; $\mathrm{Yu}$ and Catterall, 2004; Jegla et al., 2009) (Figure 4). $\mathrm{Ca}_{\mathrm{v}}$ channel genes independently expanded in cnidarians, such as the sea anemone Nematostella vectensis, to produce three $\mathrm{Ca}_{\mathrm{v}} 2$ channel genes 


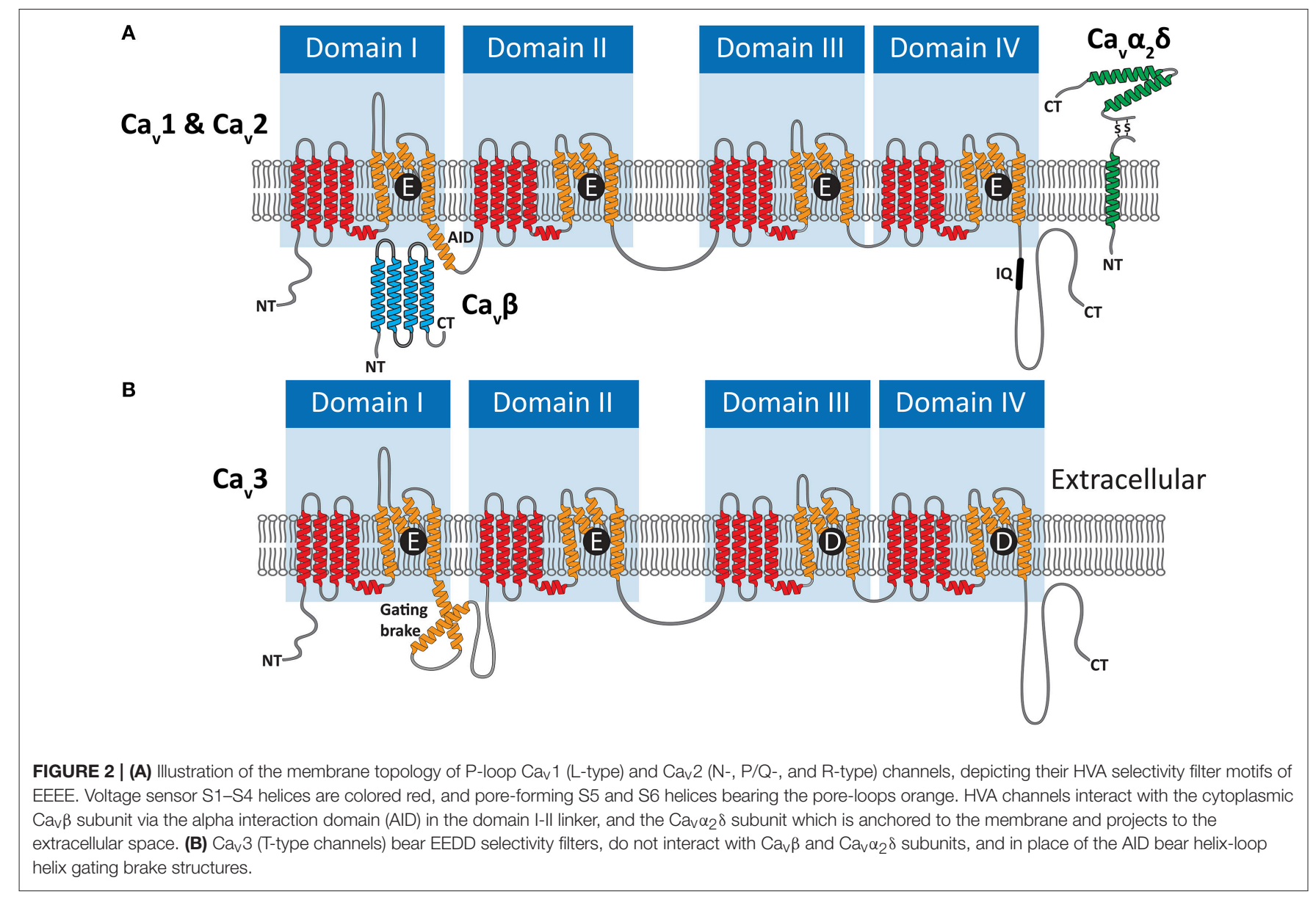

$\left(\mathrm{Ca}_{\mathrm{v}} 2 \mathrm{a}, \mathrm{Ca}_{\mathrm{v}} 2 \mathrm{~b}\right.$, and $\left.\mathrm{Ca}_{\mathrm{v}} 2 \mathrm{c}\right)$, two $\mathrm{Ca}_{\mathrm{v}} 3$ channel genes $\left(\mathrm{Ca}_{\mathrm{v}} 3 \mathrm{a}\right.$ and $\mathrm{Ca}_{\mathrm{v}} 3 \mathrm{~b}$ ), and a single $\mathrm{Ca}_{\mathrm{v}} 1$ channel gene (Moran and Zakon, 2014). Protostome invertebrates, such as arthropods, nematodes, and molluscs, as well as placozoans, all retain single genes for each of the three types of $\mathrm{Ca}_{\mathrm{v}}$ channels (Figures 1, 3). Homologs of $\mathrm{Ca}_{\mathrm{v}}$ channels and their subunits are present in the genomes and transcriptomes of pre-metazoans and early-diverging animals. However, extensive loss of ion channel gene content in these lineages (Liebeskind et al., 2015), combined with an unresolved phylogeny at the base of Metazoa, has made it difficult to define their evolutionary relationships with absolute certainty (Moran and Zakon, 2014). $\mathrm{Ca}_{\mathrm{v}} 3$ channels appear absent in ctenophore and sponge genomes, but are present in choanoflagellates (Fairclough et al., 2013), indicating that they predate animals but were likely lost in Ctenophora and Porifera (Moran and Zakon, 2014). Thus, Trichoplax adhaerens is the most basal extant animal known to possess bona fide homologs for all three types of cnidarian/bilaterian $\mathrm{Ca}_{\mathrm{V}}$ channels types (Senatore et al., 2012) (i.e., $\mathrm{Ca}_{\mathrm{v}} 1-\mathrm{Ca}_{\mathrm{v}} 3$; Figure 4). $\mathrm{Ca}_{\mathrm{v}} 1$ and $\mathrm{Ca}_{\mathrm{v}} 2$ channels have more ambiguous phylogenies. In a recent study, the single $\mathrm{Ca}_{\mathrm{v}}$ channel from sponge $A$. queenslandica was found to form a sister clade with $\mathrm{Ca}_{\mathrm{v}} 1$ and $\mathrm{Ca}_{\mathrm{v}} 2$ channels (hence dubbed $\mathrm{Ca}_{\mathrm{v}} 1 / 2$ ), as did a $\mathrm{Ca}_{\mathrm{v}}$ channel from choanoflagellate Salpingoeca rosetta (Moran and Zakon, 2014). Thus, the authors proposed that $\mathrm{Ca}_{\mathrm{v}} 1$ and $\mathrm{Ca}_{\mathrm{v}} 2$ channels emerged via gene duplication of an ancestral
$\mathrm{Ca}_{\mathrm{v}} 1 / 2$ channel, either early in Metazoa, or just before its emergence. Notably, node support for the phylogenetic position of the Amphimedon $\mathrm{Ca}_{\mathrm{v}}$ channel was low, and in our hands, the channel clusters with $\mathrm{Ca}_{\mathrm{v}} 1$ channels under maximum likelihood inference, albeit with poor bootstrap support (Figure 4). Instead, the single $\mathrm{Ca}_{\mathrm{v}}$ channels from ctenophores M. leidyi and Beroe ovata cluster with $\mathrm{Ca}_{\mathrm{v}} 2$ types (Moran and Zakon, 2014) (Figure 4). Clearly, the phylogeny of $\mathrm{Ca}_{\mathrm{v}}$ channels at the base of Metazoa requires further analysis, perhaps resolvable via inclusion of additional $\mathrm{Ca}_{\mathrm{v}}$ channel protein sequences from early and pre metazoans as they become available, and resolution of the phylogeny of Porifera vs. Ctenophora. With respect to protein sequence, the different $\mathrm{Ca}_{\mathrm{v}}$ channels from the four basal metazoan phyla of Cnidaria, Placozoa, Porifera, and Ctenophora share canonical voltage sensors, appropriate selectivity filters of EEEE (i.e., $\mathrm{Ca}_{\mathrm{v}} 1, \mathrm{Ca}_{\mathrm{v}} 2$, and $\mathrm{Ca}_{\mathrm{v}} 1 / 2$ types) or $\operatorname{EEDD}\left(\mathrm{Ca}_{\mathrm{v}} 3\right.$ type), a gating brake ( $\mathrm{Ca}_{\mathrm{v}} 3$ channels), and $\mathrm{C}$-terminal IQ motifs $\left(\mathrm{Ca}_{\mathrm{v}} 1, \mathrm{Ca}_{\mathrm{v}} 2\right.$, and $\mathrm{Ca}_{\mathrm{v}} 1 / 2$ channels) (Figure 3$)$. Indeed, in light of recent advances in cryo-electron microscopy for rendering $\mathrm{Ca}_{\mathrm{v}}$ channel secondary, tertiary and quaternary structures (Wu et al., 2015, 2016), an interesting prospect is to evaluate the structural homology between distant $\mathrm{Ca}_{\mathrm{v}}$ channels, perhaps shedding additional light on their evolution.

As alluded to above, HVA (but not LVA) channels have a functional dependency on accessory $\mathrm{Ca}_{\mathrm{v}} \beta$, as well as $\mathrm{Ca}_{\mathrm{v}} \alpha_{2} \delta$ 
A

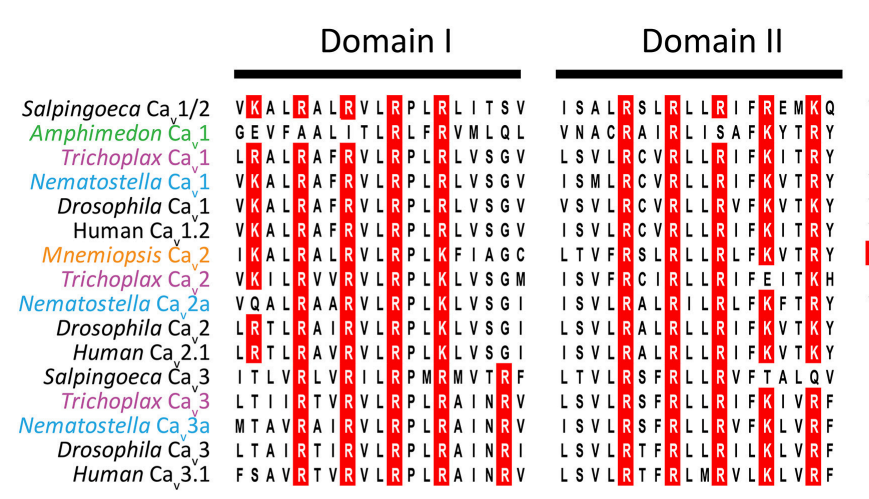

\section{Domain III}

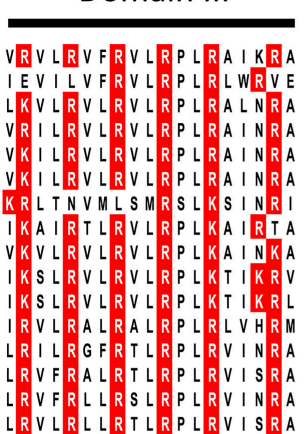

\section{Domain IV}

GVN I GF LRLFRVARLLKL

NS I WRYSQ I ASCLRVLRL

DFSVNFFRLFRAMRLVKL

MFAFGFRLFRALRLVKL

RISITFFRLFRVMRLVKL

FMI SRLVKMFRAARLIKL

TVSISFFRLFRAGRLIKL

PFDPSLFRLFRAARL IKL

FINLSFLRLFRARLIKL

PTVLRVRILRVARVFL

PTIIIRVMRLLRIVRILKL

PTIIIRVMRVLRIARVLKL

PT I IRVMRVLR I ARVLKL
PT I IRR I MRVLLR I ARVLKL
B

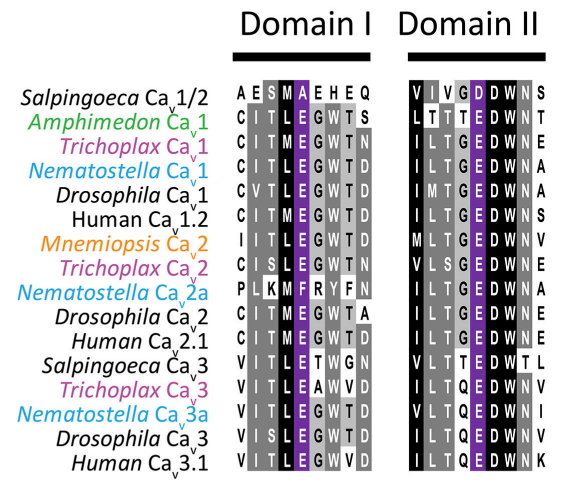

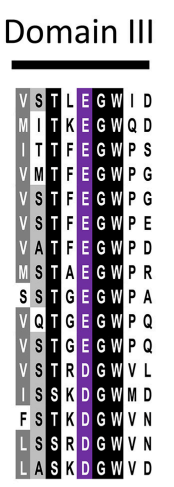

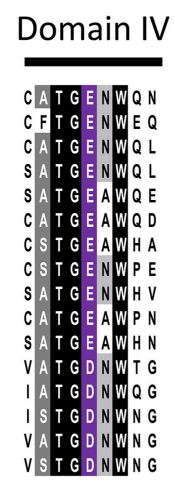

C

Pre-IQ

IQ

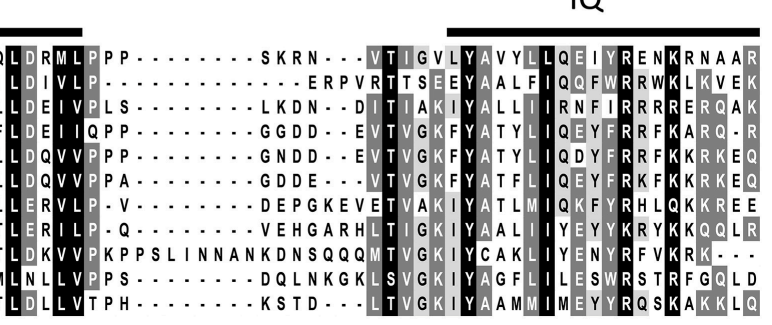

FIGURE 3 | (A) Protein sequence alignment of domain I to IV S4 helices from Cav channel voltage sensors, depicting the strong conservation of positively charged lysine $(K)$ and arginine $(R)$ residues critical for voltage sensitivity. (B) Alignment of selectivity filter motifs and flanking amino acids from various Cav channel proteins, revealing conserved EEEE motifs for Cav1, Cav2, and Cav1/2 channels, and EEDD for Cav3 channels. (C) Protein sequence alignment of C-terminal IQ motifs found in $\mathrm{Ca}_{\mathrm{v}} 1, \mathrm{Ca} 2$, and $\mathrm{Ca}_{\mathrm{v}} 1 / 2$ channel types.

subunits (Curtis and Catterall, 1984; Catterall et al., 2005), which regulate channel membrane expression and biophysical properties (Figure $2 \mathrm{~A}$ ). $\mathrm{Ca}_{\mathrm{v}} \beta$ subunits influence the biophysical properties of $\mathrm{Ca}_{\mathrm{v}} 1$ and $\mathrm{Ca}_{\mathrm{v}} 2$ channels, and bind cytoplasmic AID helices to also increase membrane trafficking through inhibition of proteosomal degradation (Altier et al., 2011) and masking of an endoplasmic reticulum retention signal (Bichet et al., 2000). $\mathrm{Ca}_{\mathrm{v}} \alpha_{2} \delta$ subunits interact with the extracellular surface of the channels, and have more minimal consequences for biophysical properties (Yasuda et al., 2004). Like $\mathrm{Ca}_{\mathrm{v}} \beta$ however, they increase channel membrane expression, and seem to play a role in targeting $\mathrm{Ca}_{\mathrm{v}} 2$ type channels to pre-synaptic terminals (Cantí et al., 2005; Hoppa et al., 2012). Interestingly, whereas the $\mathrm{Ca}_{\mathrm{v}} \alpha_{2} \delta$ subunit was initially thought to be tethered to the extracellular surface of the membrane via a C-terminal transmembrane helix (Figure 2A), recent evidence suggests that instead the subunit is completely extracellular, held in place via a glycophosphatidylinositol anchor (Davies et al., 2010; Kadurin et al., 2012; Wu et al., 2016). Similar to the $\mathrm{Ca}_{\mathrm{v}}$ channel subunits, the accessory subunit genes underwent independent gene duplication events in several animal lineages, including vertebrates which bear four $\mathrm{Ca}_{\mathrm{v}} \beta$ and four $\mathrm{Ca}_{\mathrm{v}} \alpha_{2} \delta$ subunit genes (Buraei and Yang, 2010; Dolphin, 2013). The $\mathrm{Ca}_{\mathrm{v}} \alpha_{2} \delta$ subunit appears absent in the genomes of early diverging sponges, ctenophores and single celled eukaryotes (Moran and Zakon, 2014), thus possibly being of eumetazoan origin, while the $\mathrm{Ca}_{\mathrm{v}} \beta$ subunit has a more ancient ancestry, present in genomes of choanoflagellates (Dawson et al., 2013; Moran and Zakon, 2014).

It is worth noting that some invertebrate $\mathrm{Na}_{\mathrm{v}}$ channels, also of the four-domain P-loop family, are capable of conducting 


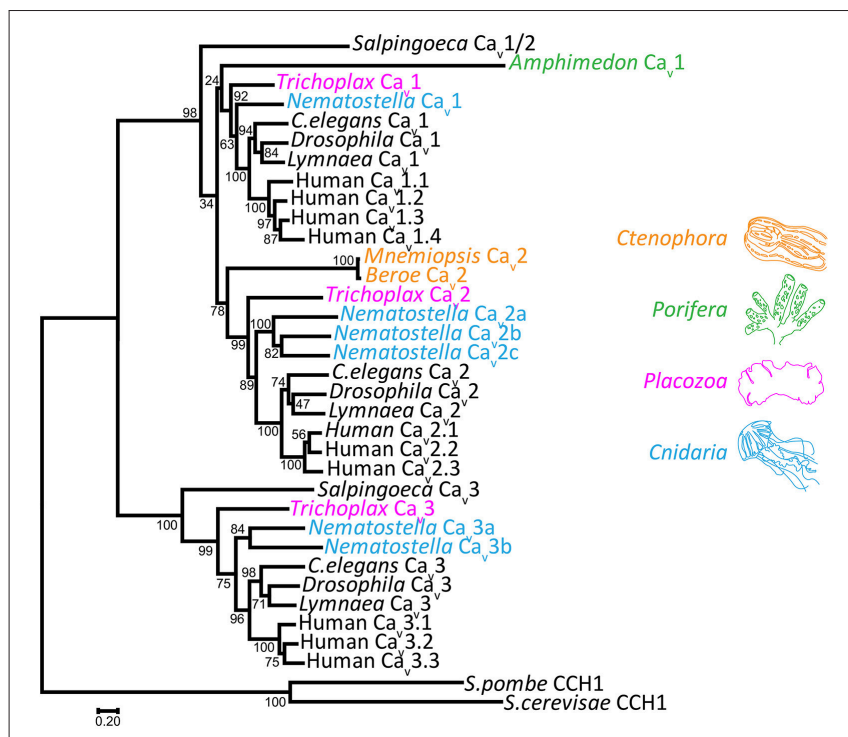

FIGURE 4 | Maximum likelihood protein phylogeny of select $\mathrm{Ca}_{\mathrm{v}}$ channels from animals, rooted with $\mathrm{Ca}_{\mathrm{v}}$ channel homologs from fungi. Inference was achieved using MUSCLE protein alignment with MEGA7, followed by alignment trimming with TrimAL. Evolutionary models for maximum likelihood phylogenetic inference were tested with MEGA7, indicating that the LG matrix with gamma frequencies was the best fit using both corrected Akaike's Information Criterion and Bayesian Information Criterion. Node support values from 500 bootstrap replicates are indicated. GenBank accession numbers: Salpingoeca $\mathrm{Ca}_{\mathrm{v}}$ 1/Cav2: XP_004989719; Amphimedon Cav1/Cav2: XP_003383036; Trichoplax Cav1: XP_002108930; Trichoplax Cav2: XP_002109775; Trichoplax Cav3: KJ466205; C.elegans Cav1 (egl-19): NP_001023079; C.elegans Cav2 (unc-2): NP_001123176; C.elegans Cav3 (cca-1): CCD68017; Drosophila Cav1 (a1-D): AAF53504; Drosophila Cav2 (cacophony): AFH07350; Drosophila Cav3 (Ca-a1T): ABW09342; Lymnaea Cav1: AAO83839; Lymnaea Cav2: AAO83841; Lymnaea Cav3: AAO83843; human Cav1.1: NP_000060.2; human Cav1.2: AAl46847.1; human Cav1.3: NP_001122312.1; human Cav1.4: NP_005174.2; human Cav2.1: O00555.2; human Cav2.2: NP_000709; human Cav2.3: NP_001192222.1; human Cav3.1: NP_061496; human Cav3.2: NP_066921; human Cav3.3: NP_066919; Mnemiopsis Cav2: AEF59085; S.cerevisae CCH1: P50077; S.pombe CCH1: NP_593894.1. Other accession numbers: Nematostella Cav1: JGI-Genome Portal protein ID 88037; Nematostella Cav2a, Cav2b, Cav2c, Cav3a, Cav3b: Transcript sequences from the sequenced transcriptome (Fredman et al., 2013) NVE4667, NVE18768, NVE1263, NVE5017, and NVE7616 respectively. Scale bar represents the number of amino acid substitutions per site along the sequence alignment.

$\mathrm{Ca}^{2+}$-selective currents (Zhou et al., 2004; Zhang et al., 2011; Barzilai et al., 2012; Gosselin-Badaroudine et al., 2016). Two phylogenetically distinct types of $\mathrm{Na}_{\mathrm{V}}$ channels have been identified in animals, $\mathrm{Na}_{\mathrm{v}} 1$ and $\mathrm{Na}_{\mathrm{v}} 2 . \mathrm{Na}_{\mathrm{v}} 2$ type channels are the most ancient, having emerged in single-celled eukaryotes before the divergence of animals and fungi (Cai, 2012). Most metazoans possess $\mathrm{Na}_{\mathrm{v}} 2$ channel genes, however, vertebrates lost this type and only possess $\mathrm{Na}_{\mathrm{v}} 1$ channels. $\mathrm{Na}_{\mathrm{v}} 1$ channels perhaps evolved from an $\mathrm{Na}_{\mathrm{v}} 2$-type channel strictly in bilaterians, and therefore, outside of vertebrates and a few other clades, most bilaterian possess both $\mathrm{Na}_{\mathrm{v}} 1$ and $\mathrm{Na}_{\mathrm{v}} 2$ channels. With respect to cation selectivity, $\mathrm{Na}_{\mathrm{v}} 2$ channels conduct $\mathrm{Ca}^{2+}$-selective currents, bearing selectivity filter motifs of DEEA which resemble glutamate/aspartate rich $\mathrm{Ca}_{\mathrm{v}}$ channel filters of EEEE and EEDD
(Liebeskind et al., 2011; Barzilai et al., 2012). In cnidarians, one $\mathrm{Na}_{\mathrm{v}} 2$ channel gene, $\mathrm{Na}_{\mathrm{v}} 2.5$, evolved high $\mathrm{Na}^{+}$-selectivity via alteration of its selectivity filter motif to DKEA. Here, the positively-charged lysine $(\mathrm{K})$ likely disrupts high affinity binding of $\mathrm{Ca}^{2+}$ (with contributions from other regions of the P-loops) (Barzilai et al., 2012), producing a $\mathrm{Na}^{+}$-selective pore. Instead, $\mathrm{Na}_{\mathrm{v}} 1$ channels independently evolved high $\mathrm{Na}^{+}$selectivity, via a glutamate to lysine conversion in domain III of the selectivity filter (i.e., DEKA). Of the four most early-diverging metazoan phyla, none possess $\mathrm{Na}_{\mathrm{v}} 1$-type channels, cnidarians possess upwards of five $\mathrm{Na}_{\mathrm{v}} 2$ channels (e.g., N. vectensis has four $\mathrm{Ca}^{2+}$ selective DEEA channels, $\mathrm{Na}_{\mathrm{v}} 2.1-\mathrm{Na}_{\mathrm{v}} 2.4$, and one $\mathrm{Na}^{+}$-selective DKEA channel, $\left.\mathrm{Na}_{\mathrm{v}} 2.5\right)$. Ctenophores and Trichoplax each possess two $\mathrm{Ca}^{2+}$-selective DEEA channels $\left(\mathrm{Na}_{\mathrm{v}} 2 \mathrm{a}\right.$ and $\left.\mathrm{Na}_{\mathrm{v}} \mathrm{b}\right)$, and sponges appear to have lost $\mathrm{Na}_{\mathrm{v}} 2$ channels (Liebeskind et al., 2011; Barzilai et al., 2012). Thus, an important caveat is that recorded voltage-gated $\mathrm{Ca}^{2+}$ currents in preparations where ion channel molecular identity is not known, could be attributed to $\mathrm{Na}_{\mathrm{v}} 2$ instead of $\mathrm{Ca}_{\mathrm{v}}$ channels.

\section{CAv CHANNEL PHYSIOLOGY IN BASAL METAZOANS}

\section{Cnidaria}

Cnidaria is an ancient and diverse phylum with animals falling into two major clades, the Anthozoa (e.g., sea anemones, sea pens, and corals) and the Medusozoa (jellyfish and hydra) (Putnam et al., 2007). Common to all cnidarians is a relatively simple nervous system, organized as nets of synaptically connected neurons with minimal condensation into centralized neuronal structures (Katsuki and Greenspan, 2013). This organization is thought to resemble a primitive state, which is also found in ctenophores and contrasts the more centralized structures of bilaterians. The phylogenetic proximity of Cnidaria to Bilateria (Figure 1), and the absence of nervous systems in both placozoans and sponges, suggests that cnidarians and bilaterians share common ancestry for the nervous system. This is certainly apparent in the sequenced genomes and predicted proteomes of various cnidarians (Putnam et al., 2007; Chapman et al., 2010; Shinzato et al., 2011; Baumgarten et al., 2015), where they have more homologs of key bilaterian nervous system genes compared to more basal animals (Moroz and Kohn, 2015, 2016). Interestingly, cnidarian proteomes also have more PDZ proteinprotein interaction motifs compared to pre-metazoans and more early-diverging animals, and less than bilaterian animals which possess more complex nervous systems. This is notable because PDZ motifs play important roles in synaptic protein scaffolding, and their expansion might have contributed to synapse evolution and complexification (Sakarya et al., 2010).

\section{Pre-synaptic Exocytosis}

In the pre-synaptic terminal of bilaterians, $\mathrm{Ca}_{\mathrm{v}} 2$ channels play a dominant role in coupling excitation with fast pre-synaptic exocytosis. $\mathrm{Ca}_{\mathrm{v}} 1$ and/or $\mathrm{Ca}_{\mathrm{v}} 3$ channels provide more peripheral contributions, or contribute to other forms of excitationsecretion coupling such as neuroendocrine secretion $\left(\mathrm{Ca}_{\mathrm{v}} 1\right.$ and $\mathrm{Ca}_{\mathrm{v}} 3$ channels $)$ and low-threshold exocytosis $\left(\mathrm{Ca}_{\mathrm{v}} 3\right.$ channels $)$ 
(Carbone et al., 2006a; Simms and Zamponi, 2014). One requirement for fast synaptic transmission is the proximal coupling of pre-synaptic $\mathrm{Ca}_{\mathrm{v}} 2$ channels with $\mathrm{Ca}^{2+}$-sensitive proteins of the exocytotic machinery (e.g., synaptotagmin, complexin), such that transient "nanodomain" $\mathrm{Ca}^{2+}$ plumes, restricted to roughly 100 nanometer radii from the channel pore, effectively saturate the exocytotic apparatus (Clapham, 2007; Stanley, 2016). Two modes for functional coupling of $\mathrm{Ca}_{\mathrm{v}} 2$ channels with exocytotic proteins appear to exist: (1) In nanodomain coupling, direct, physical interaction of $\mathrm{Ca}_{\mathrm{v}} 2$ channels with proteinaceous elements of docked pre-synaptic vesicles allows single channels to trigger exocytosis of single vesicles (i.e., one-to-one coupling); (2) Instead, microdomain coupling involves a slightly more distal apposition between $\mathrm{Ca}_{\mathrm{v}}$ channels and synaptic vesicles, without necessarily direct physical contact. Here, numerous $\mathrm{Ca}_{\mathrm{v}}$ channel $\mathrm{Ca}^{2+}$ nanodomains sum into larger "microdomains," which trigger exocytosis of numerous docked vesicles (i.e., group-to-group coupling) (Stanley, 2016).

Fast chemical synaptic transmission in cnidarians, as in bilaterians, requires $\mathrm{Ca}^{2+}$ influx through voltage-gated calcium channels (Bullock, 1943; Kerfoot et al., 1985). However, whether cnidarian $\mathrm{Ca}_{\mathrm{v}} 2$ channels similarly act as major drivers of pre-synaptic exocytosis remains to be determined. A recent study of the spatial expression of $\mathrm{Ca}_{\mathrm{v}}$ channel mRNAs in the developing anthozoan sea anemone $N$. vectensis (Moran and Zakon, 2014), revealed that all of its $\mathrm{Ca}_{\mathrm{v}}$ channel genes, including its three $\mathrm{Ca}_{\mathrm{v}} 2$ channels, are expressed in regions that overlap with expressed neurogenic marker genes ELAV and Musashi identified in a separate study (Marlow et al., 2009). However, direct evidence that $\mathrm{Ca}_{\mathrm{v}} 2$ channels are expressed in cnidarian neurons and exhibit pre-synaptic localization has yet to be provided. Indirectly, electrophysiological recordings of motor neurons from the hydrozoan jellyfish Polyorchis penicillatus reveal a prominent $\mathrm{HVA} \mathrm{Ca}^{2+}$ current that resembles $\mathrm{Ca}_{\mathrm{v}} 2$ channels by lacking fast $\mathrm{Ca}^{2+} /$ calmodulin-dependent inactivation (Przysiezniak and Spencer, 1992), a conserved feature of protostome and deuterostome $\mathrm{Ca}_{\mathrm{v}} 1$-type channels (Peterson et al., 1999; Spafford et al., 2006; Taiakina et al., 2013), also evident for the cloned and ectopically expressed $\mathrm{Ca}_{\mathrm{v}} 1$ channel from jellyfish Cyanea capillata (Jeziorski et al., 1998). Interestingly, neuromuscular junction (NMJ) synapses in Polyorchis have properties suggestive of nanodomain (oneto-one) coupling. In vitro voltage-clamp recording across the NMJ revealed that rapid and transient pre-synaptic $\mathrm{Ca}^{2+}$ influx elicits stronger post-synaptic responses than slower, more longlasting $\mathrm{Ca}^{2+}$ influx, despite the former providing less total $\mathrm{Ca}^{2+}$ into the pre-synaptic terminal (Spencer et al., 1989). The increased efficiency for synaptic transmission with faster onset $\mathrm{Ca}^{2+}$ influx suggests that endogenous mechanisms for $\mathrm{Ca}^{2+}$ sequestration and extrusion impose spatial/temporal constraints on the calcium channel's ability to activate the exocytotic machinery. Instead, efficient transmission at this particular synapse requires fast plumes of cytoplasmic $\mathrm{Ca}^{2+}$, consistent with nanodomain coupling. Synapses with microdomain coupling tend to improve their efficacy (i.e., facilitate) with increased presynaptic $\mathrm{Ca}^{2+}$ influx, such as occurs during a burst of action potentials (Stanley, 2016). Such $\mathrm{Ca}^{2+}$-dependent facilitation has been observed in other cnidarian synapses (Roberts and Mackie, 1980), suggesting they are similar to vertebrates in having different synapses with either nanodomain or microdomain coupling, depending on developmental state or physiological requirements (Stanley, 2016).

Given the similar genomic content of pre-and post-synaptic genes between bilaterians and cnidarians, and their shared ancestry of the nervous system, it will be interesting to evaluate the homology in their mechanisms for synaptic transmission at the molecular level. With respect to nanodomain tethering of $\mathrm{Ca}_{\mathrm{v}} 2$ channels, there is at least evidence for homology between protostomes and deuterostomes, which diverged roughly 520 Mya (Blair and Hedges, 2005), around when medusozoans and anthozoans diverged from each other (Putnam et al., 2007). In both Drosophila and mouse, the presynaptic scaffolding protein Rab-3 interacting molecule (RIM) is essential for the appropriate pre-synaptic localization of $\mathrm{Ca}_{\mathrm{v}} 2$ channels, forming part of a molecular bridge between the channels and synaptic vesicles (Han et al., 2011; Kaeser et al., 2011; Graf et al., 2012). The interaction seems to occur via a RIM PDZ motif that binds the $\mathrm{Ca}_{\mathrm{v}} 2$ channel C-terminus; in mouse, targeted deletion of the RIM PDZ disrupts proper channel localization and synaptic transmission, and a direct physical interaction was observed between this motif and the channel C-terminus via yeasttwo hybrid and NMR spectroscopy assays. However, a similar interaction was not observed in the chick synapse using coimmunoprecipitation (Khanna et al., 2006; Wong and Stanley, 2010), and a separate study found that RIM tethering of $\mathrm{Ca}_{\mathrm{v}} 2$ channels requires the $\mathrm{Ca}_{\mathrm{v}} \beta$ subunit to serve as an intermediary between the two proteins (Kiyonaka et al., 2007). Recently, evidence has emerged that $\mathrm{Ca}_{\mathrm{v}} 2$ channel pre-synaptic scaffolding undergoes a developmental switch in Drosophila, where different mRNA splice isoforms of the vesicle priming protein UNC-13 interact with distinct scaffolding proteins for either microdomain tethering in immature synapses (i.e., with Syd-1 and Liprin- $\alpha$ ), or nanodomain tethering in mature synapses (i.e., with Bruchpilot and RIM-associated protein complexes) (Böhme et al., 2016). Thus, although it appears as though RIM plays conserved roles in $\mathrm{Ca}_{\mathrm{v}} 2$ channel tethering in protostome and deuterostome synapses, complex and dynamic processes are likely at play. In accordance, pre-synaptic scaffolding proteins Mint1 and CASK, have been also been found to contribute to proximal coupling of $\mathrm{Ca}_{\mathrm{v}} 2$ channels with the exocytotic machinery in both rodents (Maximov and Bezprozvanny, 2002) and the mollusc snail Lymnaea stagnalis (Spafford et al., 2003). Furthermore, unique specializations appear in distinct lineages, such as vertebrate synaptic protein interaction ("synprint") sites in the II-III linkers of vertebrate $\mathrm{Ca}_{\mathrm{v}} 2.1$ and $\mathrm{Ca}_{\mathrm{v}} 2.2$ channels, which directly interact with vesicular SNARE complex proteins syntaxin-1A/B and SNAP-25 to regulate channel pre-synaptic tethering and gating (Sheng et al., 1994; Rettig et al., 1996).

As noted above, low voltage activated $\mathrm{Ca}_{\mathrm{v}} 3$ type channels are implicated in "low threshold exocytosis" occurring in neuroendocrine cells (Carbone et al., 2006a,b) and neurons capable of graded synaptic transmission (Weiss et al., 2012; Weiss and Zamponi, 2013). Though less well documented than 
spike-dependent transmission (i.e., elicited by action potentials and $\mathrm{Ca}_{\mathrm{v}} 2$ channels), graded transmission plays important roles in certain neurophysiological contexts in both vertebrates and invertebrates. In invertebrates, LVA calcium channels and graded synaptic transmission play major roles in the activity of intrinsically rhythmic neural circuits (i.e., central pattern generators or CPGs), such as the interneuron network that drives heart contraction in the protostome leech (Angstadt and Calabrese, 1991; Lu et al., 1997). In vertebrates, $\mathrm{Ca}_{\mathrm{v}} 3$ channels also contribute to graded synaptic transmission, including in the retina, and between neurons located in the central and peripheral nervous systems (Weiss and Zamponi, 2013). The first detailed description of graded vs. spike-dependent transmission came from leech interneurons of the heart CPG, where classical spikedependent synaptic transmission, driven by an $\mathrm{HVA} \mathrm{Ca}_{\mathrm{V}}$ channel (perhaps $\mathrm{Ca}_{\mathrm{v}} 2$ ), was found to co-exist in the same neurons with graded transmission driven by an LVA $\mathrm{Ca}_{\mathrm{v}}$ channel (perhaps $\mathrm{Ca}_{\mathrm{v}} 3$ ) (Angstadt and Calabrese, 1991; Lu et al., 1997). Here, two alternate modes of cellular excitability, action potentials vs. sub-threshold plateau potentials, were respectively found to elicit strong or graded inhibitory post-synaptic responses between paired CPG neurons. Subsequently, similar bimodal cellular excitability and synaptic transmission was documented in the vertebrate olfactory bulb (Egger et al., 2003).

Interestingly, "bimodal" excitability and graded vs. spikedependent synaptic transmission have also been documented in the neuromuscular junction of medusozoan jellyfish Aglantha digitale. Here, neuromuscular synapses of large axon motor neurons manifest either low-threshold, spike-independent synaptic transmission, which elicit graded contractions of the bell myoepithelium during slow pelagic swimming, or spike-dependent synaptic transmission, triggered by aggressive, predatory tactile cues, which elicit strong contractions of the bell during fast escape swimming (Mackie, 1980; Roberts and Mackie, 1980; Kerfoot et al., 1985; Mackie and Meech, 1985; Meech and Mackie, 1993). During pelagic swimming, spontaneous depolarizing synaptic inputs into motor neurons activate an LVA channel resembling a $\mathrm{Ca}_{\mathrm{v}} 3$ type, generating low threshold $\mathrm{Ca}^{2+}$ spikes with peak depolarization just below action potential threshold (i.e., about -25 millivolts or $\mathrm{mV}$ ). These subthreshold $\mathrm{Ca}^{2+}$ spikes occur as spontaneous bursts at a rate of about 3-4 per second (Meech and Mackie, 1993), and trigger exocytosis and mild graded contractions in myoepithelial striated muscle cells. In the same axons, strong depolarizing sensory inputs generate $\mathrm{Na}^{+}$-dependent action potentials, which trigger all-or-none exocytosis and transmission producing much stronger contraction of the bell myoepithelium for the escape response. Of note, the data does not rule out the possibility that the Aglantha $\mathrm{Ca}_{\mathrm{v}}$ 3-like channel activates an HVA $\mathrm{Ca}_{\mathrm{v}}$ channel which in turn associates with the exocytotic machinery. However, the peak of the LVA $\mathrm{Ca}^{2+}$ spike only reaches about $-25 \mathrm{mV}$ (Meech and Mackie, 1993), which is barely at the activation threshold for recorded $\mathrm{HVA} \mathrm{Ca}_{\mathrm{V}}$ channels from cnidarians (Przysiezniak and Spencer, 1992; Jeziorski et al., 1998). Thus, the LVA calcium channel observed in Aglantha axons might well be positioned within nanometer proximity of the exocytotic machinery, able to directly activate exocytosis. Such an association is not without precedent: The three vertebrate $\mathrm{Ca}_{\mathrm{v}} 3$ channel isotypes were recently found to directly interact with core SNARE proteins syntaxin-1A (all three channel isotypes) and SNAP-25 (only $\mathrm{Ca}_{\mathrm{v}} 3.2$ ), and disruption of the syntaxin- $\mathrm{Ca}_{\mathrm{v}} 3.2$ channel interaction was found to abrogate the channel's contribution to low-threshold exocytosis in a neuroendocrine cell line (Weiss et al., 2012).

\section{Muscle Contraction}

Whereas both $\mathrm{Ca}_{\mathrm{v}} 1$ and $\mathrm{Ca}_{\mathrm{v}} 2$ type channels are expressed in bilaterian neurons and neuroendocrine cells, $\mathrm{Ca}_{\mathrm{v}} 1$ channels are often the only type found in smooth, cardiac, and striated muscle, with a few instances of $\mathrm{Ca}_{\mathrm{v}} 3$ channel expression (Ren et al., 1998; Jeziorski et al., 2000; Jospin et al., 2002; Catterall, 2011; Senatore et al., 2014). Thus, in most smooth and cardiac muscle cells, $\mathrm{Ca}^{2+}$ influx through L-type/ $\mathrm{Ca}_{\mathrm{v}} 1$ channels serves to directly activate contractile proteins, and to trigger further increases in cytoplasmic $\mathrm{Ca}^{2+}$ by activating ryanodine receptors in the sarco/endoplasmic reticulum (SER) (i.e., calcium-induced calcium release or CICR)(Reuter, 1979; Tsien, 1983; Bers, 2002). In vertebrate skeletal muscle, $\mathrm{Ca}_{\mathrm{v}} 1$ channels have evolved a specialized ability to sidestep the CICR process. Here, membrane-localized $\mathrm{Ca}_{\mathrm{V}} 1$ channels directly interact with SER ryanodine receptors; activation of $\mathrm{Ca}_{\mathrm{v}} 1$ channels at the membrane relays conformational changes in the ryanodine receptor leading to release of SER $\mathrm{Ca}^{2+}$, without a need for $\mathrm{Ca}_{\mathrm{v}} 1$ channel $\mathrm{Ca}^{2+}$ influx (Tanabe et al., 1990, 1993; Catterall, 1991).

Interestingly, the coupling of cytoplasmic $\mathrm{Ca}^{2+}$ influx with rapid activation of contractile proteins seems to be a metazoan innovation. A recent in-depth genomic study found that the $\mathrm{Ca}^{2+}$ - calmodulin (CaM)-myosin light chain kinase (MLCK) cascade, critical for excitation-contraction coupling, occurs strictly in metazoans where MLCK is absent in the genomes of choanoflagellates and other non-metazoan organisms (Steinmetz et al., 2012). Also interesting is that although "core" contractile proteins appear to have been present prior to the emergence of Metazoa, key proteins associated specifically with striated muscle in bilaterians are absent in cnidarians and ctenophores, which also possess striated muscle. As such, fast-twitching striated muscle likely evolved independently between at least bilaterians and cnidarians/ctenophores (Burton, 2008; Steinmetz et al., 2012).

Outside of a few species of swimming sea anemones, anthozoans are mostly devoid of striated muscle for contractile movement, bearing primitive smooth muscle cells with roles in feeding (mouth and tentacles) and digestion/reproduction (gastrovascular cavity) (Chapman, 1974; Burton, 2008). Medusozoans, which can become motile medusae (i.e., jellyfish), possess extensive striated musculature ("muscle sheets") in the bell epithelium for swimming, in addition to smooth muscle cells (Chapman, 1974; Burton, 2008). The striated swimming muscles seem to lack extensive SER structures (Chapman, 1974; Keough and Summers, 1976; Singla, 1978; Spencer, 1979), suggesting a reduced dependency on CICR in lieu of $\mathrm{Ca}^{2+}$ influx through plasma membrane $\mathrm{Ca}^{2+}$ channels. Accordingly, removal of external $\mathrm{Ca}^{2+}$ during intracellular recording of bell striated 
muscle cells from Aglantha completely abrogates muscle action potentials and contraction (Kerfoot et al., 1985). Notably, the action potentials of these muscle cells are slow to reach peak (Kerfoot et al., 1985) compared to the $\mathrm{Na}^{+}$-dependent action potentials of their pre-synaptic effector neurons (Mackie and Meech, 1985; Meech and Mackie, 1993). This suggests the absence of fast, $\mathrm{Na}^{+}$-selective $\mathrm{Na}_{\mathrm{v}}$ channels for depolarization (i.e., $\mathrm{Na}_{\mathrm{v}}$ 2.5-like channels, Barzilai et al., 2012). Instead, the long-lasting and complex waveform of Aglantha muscle action potentials (Roberts and Mackie, 1980) indicates that multiple $\mathrm{Ca}^{2+}$ conductances are at play, perhaps for endowing the cells with a capacity to respond to bimodal pre-synaptic innervation as discussed above (Kerfoot et al., 1985).

Long-lasting action potentials have also been observed in striated swimming muscle of another hydrozoan medusa, $P$. penicillatus. Here, intracellular recordings revealed action potentials whose depolarization depends on both $\mathrm{Na}^{+}$and $\mathrm{Ca}^{2+}$ influx (Spencer and Satterlie, 1981). Like in Aglantha swim muscles, these spikes also exhibits long lasting plateau phases, reminiscent of vertebrate cardiac muscle in which prolonged $\mathrm{Ca}^{2+}$ influx through $\mathrm{Ca}_{\mathrm{v}} 1$ channels ensures effective contraction of the heart for expulsion of blood (Grant, 2009). Given the similarity in waveforms between vertebrate cardiac muscle and jellyfish swimming muscle, and the predominance of $\mathrm{Ca}_{\mathrm{v}} 1$ channels in driving bilaterian muscle contraction, it is tempting to speculate that the single $\mathrm{Ca}_{\mathrm{v}} 1$ channel in cnidarians also drives muscle contraction. However, the data is sparse in this regard and other types of $\mathrm{Ca}^{2+}$ permeable channels could certainly be involved. As noted earlier, the most detailed molecular description of cnidarian $\mathrm{Ca}_{\mathrm{v}} 1$ channels comes from the cloning and ectopic expression of a homolog from schyphozoan jellyfish C. capillata (Jeziorski et al., 1998). When expressed in Xenopus oocytes, Cyanea $\mathrm{Ca}_{\mathrm{v}} 1$ behaves like protostome and deuterostome $\mathrm{Ca}_{\mathrm{v}} 1$ channels by exhibiting high voltage of activation/inactivation, as well as apparent $\mathrm{Ca}^{2+}$. dependent inactivation evidenced by more rapid decay of its macroscopic currents in the presence of external $\mathrm{Ca}^{2+}$ compared to $\mathrm{Ba}^{2+}$.

\section{Unique $\mathrm{Ca}_{\mathrm{v}}$ Channel Physiology}

Cnidarians get their name from cnidocytes, or "stinging cells," best known for their role in jellyfish tentacles where they discharge thread-like tubules laced with painful and sometimes lethal toxins for defense and predation. As cnidocytes can only be used once, their discharge is highly regulated, especially those involved in prey capture (Anderson and Bouchard, 2009). Regulation involves a convergence of chemosensory and mechanosensory neural synaptic inputs (Pantin, 1942; Westfall, 2004; Anderson and Bouchard, 2009), intrinsic mechano- and chemo-sensitivity of the cnidocytes themselves (Brinkmann et al., 1996; Thurm et al., 1998, 2004), and cnidocyte-cnidocyte communication either directly via gap junctions (Mire et al., 2000; Price and Anderson, 2006), or through local synaptic circuits between cnidocytes and intermediate sensory cells located nearby (Holtmann and Thurm, 2001a). Notably, only hydrozoans and perhaps anthozoan sea anemones bear gap junction genes (Putnam et al., 2007; Chapman et al., 2010;
Shinzato et al., 2011; Baumgarten et al., 2015), and electrical coupling between cnidocytes need not occur, even when gap junction genes are likely present (Holtmann and Thurm, 2001a,b).

Intracellular recording has revealed that cnidocytes are highly electrically active. Application of species-specific prey extracts via perfusion in sea water saline evokes depolarizing synaptic potentials and bursts of action potentials in impaled tentacle cnidocytes (Brinkmann et al., 1996; Price and Anderson, 2006); perfusion of $\mathrm{Ca}^{2+}$-free saline and calcium channel blocker $\mathrm{Ni}^{2+}$ disrupt this induced activity, likely through pre-synaptic disruption $\mathrm{Ca}_{\mathrm{v}}$ channels and exocytosis (Price and Anderson, 2006). Interestingly the cnidocyst, an endomembrane-derived organelle harboring the cnidocyte stinging thread, is thought to resemble synaptic and neuroendocrine vesicles in that its exocytotic discharge depends on both membrane depolarization and $\mathrm{Ca}^{2+}$ influx (Skaer, 1973; Gitter et al., 1994). Patch clamp recording of cnidocytes has failed to directly identify $\mathrm{Ca}_{\mathrm{v}}$ channel currents, but this has been attributed to washing out of endogenous currents during patch clamp recording (Anderson and Bouchard, 2009). Furthermore, in situ localization of $\mathrm{Ca}_{\mathrm{v}}$ channel transcripts in $N$. vectensis revealed that one of the three $\mathrm{Ca}_{\mathrm{v}} 2$ channel isotypes, $\mathrm{Ca}_{\mathrm{v}} 2 \mathrm{a}$, is strongly expressed in cnidocytes (Moran and Zakon, 2014), and both a full length $\mathrm{Ca}_{\mathrm{v}} \beta$ subunit and a fragment of an unspecified $\mathrm{Ca}_{\mathrm{V}}$ channel have been detected in cnidocyte-specific mRNA from the Portugese man'o war (Physalia physalis) (Bouchard et al., 2006; Dunn, 2009). Thus, it is likely that in vivo $\mathrm{Ca}_{\mathrm{v}}$ channels contribute to exocytosis of the cnidocyst, perhaps using similar machinery used for pre-synaptic and neuroendocrine secretion. However, cnidocyst exocytosis likely involves additional molecular adaptations that prevent exocytosis in the absence of proper chemosensory and mechanosensory inputs (Anderson and Bouchard, 2009).

Finally, $\mathrm{Ca}_{\mathrm{v}}$ channels have been implicated in calcification of corals, which accumulate $\mathrm{CaCl}_{2}$ at a rate of about $10 \mathrm{~kg}$ per meter squared of coral reef per year (Chave et al., 1972). Application of phenylalkylamine and dihydropyridine $\mathrm{Ca}_{\mathrm{v}} 1$ channel blockers attenuates calcification in corals Stylophora pistillata (Tanbutté et al., 1996) and Galaxea fascicularis (Marshall, 1996), and a cloned $\mathrm{Ca}_{\mathrm{v}} 1$ channel gene was detected as an expressed protein in the calicoblastic ectoderm of Stylophora, which is involved in calcium carbonate precipitation (Zoccola et al., 1999). Thus, for at least some species of coral, $\mathrm{Ca}_{\mathrm{v}}$ channels might contribute to the calcification process, but certainly other $\mathrm{Ca}^{2+}$-handling channels, pumps and exchangers also likely contribute (Marshall, 1996; Tanbutté et al., 1996).

\section{Placozoa}

Although the genome was sequenced for T. adhaerens (Srivastava et al., 2008), the only identified species of the phylum Placozoa, we understand little about placozoan species diversity, life cycle, reproduction or ecology (Schierwater, 2005; Eitel et al., 2013). Trichoplax was first discovered in 1883 by German zoologist F. E. Schulze, residing in a seawater aquarium in Austria (Schulze, 1883). Schulze named this peculiar animal based on its flat, hairy (tricho) plate (plax)-like appearance (Figure 5A), attributed to its ciliated epithelium used for adhering (adhaerens) to and 

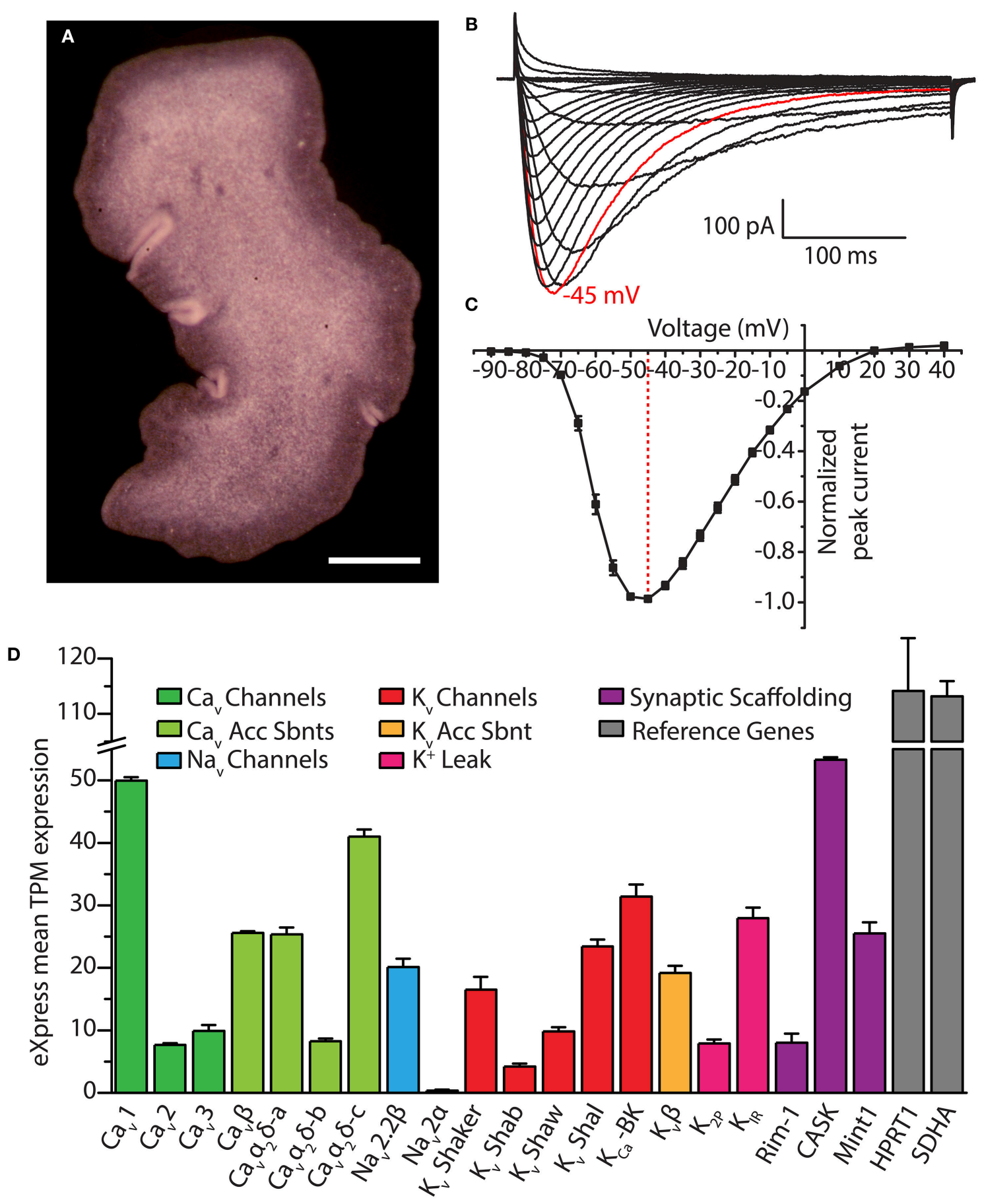

FIGURE 5 | (A) Dorsal view of Trichoplax adhaerens photographed through a stereomicroscope, revealing its irregularly-shaped body lacking symmetry outside of dorsal-ventral polarity. Gland cells are located in the ventral epithelium, most concentrated along the outside rim (i.e., within the darker band visible in the image). Scale bar is $200 \mu \mathrm{m}$. (B) Whole cell patch-clamp recorded $\mathrm{Ca}^{2+}$ currents of the cloned Trichoplax Cav3 channel expressed in HEK-293T cells, bearing rapid activation and inactivation kinetics, and a crossing over of current traces during inactivation with increasing depolarization (recorded in 2 mM external Ca ${ }^{2+}$ solution). (C) Current-voltage plot of average normalized peak inward $\mathrm{Ca}^{2+}$ current of Trichoplax Cav3, revealing its low voltage of activation with peak inward current at -45 $\mathrm{mV}$ ( $n=10$, error bars indicate SE from the mean). (D) Bar graph of mean mRNA expression levels of select Trichoplax ion channel genes and their subunits estimated with the program eXpress (Roberts and Pachter, 2013), quantified as transcripts per million (TPM) from assembled transcriptome data and four separate Illumina sequencing datasets of whole animal poly(A)-extracted mRNA (2x125 base pair reads; manuscript in preparation). Channels were identified via BLAST homology with mammalian protein sequences using an expect value cut-off of $1 \times 10^{-5}$. Two ubiquitously expressed genes, Hypoxanthine Phosphoribosyltransferase 1 (HPRT1) and Succinate Dehydrogenase A (SDHA), are included as reference genes. Error bars indicate standard error from the mean TPM expression. 
gliding along hard surfaces. After its initial discovery and a few years thereafter, Trichoplax was largely forgotten until being rediscovered nearly a century later in the 1960s, spurring a new wave of research. Recently, interest has piqued again in light of the available genome sequence, and the phylogenetic placement of Trichoplax as sister to cnidaria/bilateria (Figure 1). This position makes Trichoplax a relevant subject for studying the evolution of complex animal traits such as development, body patterning and nervous system function, since it lacks these features yet harbors most genes necessary for their implementation and function (Srivastava et al., 2008). Trichoplax is a small marine invertebrate (i.e., $0.1-1 \mathrm{~mm}$ diameter; Figure 5A), which lives in shallow tropical and subtropical ocean waters, and can be easily grown in the lab where it divides asexually via binary fission, needing only a supply of healthy living algae for nourishment (Heyland et al., 2014; Smith et al., 2015). Microscopy studies indicate that Trichoplax possesses only six cell types, the least of any known animal, with no evidence for either chemical or electrical synapses, nor organized muscle fibers (Grell and Benwitz, 1971, 1974; Rassat and Ruthmann, 1979; Smith et al., 2014). Remarkably, despite these absences, Trichoplax is able to carry out motile behavior including feeding, chemotaxis and phototaxis (Ueda et al., 1999; Heyland et al., 2014; Smith et al., 2015). Unfortunately, electrophysiological recording of Trichoplax cells has yet to be reported, so we know little about the roles of ion channels and electrical excitability in Trichoplax biology. However, the persistence of electrogenic genes in its genome, including single representatives for each type of $\mathrm{Ca}_{\mathrm{v}}$ channel $\left(\mathrm{Ca}_{\mathrm{v}} 1-\mathrm{Ca}_{\mathrm{v}} 3\right.$; Figure 4), suggests that electrical and $\mathrm{Ca}^{2+}$-signaling do occur in Trichoplax. Here, we include in the discussion some of our own ongoing research, characterizing Trichoplax $\mathrm{Ca}_{\mathrm{v}}$ channels.

\section{Neurosecretory-Like Gland Cells}

Of the six documented Trichoplax cell types, gland cells most resemble neurons and neurosecretory cells in their expression of exocytotic SNARE proteins and membrane-apposed vesicles (Syed and Schierwater, 2002; Smith et al., 2014). Gland cells are concentrated around the periphery of the flat irregularlyshaped animal (Figure 5A), with some sparsely distributed along the ciliated ventral epithelium. Interestingly, gland cell vesicles exhibit cell-specific variability in electron density when observed under transmission electron microscopy (Smith et al., 2014). Thus, some gland cells appear specialized for secreting regulatory peptides, many of which are predicted from the genome (Nikitin, 2015) (i.e., those bearing electron dense vesicles), while others perhaps transmit small molecules such as amino acids and biogenic amines (Srivastava et al., 2008) (pale vesicles). Heterogeneity of gland cell vesicular content is also apparent through immunolabeling with antibodies against RFamide and FMRFamide neuropeptides (Schuchert, 1993; Smith et al., 2014), which selectively label a subset of gland cells located on the animal's periphery. Indeed, key questions remain about the role of gland cells in Trichoplax physiology and behavior, however their apparent exocytotic nature, coupled with their peripheral localization, suggests that they exert paracrine control over other cells for coordinating activity (Smith et al., 2014, 2015). For example, Trichoplax feeding behavior begins with the animal pausing over patches of algae detected under its body, via coordinated cessation of beating monociliated cells on the ventral epithelium (Ueda et al., 1999; Smith et al., 2014). The detected algae are then lysed by hydrolytic secretions from lipophil cells, but only those positioned close by. The animal remains sessile after algal lysis, anchored along the periphery while internally located cells undergo a churning movement. Afterwards, ventral epithelial cells resume beating, and the animal glides on to new algae (Smith et al., 2015). Here, peripherally-located gland cells are optimally positioned to exocytose paracrine factors over the entire ventral epithelium (Smith et al., 2014, 2015). Instead, more centrally located gland cells are proposed to function as chemosensory cells, which exocytose factors to inform adjacent lipophil cells of the presence of algae (Singla and Reiter, 2006; Smith et al., 2015). Further work needs to be done to understand how Trichoplax cells are coordinated in the absence of synapses during feeding and other behaviors. However, the expression of SNARE proteins in gland cells, combined with the presence of $\mathrm{Ca}^{2+}$-sensitive elements of the exocytotic machinery in the genome (Srivastava et al., 2008) (e.g., synaptotagmin, synaptophysin, and complexin), hints that these particular cells exhibit $\mathrm{Ca}^{2+}$-dependent exocytosis.

Our ongoing research on Trichoplax $\mathrm{Ca}_{\mathrm{v}}$ channels provides indirect support for the potential dependence on calcium for exocytosis in gland cells. We recently cloned and in vitro expressed the single T-type $\mathrm{Ca}^{2+}$ channel homolog from Trichoplax, finding that despite more than 600 million years of divergence from vertebrate channels, it bears the distinguishing structural features of this channel type including a selectivity filter motif of EEDD, and a predicted helixloop-helix gating brake structure in the domain I-II linker (Figure 2B). Also conserved with other T-type channels are its biophysical properties, where in vitro recorded $\mathrm{Ca}^{2+}$ currents exhibit hallmark attributes including a low voltage of activation, rapid activation and inactivation kinetics (Figures 5B,C), and a reduced selectivity for $\mathrm{Ca}^{2+}$ over $\mathrm{Na}^{+}$compared to $\mathrm{HVA} \mathrm{Ca}_{\mathrm{v}} 1$ and $\mathrm{Ca}_{\mathrm{v}} 2$ channels (in review). Thus, it seems as though the basic structural and functional features of $\mathrm{Ca}_{\mathrm{v}} 3$ channels, optimized for regulating excitability and driving low threshold exocytosis, were established very early on during evolution and perhaps extend beyond Trichoplax to the even more primitive homolog identified in the genome of choanoflagellate Salpingoecca rosetta (Fairclough et al., 2013; Moran and Zakon, 2014).

Interestingly, immunoabeling with specific custom antibodies against $\mathrm{TCa}_{\mathrm{v}} 3$ produced labeling exclusively in gland cells, with intense staining along the outside edges where vesicular exocytosis is likely to take place (Smith et al., 2014). We also recently cloned and in vitro expressed the Trichoplax $\mathrm{Ca}_{\mathrm{v}} 2$ channel homolog, and, similarly, immunolabeling points to exclusive expression in gland cells, along with the HVA subunit $\mathrm{Ca}_{\mathrm{V}} \alpha_{2} \delta$ (unpublished data). Thus, beyond the presence of exocytotic machinery and "neurosecretory" ultrastructural markers, gland cells resemble select neurons and neurosecretory cells in their expression of both HVA $\left(\mathrm{Ca}_{\mathrm{v}} 2\right)$ and LVA $\left(\mathrm{Ca}_{\mathrm{v}} 3\right)$ channels (Weiss and Zamponi, 2013). It will certainly be interesting to determine whether gland cells exhibit homologous 
interactions between $\mathrm{Ca}_{\mathrm{v}} 2$ and $\mathrm{Ca}_{\mathrm{v}} 3$ channels and proteins which in neurons and neurosecretory cells complex the channels within nanometers of the exocytotic machinery, as discussed above (e.g., RIM, Mint1 and CASK, and the SNARE proteins). We note from an ongoing transcriptomic study that mRNAs of numerous pre- and post-synaptic scaffolding genes are indeed expressed in Trichoplax, including RIM, Mint1 and CASK (Figure 5B). Also of interest will be to determine how gland cells and other cell types might be electrically activated in the absence of synaptic inputs, perhaps via paracrine signaling, or, via cell-intrinsic sensory pathways as occurs in cnidarian cnidocytes. Indeed, the nature and purpose of electrical signaling in Trichoplax remains a mystery. However, it is likely of significant importance, where in addition to $\mathrm{Ca}_{\mathrm{v}}$ channels, the animal expresses mRNAs of a core set of genes required for generating action potentials and propagating fast electrical signals: One of the two $\mathrm{Na}_{\mathrm{v}} 2$ channels predicted from the genome (Srivastava et al., 2008; Liebeskind et al., 2011), $K_{v}$ channels of the Shaker, Shab, Shal, and Shaw varieties, a $\mathrm{Ca}^{2+}$-activated $\mathrm{K}^{+}$channel (i.e., large conductance $\mathrm{BK})$, a $\mathrm{K}_{\mathrm{V}}$ channel accessory $\beta$ subunit, and 2 -pore $\mathrm{K}^{+}\left(\mathrm{K}_{2 \mathrm{P}}\right)$ leak channels and inward rectifying $\mathrm{K}^{+}\left(\mathrm{K}_{\mathrm{IR}}\right)$ channels, essential for setting the polarized resting membrane potential of excitable cells (Figure 5D).

\section{Cellular Contractility}

It is interesting that of the three $\mathrm{Ca}_{\mathrm{v}}$ channel types, the $\mathrm{Ca}_{\mathrm{v}} 1$ channel appears to be the most highly expressed in the Trichoplax transcriptome (Figure 5D), considering the specialized role that $\mathrm{Ca}_{\mathrm{v}} \mathrm{l}$ channels play in excitation-contraction coupling in muscle, and the absence of ultrastructural markers for muscle in Trichoplax (Smith et al., 2014). The animal possesses the core genetic elements required for the establishment and operation of rapidly contracting muscle cells, and in fact shares slightly more of these genes with bilaterians/cnidarians than do ctenophores (Steinmetz et al., 2012), which appear to have independently evolved muscle (Ryan et al., 2013). Still debated is whether Trichoplax represents a simplified animal (Ryan and Chiodin, 2015), where the absence of clear ultrastructural markers for muscle might reflect a lost or diminished phenotype. However, the retention of contractile genes in the genome indicates utility, where they might play roles in contractile cellular processes nonetheless, or perhaps serve completely different functions. In support of the former, Trichoplax performs movements that appear independent of the ciliated ventral epithelium, such as the churning motion during feeding, and folding or rippling along its edges (Heyland et al., 2014; Smith et al., 2015). It might be the case that rudimentary contractile mechanisms underlie these movements; fiber cells, which lie between the dorsal and ventral epithelia and have branched protrusions that contact all other cell types, have been proposed to mediate contractile movements (Schierwater, 2005). However, whether these or any other Trichoplax cell types employ contractile genes in a manner homologous to muscle remains to be determined, as is the role for the single $\mathrm{Ca}_{\mathrm{v}} 1$ channel.

\section{Ciliary Beating}

Trichoplax ciliary locomotion presents distinct modalities, including starting and stopping, as well as rotation and direction changes (Ueda et al., 1999; Heyland et al., 2014; Smith et al., 2015). Although poorly understood, transitions in Trichoplax locomotive states are dependent on food concentration (Ueda et al., 1999), and might require altered beating modes of cilia that project from the ventral epithelium. In other eukaryotic cells, alterations in ciliary waveform depend on $\mathrm{Ca}_{\mathrm{v}}$ channels (Quarmby, 2009). Well documented examples of alternate modes for ciliary beating come from ctenophores (discussed below), as well as single-celled protists such as paramecia and the green algae Chlamydomonas reinhardtii, which alter ciliary waveforms in response to external stimuli, temporarily changing swimming trajectory. Early studies on paramecia revealed that their ability to reverse upon mechanical stimulation relies on external $\mathrm{Ca}^{2+}$, whose transient influx specifically into cilia triggers a switch in the beat cycle (Naitoh, 1968; Kung and Naitoh, 1973). Ciliary beating in paramecia is referred to as the "ciliary" waveform, which consists of an asymmetric power stroke in one direction followed by a weaker recovery stroke in the other. The ciliary waveform is common in metazoans, exemplified in the human lung where epithelial cilia use this pattern to expel particles and fluid into the pharynx (Satir and Christensen, 2007). In paramecia, electrophysiological recording revealed that the calcium channels responsible for switching the direction of the ciliary power and recovery strokes, and hence direction of movement, reside exclusively along the cilia and not the cell body (Dunlap, 1977). Chlamydomonas also exhibits direction changes, where light or mechanical stimulation causes a switch in ciliary waveform. Normally, the two cilia of Chlamydomonas exhibit ciliary waveforms with the power strokes that pull the cell body forward; upon optical/mechanical stimulation, and in a $\mathrm{Ca}^{2+}$. dependent manner, the cilia switch to a symmetrical "flagellar" waveform (Bessen et al., 1980), much like that of swimming sperm, temporarily reversing movement such that cell body leads while the cilia push from behind. Here, light or mechanical stimulation generates a depolarizing membrane potential (Harz and Hegemann, 1991), activating a pre-metazoan $\mathrm{Ca}_{\mathrm{v}}$ channel homolog positioned along the distal portion of the cilia (Fujiu et al., 2009), consistent with the calcium channel localization in paramecia cilia. Gene disruption of the Chlamydomonas channel, dubbed CAV2, abrogates both the light and mechanical induced reversal, indicating a convergence of the two sensory modalities on CAV2 channel activation (Matsuda et al., 1998; Fujiu et al., 2009).

The mechanisms by which $\mathrm{Ca}^{2+}$ influx controls ciliary waveform transition involves dynamic regulation of dynein motor complexes positioned between pairs of ciliary microtubules (Yang et al., 2001; Hayashi et al., 2002; PatelKing et al., 2002; Wargo and Smith, 2003, 2007). Notably, $\mathrm{Ca}_{\mathrm{v}}$ channels and $\mathrm{Ca}^{2+}$ influx are not necessary for maintaining ciliary beating per se, and might be specific for altering waveforms under transient, induced conditions (Tamm, 1994, 2014a). A recent study looking at the roles of $\mathrm{Ca}_{\mathrm{v}}$ channels in ciliary beating of mammalian ependymal cells, which move cerebral spinal fluid in the central nervous system, found no effect of $\mathrm{Ca}^{2+}$ influx on ciliary beating and fluid movement, where $\mathrm{Ca}_{\mathrm{v}} 1$ channels were found localized mostly in the cell soma (Doerner et al., 2015). Instead, $\mathrm{Ca}^{2+}$ influx through CatSper channels in sperm triggers hyperactivation of the flagellar beat (Qi et al., 2007). Indeed, 
whether the cilia on Trichoplax's dorsal and ventral epithelium exhibit alternate or modulated beating modes remains to be determined; if so, it will be interesting to evaluate whether $\mathrm{Ca}_{\mathrm{v}}$ channels are involved.

\section{Porifera}

Sponges are phylogenetically more basal than Placozoans (Figure 1), however, they are considerably more complex bearing at least 16 different cell types (Simpson, 2012) organized into various simplified tissues (Leys, 2015). Like Trichoplax, sponges lack synaptically-connected neurons and true muscle cells. However, there are at least two cell types, pinacocytes and actinocytes, which are thought to contract and bear some structural resemblance to muscle (Leys and Meech, 2006; Nickel et al., 2011). Sponges are sedentary and consume microorganisms such as bacteria and protozoans by filtering them from sea water, drawn through internal canals by the beating of ciliated choanocyte cells. The most obvious behaviors of sponges revolve around feeding. Glass sponges, named so because of their rigid silica skeletons, respond to excessive particulates in the water by propagating $\mathrm{Ca}^{2+}$-dependent electrical impulses along cellular syncytia in order to pause choanocyte ciliary beating and arrest the feeding current (Leys and Mackie, 1997; Leys and Meech, 2006). Most other sponges are soft-bodied and lack syncytia (i.e., are "cellular"), and instead contract their entry/exit points for water flow (i.e., ostia and osculum, respectively), or their entire aquiferous systems, in order to prevent particulates from getting into canals (Nickel, 2010; Nickel et al., 2011), or to expel them (Elliott and Leys, 2007). Another fairly well characterized sponge behavior is larval swimming, which serves for dispersal and location of suitable sea floor settling grounds (Maldonado and Bergquist, 2002). Swimming is mediated by beating cilia on the larval epithelium, sometimes arranged asymmetrically between the poles of oblong species (Maldonado and Bergquist, 2002). Interestingly, numerous sponge larvae exhibit phototactic swimming, mediated by rapid, light-induced changes in ciliary beating (Leys and Degnan, 2001; Leys et al., 2002; Leys, 2015), reminiscent of light-dependent ciliary responses in Chlamydomonas but mediated by different photosensitive effectors [i.e., channel rhodopsins in algae (Nagel et al., 2003) vs. cryptochromes in sponges (Leys et al., 2002; Rivera et al., 2012)].

As contenders for the most basal surviving animal phylum, poriferans are positioned to provide important insights into animal evolution. Recent genomic and transcriptomic studies reveal that sponges possess and express key genes associated with nervous system development and function (Srivastava et al., 2010; Conaco et al., 2012; Riesgo et al., 2014; FernandezValverde et al., 2015; Guzman and Conaco, 2016). Understanding how these genes operate and interact in sponges in vivo can shed light on conserved and ancient modules of gene function which served as building blocks for nervous system evolution (Ryan and Grant, 2009). Several such insights have already emerged, such as the apparent co-expression of postsynaptic scaffolding genes in certain sponge tissues, most bearing conserved protein-protein interaction motifs required for synaptic complexing (Sakarya et al., 2007); the presence of subsets of genes involved in neurotransmitter biosynthesis and transport, as well as corresponding ionotropic and/or metabotropic receptors including those for GABA and Lglutamate (Srivastava et al., 2010; Riesgo et al., 2014; Moroz and Kohn, 2015); and in conjunction, physiological sensitivity to some of these transmitters, most evident by alterations in contractile behavior (Elliott and Leys, 2010; Leys, 2015). Interestingly however, outside of glass sponges Porifera appear mostly devoid of fast electrical impulses, and they lack both $\mathrm{Na}_{\mathrm{v}}$ and $\mathrm{K}_{\mathrm{v}}$ channels which mediate most action potentials (Tompkins-Macdonald et al., 2009; Srivastava et al., 2010; Riesgo et al., 2014), as well as gap junction genes which permit electrical coupling between cells (Leys, 2015). Thus, with respect to fast electrical signaling, sponges are likely simplified from the root metazoan ancestor, since most electrogenic genes are present in pre-metazoan genomes (Moran et al., 2015). We know little about the biological roles of the remaining electrogenic genes in sponges, including the single $\mathrm{Ca}_{\mathrm{v}}$ channel whose phylogenetic relationship to other metazoan $\mathrm{Ca}_{\mathrm{v}}$ channels remains unclear (Figure 4). In this section, we briefly highlight some of the few examples of poriferan physiology and behavior where $\mathrm{Ca}_{\mathrm{v}}$ channels might possibly play a role, and further, discuss the atypical contraction of sponge cells where cell excitation and $\mathrm{Ca}_{\mathrm{v}}$ channels appear not to be involved.

\section{Cellular Contractility}

Placozoans and cellular sponges both exhibit quasi-coordinated contractile behavior in the complete absence of neurons and muscle. However, whereas Trichoplax has the majority of genes required for excitation-contraction coupling, the absence of $\mathrm{Na}_{\mathrm{V}}$ and $\mathrm{K}_{\mathrm{v}}$ channels in sponges precludes rapid fluctuations in membrane potential, at least by canonical means. Sponges do possess $\mathrm{K}_{2 \mathrm{P}}$ leak (Wells et al., 2012) and inward rectifying (Tompkins-Macdonald et al., 2009) $\mathrm{K}^{+}$channels, which if expressed in contractile cells would establish negative resting membrane potentials. However, in fresh and sea water sponges from the genus Microciona, increasing external $\left[\mathrm{K}^{+}\right]$, which diminishes the $\mathrm{K}^{+}$membrane gradient and would depolarize cells, has no bearing on contraction (Prosser, 1967). However, contraction does depend on the presence of external cations, which presumably move across the cell membrane, albeit in a non-selective manner: External $\mathrm{Na}^{+}$can be substituted with $\mathrm{K}^{+}$ or $\mathrm{Li}^{+}$, and $\mathrm{Ca}^{2+}$ can be replaced with $\mathrm{Mg}^{2+}$ or $\mathrm{Sr}^{2+}$. Notable is that cellular contractility appears highly atypical in this clade, in its dependence on both external $\mathrm{Ca}^{2+}$ and $\mathrm{Mg}^{2+}$, but perhaps more $\mathrm{Mg}^{2+}$, being roughly 5 -fold more concentrated than $\mathrm{Ca}^{2+}$ in sea water. Instead, specimens from the genus Euspongia do show a selective dependency on external $\mathrm{Na}^{+}$and $\mathrm{Ca}^{2+}$, and increasing external $\left[\mathrm{K}^{+}\right]$triggers marked and prolonged contraction consistent with depolarization-induced contractility (Pavans de Ceccatty, 1971). Nonetheless, these contraction events occur in the absence of measurable electrical impulses, and their slow and long-lasting kinetics make it unlikely that voltage-gated channels play a role.

The absence of gap junctions in sponges, combined with the absence of electrical signaling in cellular sponge species in general, indicate that contraction and its propagation from 
cell-to-cell occurs though much slower cellular pathways. Some have therefore speculated that contractile waves spread along sponge tissues by means of paracrine secretion, where incoming paracrine factors cause cells to both contract and to secrete (Leys and Meech, 2006). With respect to cellular contraction, its dependency on extracellular cations implies that ions move across the membrane, perhaps through ion channels, pumps and/or exchangers which are regulated by ligand-dependent receptors such as G-protein coupled receptors (GPCRs). Several "slow" GPCR pathways exist in muscle which dynamically regulate myosin light chain phosphorylation/dephosphorylation and hence contraction of actin/myosin filaments (Somlyo and Somlyo, 2003). In addition, some GPCR pathways directly regulate muscle contraction and tone through release of $\mathrm{Ca}^{2+}$ from internal stores and/or activation of other muscle effector kinases such as protein kinase $\mathrm{C}$ and Rho-associated protein kinase (Sanderson et al., 2008); in this context, membrane $\mathrm{Ca}^{2+}$ influx is thought necessary only for the replenishment of internal stores, and not for regulating contraction per se. Thus, contractile activity in the absence of fast electrical signaling is not unprecedented. Beyond pinacocytes and actinocytes, other sponge cells exhibit extensive motility, which depends on influx of extracellular calcium and could contribute to gross body movement via cumulative action of multiple cells (Lorenz et al., 1996).

\section{Electrical Signaling}

Glass sponges (class Hexactinellida) are the only poriferan group known to exhibit electrical signaling, in the form of $\mathrm{Ca}^{2+}$ action potentials which travel through a multinucleated syncytium comprising the entire body (Leys and Mackie, 1997; Leys and Meech, 2006). Although some cells remain separate, they are nevertheless connected to the syncytium though cytoplasmic bridges (Mackie, 1981), making the entire glass sponge body one large electrically conductive system. Unlike cellular sponges, glass sponges are incapable of contracting, and as noted above, prevent particulates from entering their aquiferous systems by arresting choanocyte ciliary beating and the feeding current (Mackie, 1979; Lawn et al., 1981). The entire process, from stimulus onset to current cessation, occurs within roughly $20 \mathrm{~s}$ and can be triggered either spontaneously, in response to excessive sediment in the water, or via applied mechanical or electrical stimulation (Lawn et al., 1981; Mackie et al., 1983). External recording of stimulated tissue reveals a biphasic action potential, with a depolarizing inward cation current preceding a repolarizing current presumably carried by efflux of $\mathrm{K}^{+}$ions (Leys and Mackie, 1997; Leys et al., 1999). Voltage-gated $\mathrm{Ca}^{2+}$ channels are thought to mediate action potential depolarization, since reduction of external $\left[\mathrm{Na}^{+}\right]$to $25 \%$ of physiological levels only minimally affects the action potential, whereas application of $\mathrm{Ca}_{\mathrm{v}}$ channel blockers $\mathrm{Co}^{2+}$ and $\mathrm{Mn}^{2+}$ and Nimodipine significantly disrupt it (Leys et al., 1999). Given the loss of $\mathrm{Na}_{\mathrm{v}} 2$ channels in sponges, the single $\mathrm{Ca}_{\mathrm{v}}$ channel found in the sponge genome is a viable molecular candidate for driving the glass sponge action potential. Not clear is how repolarization takes place in the absence of $K_{v}$ channels. Application of $K_{v}$ channel blocker tetraethylammonium (TEA) delays and diminishes the amplitude of the action potential, but it does not specifically prolong the depolarization phase, which would be expected if blocking a repolarizing $\mathrm{K}_{\mathrm{v}}$ channel current. Given the slow kinetics of the action potential, it might be that repolarization involves slower $\mathrm{K}^{+}$conductances, such as $\mathrm{K}_{2 \mathrm{P}}$ or $\mathrm{K}_{\mathrm{IR}}$ channels. Furthermore, contributions to repolarization might be attributed to accumulated inactivation of the voltage-gated $\mathrm{Ca}^{2+}$ channel, consistent with the observed refractory period of the sponge action potential of roughly $29 \mathrm{~s}$ (Leys et al., 1999).

Also not clear is how propagating $\mathrm{Ca}^{2+}$ action potentials lead to arrest of choanocyte ciliary beating. Based on the observed involvement of calcium channels in regulating Chlamydomonas and protozoan ciliary beating, $\mathrm{Ca}_{\mathrm{v}}$ channels and $\mathrm{Ca}^{2+}$ influx have been suggested to play a role (Leys and Meech, 2006), however, their localization to choanocytes, and the $\mathrm{Ca}^{2+}$-sensitivity of choanocyte-driven feeding current, have yet to be explored. Likewise, involvement of the sponge $\mathrm{Ca}_{\mathrm{v}}$ channel in altered ciliary beating of larvae in response to light stimulation has not been explored, where perhaps the mechanisms underlying both choanocyte ciliary arrest and larval ciliary switch use overlapping mechanisms.

\section{Ctenophora}

Ctenophores, or comb jellies, were classically grouped with cnidarians in the clade Coelenterata (Leuckart, 1848), bearing similar morphological characters to jellyfish. Current phylogenetic studies however provide compelling evidence against the monophyly Coelenterata (see above), where instead, ctenophores might represent most early-diverging animals, separated from cnidarians by Porifera and Placozoa. Accordingly, detailed comparison of morphological, physiological, and gene content characters between ctenophores and cnidarians points to a deep and ancient divergence. For example, ctenophores exhibit complex bi-radial body patterning acquired through a distinct developmental program (Chun, 1880; Driesch and Morgan, 1895; Freeman, 1977; Fischer et al., 2014), yet they lack key homologs for genes involved in body patterning and development crucial in Cnidaria and Bilateria, including homeobox genes of the Hox and ParaHox classes (Ryan et al., 2010) and major components of the Notch and Hedgehog cell signaling pathways (Walton et al., 2006; Gazave et al., 2009; Ingham et al., 2011; Ryan et al., 2013; Moroz et al., 2014). Both ctenophores and cnidarians possess diffuse "polygonal" nerve nets. However, nodes of the ctenophore net are connected by anastomosed (bundled) axon/neurite projections (Jager et al., 2011), while in cnidarians they are connected by only single neurites (Satterlie, 2011). The ultrastructure of the ctenophore chemical synapse is also different, consisting of a unique "presynaptic triad" arrangement of a row of membrane-lined vesicles separated from closely apposed mitochondria by a thin finger-like projection of smooth endoplasmic reticulum (SER)(Horridge and Mackay, 1964; Hernandez-Nicaise, 1973a) (Figure 6A). Some reciprocal synapses in cnidaria also consist of membranelined vesicles and an adjacent cisternal structure (Ryan and Chiodin, 2015), however, close apposition of mitochondria is not ubiquitous, and vesicles are documented to not bud off of the cisternal structure as they appear to do in ctenophores 

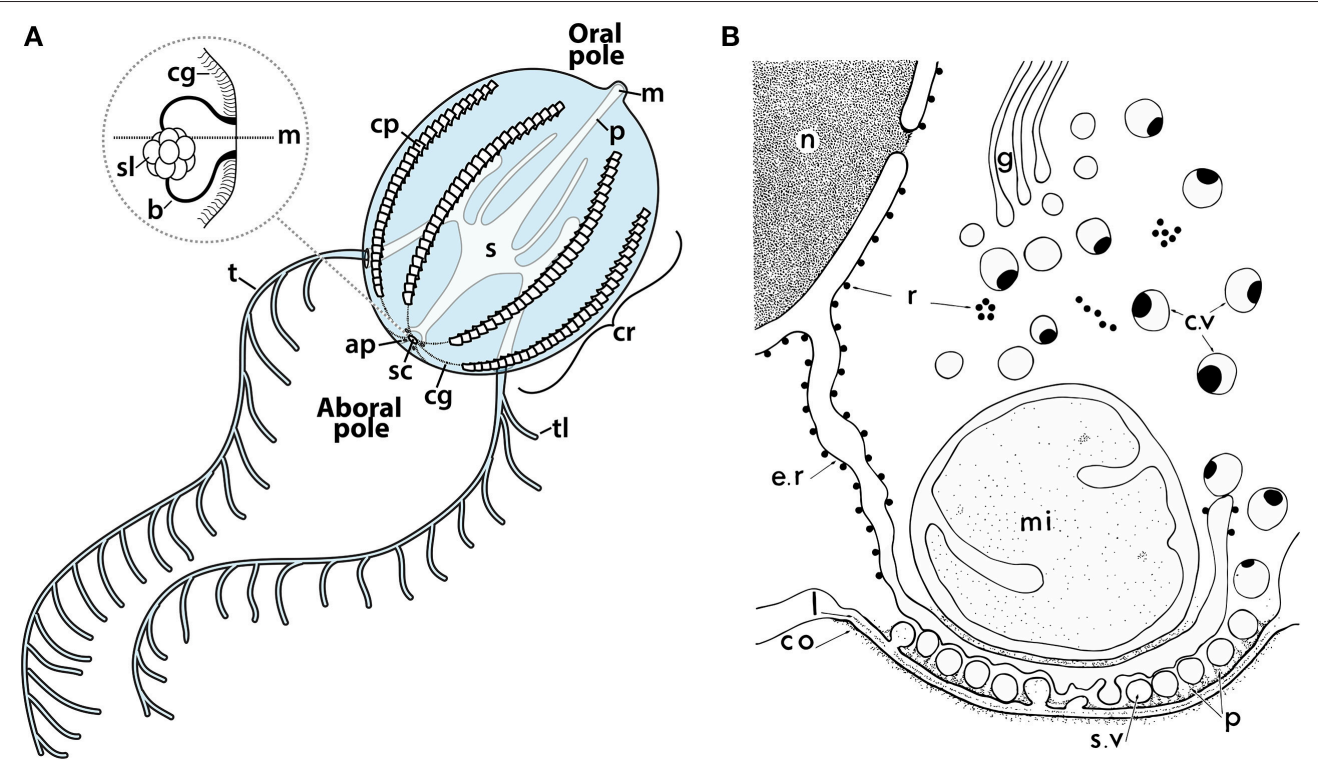

FIGURE 6 | (A) Illustration of a cydippid ctenophore, showing the oral and aboral poles bearing the mouth (m) and statocyst (sc), respectively. Ctenophores possess eight comb rows (cr), each made up of a series of comb plates (cp) which beat in the oral-aboral direction during forward swimming, or aboral-oral direction during reverse and rotational swimming. Geotactic control of comb row beating occurs via signal transduction from the statocyst, a ciliated gravitometric organ, to the beginning of each comb row via ciliated grooves (cg). Tentacles ( $\mathrm{t}$ ) and tentilla (tl) bear colloblasts, laden with adhesive granules used for prey capture; injested food enters the mouth into the pharynx (p), and eventually the stomach (s) and digestive system. Inset: Side view of two balancers (b) of the statocyst of an animal in the horizontal position, connected at their tips to the statolith (sl). Weight from the statolith mechanically deflects the balancers either toward or away from the midline (m), mechanically activating the beating of balancer cilia; these then activate waves of beating in the ciliated grooves (cg) which propagate to the comb rows. (B) Illustration of the pre-synaptic triad of ctenophore synapses, consisting of rows of synaptic vesicles (sv) arranged along the membrane, adjacent to a finger-like projection of smooth endoplasmic reticulum, which lacks ribosomes (r) of the rough endoplasmic reticulum, and one or several large mitochondria (mi). $\mathrm{n}$, nucleus; g, Golgi, c.v, cytoplasmic vesicles; co, post-synaptic dense coat; p, pre-synaptic dense projections. Reprinted with permission from Hernandez-Nicaise (1973a).

(Hernandez-Nicaise, 1973a; Anderson and Grünert, 1988). Synaptic divergence is also evident in corresponding chemical lexicons used for synaptic transmission, where ctenophores lack key genes for the biosynthesis and transport of neurotransmitters in cnidarians/bilaterians; instead, ctenophores exhibit unique gene duplications suggesting that synaptic transmission relies on expanded peptidergic and glutamatergic signaling systems (Moroz et al., 2014; Moroz and Kohn, 2015, 2016). Fundamental distinctions between ctenophores and cnidarians also extend to the tentacles and muscle. Both use tentacles for prey capture, however, jellyfish tentacles bear stinging cnidocytes which are unique to the Cnidaria (see above), whereas ctenophore tentacles contain colloblasts (a.k.a. glue cells), unique to ctenophores and lined with granules of sticky substances that burst open upon contact to ensnare prey by adhesion (Franc, 1978). Ctenophores possess smooth (Hernandez-Nicaise, 1991) and striated (Hertwig and Hertwig, 1879; Mackie et al., 1988) muscle cells derived from a "mesoderm" cell layer (Martindale, 2005), thought to be absent in Cnidaria (Martindale et al., 2004; Burton, 2008). Thus, ctenophores appear to resemble bilaterians, having mesoderm-derived muscle cells, while cnidarians independently evolved striated muscle (Steinmetz et al., 2012) and likely their epithelium-derived muscle sheets involved in bell contraction (i.e., the myopeithelium). However, ctenophore genomes have a major deficiency in genes required for mesoderm development in bilaterians (Ryan et al., 2013; Moroz et al., 2014), arguing against ctenophore-bilaterian homology and suggesting that ctenophores also independently evolved muscle (and the mesoderm).

One of the most distinguishing features of ctenophores are their comb rows, eight longitudinal strips of beating ciliary paddles (a.k.a. comb plates or ctenes) used for swimming, that run from the statocyst (aboral pole) to the mouth of the animals (oral pole) (Tamm, 2014a) (Figure 6A), and diffract light to generate the striking and characteristic rainbow coloration of comb jellies. Each comb plate is made up of thousands of amalgamated cilia which beat in unison with asymmetric power and recovery strokes. Ctenophore locomotion thus results from propagating waves of comb plate power strokes that travel along the comb rows in either an aboral-oral direction (i.e., during forward swimming), or an oral-aboral direction (during reverse swimming) (Tamm and Tamm, 1981). Comb row beating is highly regulated by neuronal and non-neuronal integrative pathways (Tamm, 2014a), and as a result, ctenophores exhibit complex swimming behaviors including positive and negative geotaxis (Horridge, 1971; Tamm, 1980, 1982; Lowe, 1997), feeding behavior (Swanberg, 1974; Tamm and Moss, 1985; Moss and Tamm, 1986, 1987, 1993; Haddock, 2007), and stimulus responses such as pausing (Göthlin, 1920) and escape reverse/fast-forward swimming (Mackie et al., 1992; Kreps et al., 1997; Tamm, 2014a). Besides comb plates, motile cilia play a major role in ctenophore biology, including toothed macrocilia 
located inside the mouths of predatory beroid species, used for biting and engulfing prey (Swanberg, 1974; Tamm and Tamm, 1988), and balancer cilia of the statocyst (Figure 6A), a gravity receptor located at the aboral pole, where four balancers transduce angular body displacement to changes in comb row beat frequency during geotactic behavior (Chun, 1880; Tamm, 1982, 2014a,b, 2015). Notably, although locomotion is largely mediated by comb rows, ctenophores employ muscles for numerous motile behaviors, in particular with respect to feeding, such as the dramatic engulfing of prey by beroids (Swanberg, 1974; Bilbaut et al., 1988a,b; Haddock, 2007), the retraction of tentacles upon prey capture (Hertwig and Hertwig, 1879; Mackie et al., 1988), and the movement of oral structures such as lobes and auricles of lobate species to direct food into the mouth (Tamm, 1982, 2014a; Larson, 1988).

Voltage-activated $\mathrm{Ca}^{2+}$ currents are implicated in numerous aspects of ctenophore biology, including electrical signaling, muscle contraction, ciliary reversal of comb rows, beat frequency of balancer cilia of the statocyst, and activation of macrocilia in the beroid mouth. As noted above, ctenophores possess a single $\mathrm{Ca}_{\mathrm{v}}$ channel phylogenetically similar to $\mathrm{Ca}_{\mathrm{v}} 2$ types (Figure 4 ), as well as two $\mathrm{Na}_{\mathrm{v}} 2$ channels which are likely $\mathrm{Ca}^{2+}$ permeable if not $\mathrm{Ca}^{2+}$ selective. Below, we discuss some experimental observations that implicate $\mathrm{Ca}_{\mathrm{v}}$ and/or $\mathrm{Na}_{\mathrm{v}} 2$ channels in ciliary and muscle function in ctenophores, and discuss their potential involvement in the less understood processes of neural excitation and synaptic transmission.

\section{Electrical Signaling and Synaptic Transmission}

Phylogenetic analyses suggest that ctenophores are the most basal animals (Dunn et al., 2008; Ryan et al., 2013; Moroz et al., 2014; Whelan et al., 2015), leading to the controversial hypothesis that they independently evolved a nervous system (Marlow and Arendt, 2014; Moroz et al., 2014; Moroz and Kohn, 2015, 2016; Ryan and Chiodin, 2015). The most identifiable feature of the nervous system are synapses, defined by the presence of pre-synaptic active zones, connected across the synaptic cleft to electron-dense post-synaptic densities (Heuser and Reese, 1977). Genome sequencing has revealed that the vast majority of genes involved in synapse formation and function are present in ctenophores (Ryan et al., 2013; Moroz et al., 2014; Moroz and Kohn, 2015), animals which lack synapses [sponges (Srivastava et al., 2010) and placozoans (Srivastava et al., 2008)], and even unicellular organisms that pre-date animals (King et al., 2008; Fairclough et al., 2013). Thus, the mere presence or absence of select synaptic genes, in particular those with more generalized functions in exocytosis not specific to synapses, is not enough to confirm or refute the independent evolution hypothesis, since most of these genes were present before the ctenophore divergence. Resolving this issue will require extensive molecular comparative analyses of nervous system development and function.

The ctenophore nervous system consists of two distinct nerve nets (Jager et al., 2011), as well as separate neural structures that innervate peripheral structures such as the tentacles, comb rows and mouth (Hernandez-Nicaise, 1973b, 1991; Mackie et al., 1992; Tamm and Tamm, 1995; Jager et al., 2011). Giant axons have been documented running under the comb rows of select species, which synapse onto comb plate polster cells and are believed to alter ciliary beating during escape swimming (Mackie et al., 1992). Here, the large-diameter axons are considered an adaptation to increase action potential velocity, with speeds greater than $0.5 \mathrm{~ms}^{-1}$ comparable to the $1.4 \mathrm{~ms}^{-1}$ of giant axons of the jellyfish $A$. digitale escape system (Mackie and Meech, 1985). Large diameter axons have also been documented in the mouths of beroids, which synapse onto smooth muscle and adhesive epithelial cells to coordinate swallowing of prey and the subsequent tight closure of the mouth (Tamm and Tamm, 1995). Thus, fast neuronal signaling is certainly confirmed in ctenophores, but the mechanisms by which these signals are transduced across the synaptic cleft remains a mystery. Indeed, the atypical ultrastructure of the ctenophore synapse suggests that the underlying mechanisms for synaptic transmission might be inherently different from other animals. Most notable is that in ctenophores pre-synaptic vesicles appear to bud off from the SER (or perhaps fuse with it), suggesting that vesicles are derived independently of the Golgi network and pre-synaptic endosomes, as in bilaterian synapses (Heuser and Reese, 1973; Jahn and Fasshauer, 2012). If this proves to be true, it would represent a striking fundamental difference in synapse organization and function consistent with independent evolution. By extension, this arrangement would provide ER-derived neuropeptides direct access to pre-synaptic vesicles, consistent with the notion that ctenophore synapses rely heavily on neuropeptides as transmitters (Jager et al., 2011; Moroz et al., 2014; Moroz and Kohn, 2016).

The presence of both SER and large mitochondria within nanometer proximity of the putative vesicle release sites suggests that $\mathrm{Ca}^{2+}$ plays a role in ctenophore synaptic exocytosis, where the two organellar systems are poised to act as sources or sinks for $\mathrm{Ca}^{2+}$ ions (Clapham, 2007). Unfortunately, only a few examples of electrophysiologically-recorded synaptic potentials are available for ctenophores (Moss and Tamm, 1987; Meech, 2015), and no experimental evidence is available describing the involvement of the single $\mathrm{Ca}_{\mathrm{v}}$ 2-like channel or other $\mathrm{Ca}^{2+}$ channels in vesicle exocytosis. In bilaterian synapses, $\mathrm{Ca}^{2+}$ influx through $\mathrm{Ca}_{\mathrm{v}} 2$ channels is required to activate $\mathrm{Ca}^{2+}$-sensitive exocytotic machinery, and this is achieved by close apposition of the channels with docked vesicles. As noted above, some interactions with scaffolding proteins that help tether $\mathrm{Ca}_{\mathrm{v}} 2$ channels at the synapse appear to have deep ancestry, occurring in both protostome and deuterostome bilaterians (e.g., Rim-1, Mint1, and CASK). If these interactions extend to both cnidarians and ctenophores, this would strengthen the argument for the single origin of the nervous system hypothesis. Instead, the obligate close apposition of SER and mitochondria to what appear to be docked vesicles in the ctenophore synapse might indicate that $\mathrm{Ca}_{\mathrm{v}}$ channel nanodomain coupling is circumvented in lieu of calcium-induced calcium release from the SER, a mechanism for synaptic transmission that would be highly atypical. Clearly, this area of research warrants further study, to explain homology or convergence between synapses in ctenophores and those in cnidarians/bilaterians. 


\section{Muscle Contraction}

The most detailed electrophysiological records of membrane ion currents in ctenophores come from enzymatically-isolated smooth muscle cells. These cells are multinucleated and can be massive (upwards of $6 \mathrm{~cm}$ long and $40 \mu \mathrm{m}$ in diameter), and are innervated by nerve net neurons at neuromuscular junctions bearing the presynaptic triad arrangement (Hernandez-Nicaise, 1973a). Isolated muscle cells from the cydippid Pleurobrachia bachei conduct action potentials and contract in response to external perfusion of L-glutamate, as less so L-aspartate, but not to other transmitters such as GABA, histamine and acetylcholine (Moroz et al., 2014). Thus, ctenophore neuromuscular junctions are proposed to be glutamatergic, although the various ionotropic glutamate receptors present in the genome have yet to be localized to muscle synapses. Intracellular voltage clamp experiments reveal diverse pools of ion channels in ctenophore smooth muscle, which generate distinct action potential waveforms in different cell types. In Mnemiopsis giant muscle cells, which project from the statocyst to the mouth and auricles (Anderson, 1984; Hernandez-Nicaise et al., 1984), the depolarization phase of the action potential is driven by at least two distinct voltage-gated channels permeable to $\mathrm{Ca}^{2+}$ and $\mathrm{Na}^{2+}$ (but more selective for $\mathrm{Ca}^{2+}$ ), both high voltage activated and sensitive to $\mathrm{Ca}_{\mathrm{v}}$ channel blockers $\mathrm{Cd}^{2+}$, $\mathrm{Co}^{2+}$ and dihydropyridines verapamil and methoxyverapamil (Anderson, 1984; Dubas et al., 1988). One notable distinction was their kinetics, with one channel bearing fast inactivation producing fast, transient $\mathrm{Ca}^{2+}$ currents, and the other much slower inactivation, producing slow, long-lasting currents (Dubas et al., 1988). Similar depolarizing $\mathrm{Ca}^{2+} / \mathrm{Na}^{+}$currents were reported for the action potential of giant muscle cells isolated from B. ovata (Hernandez-Nicaise et al., 1980, 1982; Bilbaut et al., 1988a,b). For both species, $\mathrm{Ca}^{2+}$ influx through the channels seems required for contraction, since removal of external $\mathrm{Ca}^{2+}$ or pharmacological disruption abrogates muscle action potentials and contractions (Hernandez-Nicaise et al., 1980; Anderson, 1984; Bilbaut et al., 1988a,b; Dubas et al., 1988; Cario et al., 1996). Unfortunately, while the available data provides convincing evidence for the existence of distinct voltage-gated $\mathrm{Ca}^{2+}$ channels present in ctenophore smooth muscle, little can be said about the specific channel types at play. The three most likely candidates, the single $\mathrm{Ca}_{\mathrm{v}} 2$ and two $\mathrm{Na}_{\mathrm{v}} 2$ channels, are expected to be highly divergent from their homologs in other animals, and their specific pharmacological, ion selectivity and biophysical properties are completely unknown. Further confounding the matter is that currents recorded from a cloned $\mathrm{Na}_{\mathrm{v}} 2$ channel (from honeybee) are sensitive to $\mathrm{Cd}^{2+}$ but not dihydropyridines (Gosselin-Badaroudine et al., 2016), while in situ currents recorded from cnidarian neurons are sensitive to both $\mathrm{Cd}^{2+}$ and dihydropyridines (Anderson, 1987; Spafford et al., 1996). $\mathrm{Ca}^{2+}$ vs. $\mathrm{Na}^{+}$selectivity is also not a good marker for channel identity, since it can be quite variable, a fact made evident by the T-type channel from snail $L$. stagnalis which becomes highly $\mathrm{Na}^{+}$permeable via alternative splicing in the domain II P-loop region, without altering its $\mathrm{Ca}^{2+}$ selectivity filter motif of EEDD (Senatore et al., 2014). Nonetheless, it is worth noting that ctenophores are the only animals with bona fide muscle cells lacking $\mathrm{Ca}_{\mathrm{v}} 1$ channels, the main drivers for excitation-contraction coupling in other animals. In this regard, and in accordance with the proposed independent evolution of ctenophore muscle (Ryan et al., 2013; Moroz et al., 2014), smooth muscle cells seem to depend on somewhat atypical depolarizing conductances for excitation-contraction coupling.

In $B$. ovata, movements of the mouth and pharynx during swallowing of prey are encoded by different conductance/contractile profiles of distinct muscle cell types, in lieu of a complex nervous system capable of sophisticated temporal and spatial synaptic outputs (Bilbaut et al., 1988a,b). Radial smooth muscle cells, which span the mesoglea and are anchored in the outer epidermis (ectoderm) and pharyngeal endoderm (Hernandez-Nicaise et al., 1980), exhibit narrow, transient action potentials required in bursts for contraction to occur. Instead, longitudinal muscles running along the ectoderm exhibit longer lasting action potentials, each capable of causing contraction. The differences in action potential waveforms are attributed to different repolarizing conductances: Radial fibers bear pronounced, rapidly activating $\mathrm{K}^{+}$currents, while longitudinal fibers bear a slow $\mathrm{Ca}^{2+}$-activated $\mathrm{K}^{+}$current $\left(\mathrm{K}_{\mathrm{Ca}}\right)$, and a transient, voltage-sensitive $\mathrm{K}^{+}$current. Worth noting is that the functional coupling of voltage-gated $\mathrm{Ca}^{2+}$ channels with $\mathrm{Ca}^{2+}$-sensitive $\mathrm{K}^{+}$channels (e.g., $\mathrm{K}_{\mathrm{Ca}}$ channels such as $\mathrm{BK}$ and SK), also documented in Mnemiopsis smooth muscle (Anderson, 1984), predates animals, observed in protists (Valentine et al., 2012) and dinoflagellates (Pozdnyakov and Skarlato, 2015). In vertebrates, both $\mathrm{BK}$ and $\mathrm{SK} \mathrm{K}_{\mathrm{Ca}}$ channels physically and functionally couple with $\mathrm{Ca}_{\mathrm{v}} 1, \mathrm{Ca}_{\mathrm{v}} 2$, and $\mathrm{Ca}_{\mathrm{v}} 3$ channels, presumably to overcome the limited diffusion range of $\mathrm{Ca}^{2+}$ ions in the cytoplasm (Clapham, 2007; Guéguinou et al., 2014). This coupling is observed in neurons which undergo spike frequency adaptation, where trains of action potentials accumulate more and more cytoplasmic $\mathrm{Ca}^{2+}$ and $\mathrm{K}_{\mathrm{Ca}}$ channel activation, leading to a slowing down of action potential frequency and an eventual disruption of the action potential spike train (Yarom et al., 1985). In accordance, longitudinal but not radial muscle in Beroe exhibit spike frequency adaptation and eventual cessation of induced spikes. As noted by the authors, the difference in muscle properties would permit bursts of synaptic inputs from the nerve net to cause short lived contractions of longitudinal fibers, while causing facilitating, long lasting contractions of radial fibers, permitting more complex movement of the mouth and pharynx (Bilbaut et al., 1988a).

It is unknown whether membrane $\mathrm{Ca}^{2+}$ influx alone activates contractile myofilaments, or whether internal stores from the sarcoplasmic reticulum or mitochondria contribute via CICR or some other mechanism. Notably, the sarcoplasmic reticulum (SR) is diminished compared to other smooth muscle cells, making up less than $1 \%$ of the total cell volume, and that the plasma membrane (sarcolemma) lacks typical invaginations and appositions with the SR (Hernandez-Nicaise and Amsellem, 1980; Hernandez-Nicaise et al., 1980, 1984), both of which serve to enhance the CICR process. Furthermore, in larger cells, the sarcolemma can be as far as $2000 \mathrm{~nm}$ away from the SR and mitochondria(Hernandez-Nicaise et al., 1980). Considering the observed range of $\mathrm{Ca}_{\mathrm{v}}$ channel cytoplasmic $\mathrm{Ca}^{2+}$ plumes of 
roughly $100 \mathrm{~nm}$, even in elevated external $\left[\mathrm{Ca}^{2+}\right]$ (Weber et al., 2010), this separation seems rather imposing. Nevertheless, ATPhydrolyzing enzymes that would shuffle $\mathrm{Ca}^{2+}$ ions into the SR and mitochondria, as well as out of the cell through the sarcolemma, have been detected (Cario et al., 1996), and $\mathrm{Ca}^{2+}$ fluorescence experiments reveal that action potentials trigger $\mathrm{Ca}^{2+}$ release from internal stores (Cario et al., 1995a,b). Thus, CICR likely takes place in ctenophore smooth muscle at least to some degree. Interestingly, all smooth muscle cells observed possess extracellular axonemes (i.e., bare cilia), which run along the lengths of the muscle fibers nestled within circumferential invaginations of the sarcolemma (Tamm and Tamm, 1989). The mechanism by which these structures are formed, and their function, remains a mystery. Given the propensity of cilia to bind $\mathrm{Ca}^{2+}$, they have been proposed to act as external $\mathrm{Ca}^{2+}$ sources/sinks for excitation-contraction coupling (Tamm, 2014a).

Ctenophores also possess striated muscle. Cydippid specimens of the genus Euplokamis possess tentacles with specialized repeating side branches (tentilla) which extend and retract to lure and capture prey with their colloblasts (Chun, 1880). Tentilla are heavily innervated, and exhibit complex localized sensory integration, where tactile or electrical stimulation can activate rapid extension of single tentilla through contraction of bundled, long striated muscle cells running along their lengths; subsequent retraction and coiling is thought to occur passively, though the elastic properties of the underlying tissue (Mackie et al., 1988). Activation of this muscle is clearly through excitation, since depolarization of the membrane with high external $\left[\mathrm{K}^{+}\right]$ or electrical stimulation causes contraction (Mackie et al., 1988). In vivo, excitation-contraction coupling is likely elicited at neuromuscular junctions located along the outside of the bundled fibers, with few mitochondria indicating low energy expenditure as expected given the infrequent use of the tentilla for prey capture. Repeating striations in the muscle are clearly evident, bearing distinct Z, I, and A bands characteristic of striated muscle, but they lack $\mathrm{H}$ bands. Ctenophores lack key genes associated with striated muscle formation and function, including those involved in Z-disc formation (Steinmetz et al., 2012). Thus, striated muscle in Euplokamis might represent a third case of independently evolved striated muscle, along with bilateria and cnidaria. Like giant smooth muscle cells of Beroe and Mnemiopsis, Euplokamis striated muscle cells lack extensive SR at their center, as well as any obvious transverse tubular systems. However, they do possess a second arrangement of SR located within a few hundreds on nanometers from the sarcolemma. The involvement of membrane $\mathrm{Ca}^{2+}$ influx through voltagegated calcium channels and CICR in contraction has not yet been examined, however the presence of synapses, the rapid speed of contraction, and electrical activation of these striated muscle cells imply these processes do occur.

\section{Balancer Cilia in the Statocyst}

On their own, comb plates are static and require external inputs to initiate beating (Sleigh, 1974; Tamm, 1980). A major source of activation arrives from tracks of ciliated epidermal cells, called ciliated grooves, which transduce gravitational signals from the statocyst to the first comb plate of each row (Chun, 1880) (Figure 6A). The four balancers of the statocyst each consist of compound cilia, which at their tips support a conglomerated mass of living cells called the statolith, much like four legs supporting a table. Angular body displacement causes the statolith to exert differential gravitational force on each of the balancers, altering their respective beating frequency according to the angle of force exertion (Tamm, 1982). The balancers act as pacemakers for the comb rows via mechanical coordination (Tamm, 1982) (Figure 6A). During negative phototactic swimming, when ctenophores seek swim to the surface mouth facing up, tilting toward the horizontal causes balancers (and hence comb rows) below the midline to beat more frequently than ones above, while the opposite occurs during downward, mouth down (i.e., positive geotactic) swimming. Once the animals are vertical, all eight comb rows beat at a similar frequency (Tamm, 1980, 1982). Interestingly, evidence suggests that deflection-induced changes in balancer beating requires membrane excitation and $\mathrm{Ca}^{2+}$ influx of through voltage-gated channels, since removal of external $\mathrm{Ca}^{2+}$, or application of non-specific calcium channel blockers $\mathrm{Co}^{2+}$ and $\mathrm{Ni}^{2+}$, disrupt deflection-induced responses of the balancers (Lowe, 1997). Furthermore, chemical depolarization of isolated balancers (via increasing external $\left[\mathrm{K}^{+}\right]$) directly increases beating frequency independent of mechanical stimulation, but only in the presence of external $\mathrm{Ca}^{2+}$ specifically at the base of the cilium. Thus, a proposed model for statolith activation of balancer beating is that deflections activate cationic stretch-receptors at the cell membrane, which in turn activate voltage-gated calcium channels at the base of the cilium. $\mathrm{Ca}^{2+}$ influx through these channels then activates ciliary beating. Notably, such an arrangement appears inconsistent with sperm flagella, where hyperactivation (i.e., an alteration of ciliary waveform) depends on the voltage-gated $\mathrm{Ca}^{2+}$ channel CatSper localized along the length of the cilium, not at the base. Noted above, in Chlamydononas, a $\mathrm{Ca}_{\mathrm{v}}$ channel homolog dubbed CAV2 causes flagellar waveform change, and is also localized strictly to the distal regions of the cilia. A notable distinction between ctenophore balancers and these two other systems is that in balancers, $\mathrm{Ca}^{2+}$ influx at the base serves to activate ciliary beating, whereas in sperm and Chlamydomonas, distal $\mathrm{Ca}^{2+}$ influx along the ciliary membrane serves to alter the waveform of ciliary beating, either by increasing asymmetry of the flagellar waveform (sperm), or by increasing waveform symmetry (Chlamydomonas). Consistent with this distinction, activation of distal voltage-gated calcium channels in comb plate cilia leads to reversal of beating during backward swimming and feeding behavior, whereas voltage-gated $\mathrm{Ca}^{2+}$ channels located at the base of beroid macrocilia activate beating. These similarities prompted Tamm to propose conserved mechanisms for voltage-gated $\mathrm{Ca}^{2+}$ channel regulation of ciliary beating, where channels located along the length of the cilia influence "reprogramming" responses of the ciliary waveform (e.g., reversal, waveform changes), whereas those at the base of the cilia influence "on-off" responses (e.g., activation, arrest, or increase in beating frequency) (Tamm, 1994, 2014a). 
The propensity of ctenophores to switch between upward swimming (negative geotaxis) and downward swimming (positive geotaxis) is referred to as their "mood," and is thought to be regulated by neural inputs to balancer cells from various sensory modalities, including those tuned to water disturbances and hydrostatic pressure (Tamm, 1982, 2014a; Lowe, 1997). Electron microscopy of the statocyst and surrounding areas reveals neurites which synapse onto balancer cells(Tamm, 1982; Hernandez-Nicaise, 1991). Furthermore, intact larvae and dissected statocysts from M. leidyi and Pleurobrachia pileus respond to ectopic electrical stimulation and membrane depolarization with high external $\left[\mathrm{K}^{+}\right]$by switching between geotactic states (Lowe, 1997), consistent with regulation by electrical signaling. Mechanistically, a switch in mood/geotactic state requires that the same deflectional forces acting on the balancer cilia produce opposite effects on their beating frequency at different times. Nonetheless, regardless of geotactic sign, ciliary deflection in the appropriate direction causes $\mathrm{Ca}^{2+}$ influx and increased beating. Thus, the mechanisms by which putative synaptic inputs alter geotactic mood in the balancers are likely independent of the stretch-activated channels and voltagegated $\mathrm{Ca}^{2+}$ channels. Finally, ctenophores are able to override geotactic behavior and exhibit different types of swimming, such as horizontal, feeding, and reverse escape. The mechanisms by which this takes place are not known (Tamm, 2014a); neural inputs to the balancers, ciliated grooves, and/or comb plates is a possiblility.

\section{Comb Plate Cilia and Macrocilia}

In Euplokamis, electrical stimulation near the mouth causes a temporary reversal of comb plate beating and thus reverse swimming, presumably via nerve impulses from giant axons running under the comb plates which synapse onto polster cells (Mackie et al., 1992). Instead, stimulation at the aboral end causes increased ciliary beating for fast-forward swimming, which based on experiments in Pleurobrachia, might occur via nerve inputs downstream of the statocyst perhaps at the ciliated grooves or the aboral-most comb plates (Tamm, 1982). Similar fast-forward and reverse swimming responses are observed for Mnemiopsis upon contact with a jellyfish predator (Kreps et al., 1997). Unilateral reversal of comb plate beating is also observed during cydippid feeding (Tamm and Moss, 1985), where in Pleurobrachia, comb rows flanking tentacles with ensnared prey reverse, leading to rotation of the animal such that the appropriate tentacle bearing food approaches the mouth. Here, direct electrical stimulation of a single tentacle or its adjacent body surface causes comb plate reversal, through an apparently bilateral conduction pathway innervating only the four ipsilateral comb rows of that tentacle (Moss and Tamm, 1993). The mechanism for comb plate reversal is thought to occur directly in comb plate polster cells, where intracellular recording at the cell soma revealed that neural stimulus-induced synaptic potentials give rise $\mathrm{Ca}^{2+}$-dependent action potentials, leading to ciliary reversal (Moss and Tamm, 1986). Extracellular recording and $\mathrm{Ca}^{2+}$ imaging of comb plate cilia revealed that action potentials propagate from base to tip of the cilium (Tamm and Terasaki, 1994), and could be abrogated by application of inorganic calcium channel blockers (Moss and
Tamm, 1987). Thus, similar to Chlamydomonas CAV2, a voltagegated $\mathrm{Ca}^{2+}$ channel distributed along the ciliary membrane mediates motor responses. It will be interesting if this channel turns out to be $\mathrm{Ca}_{\mathrm{v}} 2$, suggesting an ancient and conserved coupling of $\mathrm{Ca}_{\mathrm{v}}$ channels types with ciliary reversal.

Finally, giant "toothed" macrocilia located inside the mouth of predatory beroid species receive synaptic input from a giant axon nerve net (Tamm and Tamm, 1985, 1995), whose excitatory inputs activate beating from an otherwise intermittent/quiescent state during engulfing of prey (Tamm, 1983, 1988a). The macrociliary power stroke is directed into the body cavity, helping to draw or macerate prey into the stomach (Swanberg, 1974). Notably, both semi-intact preparations of macrocilia, as well as isolated macrociliary cells, become activated in response to depolarization with high external $\left[\mathrm{K}^{+}\right]$, but only in the presence of external $\mathrm{Ca}^{2+}$ which need only be applied by perfusion to the base of the cilium (Tamm, 1988a,b). Furthermore, application of non-selective calcium channel blockers prevents macrociliary activation (Tamm, 1988a). Indeed, all of the data is consistent with a model where synaptic inputs depolarize the membrane to activate voltage-gated $\mathrm{Ca}^{2+}$ channels strictly at the base of the cilia to initiate beating (Tamm, 2014a). Thus, either differential localization of the same voltagegated calcium channel used to reverse beating of comb plate cilia, or a different channel altogether (perhaps also used at the base of balancers), plays the role of activating beating of macrocilia, consistent with Tamm's hypothesis on localizationdependent "on-off" vs. "reprogramming" function of ciliary calcium channels.

\section{CONCLUSIONS}

Recent studies suggest that four domain P-loop channels, which include $\mathrm{Ca}_{\mathrm{v}}$ and $\mathrm{Na}_{\mathrm{v}}$ channels, evolved as $\mathrm{Ca}^{2+}$-selective channels with selectivity filter motifs enriched in glutamate and aspartate residues, producing high-affinity binding sites for $\mathrm{Ca}^{2+}$ in the pore (Liebeskind et al., 2011; Moran et al., 2015). Later, in bilaterians and cnidarians, $\mathrm{Na}^{+}$selective channels emerged, allowing for separation of electrogenic depolarizing $\mathrm{Na}^{+}$currents from $\mathrm{Ca}^{2+}$ signaling (Barzilai et al., 2012). In general, $\mathrm{Ca}_{\mathrm{v}}$ and $\mathrm{Ca}^{2+}$-selective $\mathrm{Na}_{\mathrm{v}} 2$ channels provide excitable cells with a means of exerting rapid and transient changes in cellular proteins through $\mathrm{Ca}^{2+}$-dependent alterations in their structure and complexing. An array of such proteins have evolved, including $\mathrm{Ca}^{2+}$-sensitive ion channels, components of the exocytotic machinery, proteins involved in control of ciliary beating, and signaling proteins. Key to these functional associations is proximity; $\mathrm{Ca}^{2+}$ is actively sequestered and extruded from the cytoplasm, so $\mathrm{Ca}_{\mathrm{v}}$ channels need to be positioned close to their cytoplasmic partners, and often physically couple with them either directly or through protein intermediaries. In the organismal lineages leading to Metazoa, different types of $\mathrm{Ca}_{\mathrm{v}}$ channels evolved with distinct voltage dependencies, kinetics of activation and inactivation, and $\mathrm{Ca}^{2+}$ selectivity, most distinguishable between high voltage-activated $\mathrm{Ca}_{\mathrm{v}} 1$ and $\mathrm{Ca}_{\mathrm{v}} 2$ type channels and low voltage activated $\mathrm{Ca}_{\mathrm{v}} 3$ type channels. In 
the nervous system, this fundamental distinction means that $\mathrm{Ca}_{\mathrm{v}} 3$ channels are best suited for helping neurons decide when to fire action potentials, while $\mathrm{Ca}_{\mathrm{v}} 1$ and $\mathrm{Ca}_{\mathrm{v}} 2$ channels are brought in as effectors once the decision has been made. This bifurcation appears quite ancient, dating at least as far back as the divergence between choanoflagellates and metazoans (Liebeskind et al., 2011; Barzilai et al., 2012; Fairclough et al., 2013; Moran and Zakon, 2014). Cnidarans are the most basal lineage of animals to have a nervous system and possess all three types of $\mathrm{Ca}_{\mathrm{v}}$ channels, which interestingly, are also present in Trichoplax which lacks a nervous system. More basal ctenophores and sponges only have a single $\mathrm{Ca}_{\mathrm{v}}$ channel, where the ctenophore channel is phylogentically more similar to $\mathrm{Ca}_{\mathrm{v}} 2$ channels, and the sponge to $\mathrm{Ca}_{\mathrm{v}} 1 / 2$ or $\mathrm{Ca}_{\mathrm{v}} 1$ channels. In cnidaria and ctenophora, there are some interesting parallels in neuromuscular physiology compared to bilaterians; it will be interesting whether homologous functional and proteomic associations of $\mathrm{Ca}_{\mathrm{v}}$ channels occur in these basal animals to account for these similarities. In Placozoa and Porifera, the lack of nervous systems begs the questions: What functions do "nervous system" genes serve in the absence of neurons and muscle? To what extent are the necessary protein complexes present, and what key elements do they lack that account for their absence of synapses?

The evolution of sophisticated processes involving $\mathrm{Ca}_{\mathrm{v}}$ channels, as observed in neurons (excitation-transcription coupling), at the pre-synaptic terminal (excitation-secretion coupling), in muscle (excitation-contraction coupling) and in cilia (alteration of ciliary beating), might have involved innovations in cellular co-expression and subcellular complexing with other proteins. This, combined with the distinguishing

\section{REFERENCES}

Altier, C., Garcia-Caballero, A., Simms, B., You, H., Chen, L., Walcher, J., et al. (2011). The $\mathrm{Ca}_{\mathrm{v}} \beta$ subunit prevents RFP2-mediated ubiquitination and proteasomal degradation of L-type channels. Nat. Neurosci. 14, 173-180. doi: $10.1038 / \mathrm{nn} .2712$

Anderson, A. V. (1984). The electrophysiology of single smooth muscle cells isolated from the ctenophore Mnemiopsis. J. Comp. Physiol. B 154, 257-268. doi: 10.1007/BF02464405

Anderson, P. A. (1987). Properties and pharmacology of a TTX-insensitive $\mathrm{Na}^{+}$ current in neurones of the jellyfish Cyanea capillata. J. Exp. Biol. 133, 231-248.

Anderson, P. A., and Bouchard, C. (2009). The regulation of cnidocyte discharge. Toxicon 54, 1046-1053. doi: 10.1016/j.toxicon.2009.02.023

Anderson, P. A., and Grünert, U. (1988). Three-dimensional structure of bidirectional, excitatory chemical synapses in the jellyfish Cyanea capillata. Synapse 2, 606-613. doi: 10.1002/syn.890020605

Angstadt, J. D., and Calabrese, R. L. (1991). Calcium currents and graded synaptic transmission between heart interneurons of the leech. J. Neurosci. 11, 746-759.

Gur Barzilai, M., Reitzel, A. M., Kraus, J. E., Gordon, D., Technau, U., Gurevitz, M., et al. (2012). Convergent evolution of sodium ion selectivity in metazoan neuronal signaling. Cell Rep. 2, 242-248. doi: 10.1016/j.celrep.2012.06.016

Baumgarten, S., Simakov, O., Esherick, L. Y., Liew, Y. J., Lehnert, E. M., Michell, C. T., et al. (2015). The genome of Aiptasia, a sea anemone model for coral symbiosis. Proc. Natl. Acad. Sci. U.S.A. 112, 11893-11898. doi: $10.1073 /$ pnas. 1513318112

Berg, J., Yang, H., and Jan, L. Y. (2012). $\mathrm{Ca}^{2+}$-activated $\mathrm{Cl}^{-}$channels at a glance. J. Cell Sci. 125, 1367-1371. doi: 10.1242/jcs.093260

Bers, D. M. (2002). Cardiac excitation-contraction coupling. Nature 415, 198-205. doi: $10.1038 / 415198$ a ion conduction properties of the different $\mathrm{Ca}_{\mathrm{v}}$ channels types, created a rich repertoire of modular interactions which could be deployed in different contexts to bring about desired cellular outputs. Not clear is whether the intrinsic properties and functional/proteomic associations of $\mathrm{Ca}_{\mathrm{v}}$ channels, essential for nervous system function, largely predate the nervous system, or where extensively "tweaked" along the way. In the case of $\mathrm{Ca}_{\mathrm{v}} 3$ channels, intrinsic properties appear highly conserved, where the homolog from Trichoplax bears striking biophysical resemblance to human orthologs. Further comparative studies, evaluating the electrophysiological properties and proteomic interactions of $\mathrm{Ca}_{\mathrm{v}}$ channels in early-diverging animals, is poised to provide valuable and interesting insights on animal evolution.

\section{AUTHOR CONTRIBUTIONS}

AS wrote the initial draft of the manuscript. AS, HR, and PL revised the manuscript and generated the analyses and figures.

\section{FUNDING}

Funding support was provided by NSERC Discovery (RGPIN2016-06023) and CFI grants (CFI Project 35297), and University of Toronto startup funds to AS, and an NSERC USRA to PL.

\section{ACKNOWLEDGMENTS}

We thank Dr. Sidney Tamm for his useful insights on ctenophore biology, and his feedback and comments on the manuscript.

Bessen, M., Fay, R. B., and Witman, G. B. (1980). Calcium control of waveform in isolated flagellar axonemes of Chlamydomonas. J. Cell Biol. 86, 446-455. doi: 10.1083/jcb.86.2.446

Bichet, D., Cornet, V., Geib, S., Carlier, E., Volsen, S., Hoshi, T., et al. (2000). The I-II loop of the $\mathrm{Ca}^{2+}$ channel $\alpha_{1}$ subunit contains an endoplasmic reticulum retention signal antagonized by the $\beta$ subunit. Neuron 25, 177-190. doi: 10.1016/S0896-6273(00)80881-8

Bilbaut, A., Hernandez-Nicaise, M. L., Leech, C., and Meech, R. (1988a). Membrane currents that govern smooth muscle contraction in a ctenophore. Nature 331, 533-535. doi: 10.1038/331533a0

Bilbaut, A., Meech, R. W., and Hernandez-Nicaise, M. (1988b). Isolated giant smooth muscle fibres in Beroe ovata: ionic dependence of action potentials reveals two distinct types of fibre. J. Exp. Biol. 135, 343-362.

Blair, J. E., and Hedges, S. B. (2005). Molecular phylogeny and divergence times of deuterostome animals. Mol. Biol. Evol. 22, 2275-2284. doi: $10.1093 / \mathrm{molbev} / \mathrm{msi} 225$

Böhme, M. A., Beis, C., Reddy-Alla, S., Reynolds, E., Mampell, M. M., Grasskamp, A. T., et al. (2016). Active zone scaffolds differentially accumulate Unc13 isoforms to tune $\mathrm{Ca}^{2+}$ channel-vesicle coupling. Nat. Neurosci. 19, 1311-1320. doi: $10.1038 / \mathrm{nn} .4364$

Borowiec, A.-S., Bidaux, G., Pigat, N., Goffin, V., Bernichtein, S., and Capiod, T. (2014). Calcium channels, external calcium concentration and cell proliferation. Eur. J. Pharmacol. 739, 19-25. doi: 10.1016/j.ejphar.2013. 10.072

Bouchard, C., Price, R. B., Moneypenny, C. G., Thompson, L. F., Zillhardt, M., Stalheim, L., et al. (2006). Cloning and functional expression of voltage-gated ion channel subunits from cnidocytes of the Portuguese Man O’War Physalia physalis. J. Exp. Biol. 209, 2979-2989. doi: 10.1242/jeb. 02314 
Brinkmann, M., Oliver, D., and Thurm, U. (1996). Mechanoelectric transduction in nematocytes of a hydropolyp (Corynidae). J. Comp. Physiol. A 178, 125-138. doi: 10.1007/BF00189597

Bullock, T. H. (1943). Neuromuscular facilitation in scyphomedusae. J. Cell. Comp. Physiol. 22, 251-272. doi: 10.1002/jcp.1030220306

Buraei, Z., and Yang, J. (2010). The $\beta$ subunit of voltage-gated $\mathrm{Ca}^{2+}$ channels. Physiol. Rev. 90, 1461-1506. doi: 10.1152/physrev.00057.2009

Burton, P. M. (2008). Insights from diploblasts; the evolution of mesoderm and muscle. J. Exp. Zool. B Mol. Dev. Evol. 310, 5-14. doi: 10.1002/jez.b.21150

Cai, X. (2012). Ancient origin of four-domain voltage-gated $\mathrm{Na}^{+}$channels predates the divergence of animals and fungi. J. Membr. Biol. 245, 117-123. doi: 10.1007/s00232-012-9415-9

Canti, C., Nieto-Rostro, M., Foucault, I., Heblich, F., Wratten, J., Richards, M. W., et al. (2005). The metal-ion-dependent adhesion site in the Von Willebrand factor-A domain of $\alpha_{2} \delta$ subunits is key to trafficking voltagegated $\mathrm{Ca}^{2+}$ channels. Proc. Natl. Acad. Sci.U.S.A. 102, 11230-11235. doi: 10.1073/pnas.0504183102

Carbone, E., and Lux, H. (1984). A low voltage-activated, fully inactivating Ca channel in vertebrate sensory neurones. Nature 310, 501-502. doi: $10.1038 / 310501 \mathrm{a} 0$

Carbone, E., Giancippoli, A., Marcantoni, A., Guido, D., and Carabelli, V. (2006a). A new role for T-type channels in fast "low-threshold" exocytosis. Cell Calcium 40, 147-154. doi: 10.1016/j.ceca.2006.04.019

Carbone, E., Marcantoni, A., Giancippoli, A., Guido, D., and Carabelli, V. (2006b). T-type channels-secretion coupling: evidence for a fast low-threshold exocytosis. Pflügers Arch. 453, 373-383. doi: 10.1007/s00424-006-0100-7

Cario, C., Laugier, J., Meech, R., and Hernandez-Nicaise, M. (1995a). Imaging of action potential-induced-calcium transients in two types of giant smooth muscle cells. J. Muscle Res. Cell Motil. 16, 141.

Cario, C., Meech, R., and Hernandez-Nicaise, M. (1995b). Calcium management in giant smooth muscle cells. First evidence for a calcium-induced-calciumrelease. J. Muscle Res. Cell Motil. 16, 162.

Cario, C., Nicaise, G., and Hernandez-Nicaise, M.-L. (1996). Cytochemical localization of $\mathrm{Ca}^{2+}$-ATPases and demonstration of ATP-dependent calcium sequestration in giant smooth muscle fibres of Beroe. J. Muscle Res. Cell Motil. 17, 85-94. doi: 10.1007/BF00140327

Catterall, W. A. (1991). Excitation-contraction coupling in vertebrate skeletal muscle: a tale of two calcium channels. Cell 64, 871-874. doi: 10.1016/00928674(91)90309-M

Cattera, W. A. (2011). Voltage-gated calcium channels. Cold Spring Harb. Perspect. Biol. 3:a003947. doi: 10.1101/cshperspect.a003947

Catterall, W. A. (2012). Voltage-gated sodium channels at 60: structure, function and pathophysiology. J. Physiol. 590, 2577-2589. doi: 10.1113/jphysiol.2011.224204

Catterall, W. A., Perez-Reyes, E., Snutch, T. P., and Striessnig, J. (2005). International union of pharmacology. XLVIII. Nomenclature and structurefunction relationships of voltage-gated calcium channels. Pharmacol. Rev. 57, 411-425. doi: 10.1124/pr.57.4.5

Chapman, D. M. (1974). Cnidarian Histology. New York,NY: Academic Press.

Chapman, J. A., Kirkness, E. F., Simakov, O., Hampson, S. E., Mitros, T., Weinmaier, T., et al. (2010). The dynamic genome of Hydra. Nature 464, 592-596. doi: 10.1038/nature08830

Chave, K. E., Smith, S. V., and Roy, K. J. (1972). Carbonate production by coral reefs. Mar. Geol. 12, 123-140. doi: 10.1016/0025-3227(72)90024-2

Chun, C. (1880). Die Ctenophoren des Golfes von Neapel und der angrenzenden Meeres-Abschnitte. Flora und Fauna des Golfes von Neapel, 1. Leipzig: W. Engelmann.

Clapham, D. E. (2007). Calcium signaling. Cell 131, 1047-1058. doi: 10.1016/j.cell.2007.11.028

Conaco, C., Neveu, P., Zhou, H., Arcila, M. L., Degnan, S. M., Degnan, B. M., et al. (2012). Transcriptome profiling of the demosponge Amphimedon queenslandica reveals genome-wide events that accompany major life cycle transitions. BMC Genomics 13:209. doi: 10.1186/1471-2164-13-209

Curtis, B. M., and Catterall, W. A. (1984). Purification of the calcium antagonist receptor of the voltage-sensitive calcium channel from skeletal muscle transverse tubules. Biochemistry 23, 2113-2118. doi: 10.1021/bi00305a001

Davies, A., Kadurin, I., Alvarez-Laviada, A., Douglas, L., Nieto-Rostro, M., Bauer, C. S., et al. (2010). The $\alpha_{2} \delta$ subunits of voltage-gated calcium channels form
GPI-anchored proteins, a posttranslational modification essential for function. Proc. Natl. Acad. Sci. U.S.A. 107, 1654-1659. doi: 10.1073/pnas.0908735107

Dawson, T. F., Boone, A. N., Senatore, A., Piticaru, J., Thiyagalingam, S., Jackson, D., et al. (2013). Gene splicing of an invertebrate beta subunit $\left(\mathrm{LCa}_{\mathrm{v}} \beta\right)$ in the $\mathrm{N}$-terminal and $\mathrm{HOOK}$ domains and its regulation of $\mathrm{LCa}_{\mathrm{v}} 1$ and $\mathrm{LCa}_{\mathrm{v}} 2$ calcium channels. PLoS ONE 9:e92941. doi: 10.1371/journal.pone.00 92941

Pavans de Ceccatty, M. (1971). Effects of drugs and ions on a primitive system of spontaneous contractions in a sponge (Euspongia officinalis). Experientia 27, 57-59. doi: 10.1007/BF02137740

Dellaporta, S. L., Xu, A., Sagasser, S., Jakob, W., Moreno, M. A., Buss, L. W., et al. (2006). Mitochondrial genome of Trichoplax adhaerens supports Placozoa as the basal lower metazoan phylum. Proc. Natl. Acad. Sci.U.S.A. 103, 8751-8756. doi: 10.1073/pnas.0602076103

Doerner, J. F., Delling, M., and Clapham, D. E. (2015). Ion channels and calcium signaling in motile cilia. eLife 4:e11066. doi: 10.7554/eLife.11066

Dolmetsch, R. (2003). Excitation-transcription coupling: signaling by ion channels to the nucleus. Sci. Signal. 2003:pe4. doi: 10.1126/stke.2003.166.pe4

Dolphin, A. C. (2006). A short history of voltage-gated calcium channels. Br. J. Pharmacol. 147, S56-S62. doi: 10.1038/sj.bjp.0706442

Dolphin, A. C. (2013). The $\alpha_{2} \delta$ subunits of voltage-gated calcium channels. Biochim. Biophys. Acta 1828, 1541-1549. doi: 10.1016/j.bbamem.2012.11.019

Driesch, H., and Morgan, T. H. (1895). Zur Analysis der ersten Entwickelungsstadien des Ctenophoreneies. Arch. Entwicklungsmechanik der Organismen 2, 204-215. doi: 10.1007/BF02084247

Dubas, F., Stein, P. G., and Anderson, P. A. (1988). Ionic currents of smooth muscle cells isolated from the ctenophore Mnemiopsis. Proc. R. Soc. Lond. B Biol. Sci. 233, 99-121. doi: 10.1098/rspb.1988.0014

Dunlap, K. (1977). Localization of calcium channels in Paramecium caudatum. J. Physiol. 271:119. doi: 10.1113/jphysiol.1977.sp011993

Dunn, C. (2009). Siphonophores. Curr. Biol. 19, R233-R234. doi: 10.1016/j.cub.2009.02.009

Dunn, C. W., Hejnol, A., Matus, D. Q., Pang, K., Browne, W. E., Smith, S. A., et al. (2008). Broad phylogenomic sampling improves resolution of the animal tree of life. Nature 452, 745-749. doi: 10.1038/nature06614

Dymek, E. E., and Smith, E. F. (2007). A conserved CaM-and radial spokeassociated complex mediates regulation of flagellar dynein activity. J. Cell Biol. 179, 515-526. doi: 10.1083/jcb.200703107

Egger, V., Svoboda, K., and Mainen, Z. F. (2003). Mechanisms of lateral inhibition in the olfactory bulb: efficiency and modulation of spike-evoked calcium influx into granule cells. J. Neurosci. 23, 7551-7558.

Eitel, M., Osigus, H.-J., Desalle, R., and Schierwater, B. (2013). Global diversity of the Placozoa. PLoS ONE 8:e57131. doi: 10.1371/journal.pone.0057131

Elliott, G. R., and Leys, S. P. (2007). Coordinated contractions effectively expel water from the aquiferous system of a freshwater sponge. J. Exp. Biol. 210, 3736-3748. doi: 10.1242/jeb.003392

Elliott, G. R., and Leys, S. P. (2010). Evidence for glutamate, GABA and NO in coordinating behaviour in the sponge, Ephydatia muelleri (Demospongiae, Spongillidae). J. Exp. Biol. 213, 2310-2321. doi: 10.1242/jeb.039859

Ertel, E. A., Campbell, K. P., Harpold, M. M., Hofmann, F., Mori, Y., Perez-Reyes, E., et al. (2000). Nomenclature of voltage-gated calcium channels. Neuron 25, 533-535. doi: 10.1016/S0896-6273(00)81057-0

Fairclough, S. R., Chen, Z., Kramer, E., Zeng, Q., Young, S., Robertson, H. M., et al. (2013). Premetazoan genome evolution and the regulation of cell differentiation in the choanoflagellate Salpingoeca rosetta. Genome Biol. 14:R15. doi: 10.1186/gb-2013-14-2-r15

Fedulova, S. A., Kostyuk, P. G., and Veselovsky, N. S. (1985). Two types of calcium channels in the somatic membrane of new-born rat dorsal root ganglion neurones. J. Physiol. 359:431. doi: 10.1113/jphysiol.1985.sp015594

Fernandez-Valverde, S. L., Calcino, A. D., and Degnan, B. M. (2015). Deep developmental transcriptome sequencing uncovers numerous new genes and enhances gene annotation in the sponge Amphimedon queenslandica. BMC Genomics 16:387. doi: 10.1186/s12864-015-1588-z

Finnerty, J. R., Pang, K., Burton, P., Paulson, D., and Martindale, M. Q. (2004). Origins of bilateral symmetry: hox and dpp expression in a sea anemone. Science 304, 1335-1337. doi: 10.1126/science.1091946

Fischer, A. H., Pang, K., Henry, J. Q., and Martindale, M. Q. (2014). A cleavage clock regulates features of lineage-specific differentiation in the development 
of a basal branching metazoan, the ctenophore Mnemiopsis leidyi. EvoDevo 5:4. doi: 10.1186/2041-9139-5-4

Franc, J.-M. (1978). Organization and function of ctenophore colloblasts: an ultrastructural study. Biol. Bull. 155, 527-541. doi: 10.2307/15 40788

Fredman, D., Schwaiger, M., Rentzsch, F., and Technau, U. (2013). Nematostella vectensis Transcriptome and Gene Models v2.0. Figshare. doi: 10.6084/m9.figshare.807696

Freeman, G. (1977). The establishment of the oral-aboral axis in the ctenophore embryo. Development 42, 237-260.

Fujiu, K., Nakayama, Y., Yanagisawa, A., Sokabe, M., and Yoshimura, K. (2009). Chlamydomonas CAV2 encodes a voltage-dependent calcium channel required for the flagellar waveform conversion. Curr. Biol. 19, 133-139. doi: 10.1016/j.cub.2008.11.068

Gazave, E., Lapébie, P., Richards, G. S., Brunet, F., Ereskovsky, A. V., Degnan, B. M., et al. (2009). Origin and evolution of the Notch signalling pathway: an overview from eukaryotic genomes. BMC Evol. Biol. 9:249. doi: 10.1186/14712148-9-249

Gitter, A., Oliver, D., and Thurm, U. (1994). Calcium-and voltage-dependence of nematocyst discharge in Hydra vulgaris. J. Comp. Physiol. A 175, 115-122. doi: 10.1007/BF00217442

Gosselin-Badaroudine, P., Moreau, A., Simard, L., Cens, T., Rousset, M., Collet, C., et al. (2016). Biophysical characterization of the honeybee DSC1 orthologue reveals a novel voltage-dependent $\mathrm{Ca}^{2+}$ channel subfamily: $\mathrm{Ca}_{\mathrm{V}} 4$. J. Gen. Physiol. 148, 133-145. doi: 10.1085/jgp.201611614

Göthlin, G. F. (1920). Experimental studies on primary inhibition of the ciliary movement in Beroe cucumis. J. Exp. Zool. 31, 403-442. doi: 10.1002/jez.1400310404

Graf, E. R., Valakh, V., Wright, C. M., Wu, C., Liu, Z., Zhang, Y. Q., et al. (2012). RIM promotes calcium channel accumulation at active zones of the Drosophila neuromuscular junction. J. Neurosci. 32, 16586-16596. doi: 10.1523/JNEUROSCI.0965-12.2012

Grant, A. O. (2009). Cardiac ion channels. Circ. Arrhythm. Electrophysiol. 2, 185-194. doi: 10.1161/circep.108.789081

Grell, K. G., and Benwitz, G. (1971). Die ultrastruktur von Trichoplax adhaerens FE Schulze. Cytobiologie 4, 216-240.

Grell, K., and Benwitz, G. (1974). Spezifische Verbindungsstrukturen der Faserzellen von Trichoplax adhaerens FE Schulze. Z. Naturforsch. 29:790.

Guéguinou, M., Chantôme, A., Fromont, G., Bougnoux, P., Vandier, C., and PotierCartereau, M. (2014). $\mathrm{K}_{\mathrm{Ca}}$ and $\mathrm{Ca}^{2+}$ channels: the complex thought. Biochim. Biophys. Acta 1843, 2322-2333. doi: 10.1016/j.bbamcr.2014.02.019

Guzman, C., and Conaco, C. (2016). Comparative transcriptome analysis reveals insights into the streamlined genomes of haplosclerid demosponges. Sci. Rep. 6, 1-10. doi: 10.1038/srep18774

Haddock, S. H. (2007). Comparative feeding behavior of planktonic ctenophores. Integr. Comp. Biol. 47, 847-853. doi: 10.1093/icb/icm088

Hagiwara, S., Ozawa, S., and Sand, O. (1975). Voltage clamp analysis of two inward current mechanisms in the egg cell membrane of a starfish. J. Gen. Physiol. 65, 617-644. doi: 10.1085/jgp.65.5.617

Halanych, K. M. (2015). The ctenophore lineage is older than sponges? That cannot be right! Or can it? J. Exp. Biol. 218, 592-597. doi: 10.1242/jeb.111872

Han, Y., Kaeser, P. S., Südhof, T. C., and Schneggenburger, R. (2011). RIM determines $\mathrm{Ca}^{2+}$ channel density and vesicle docking at the presynaptic active zone. Neuron 69, 304-316. doi: 10.1016/j.neuron.2010.12.014

Harz, H., and Hegemann, P. (1991). Rhodopsin-regulated calcium currents in Chlamydomonas. Nature 351, 489-491. doi: 10.1038/351489a0

Hayashi, M., Yanagisawa, H. A., Hirono, M., and Kamiya, R. (2002). Rescue of a Chlamydomonas inner-arm-dynein-deficient mutant by electroporationmediated delivery of recombinant p28 light chain. Cell Motil. Cytoskeleton 53, 273-280. doi: 10.1002/cm.10075

Hernandez-Nicaise, M.-L. (1973a). The nervous system of ctenophores III. Ultrastructure of synapses. J. Neurocytol. 2, 249-263. doi: 10.1007/BF01104029

Hernandez-Nicaise, M.-L (1973b). The nervous system of ctenophores. I. Structure and ultrastructure of the epithelial nerve-nets. Z. Zellforsch. Mikrosk. Anat. 137, 223.

Hernandez-Nicaise, M.-L. (1991). Ctenophora. Microsc. Anat. Invertebrates 2, 359-418.
Hernandez-Nicaise, M.-L., and Amsellem, J. (1980). Ultrastructure of the giant smooth muscle fiber of the ctenophore Beroe ovata. J. Ultrastruct. Res. 72, 151-168. doi: 10.1016/S0022-5320(80)90053-2

Hernandez-Nicaise, M.-L., Bilbaut, A., Malaval, L., and Nicaise, G. (1982). Isolation of functional giant smooth muscle cells from an invertebrate: structural features of relaxed and contracted fibers. Proc. Natl. Acad. Sci.U.S.A. 79, 1884-1888. doi: 10.1073/pnas.79.6.1884

Hernandez-Nicaise, M.-L., Mackie, G., and Meech, R. (1980). Giant smooth muscle cells of Beroë. Ultrastructure, innervation, and electrical properties. J. Gen. Physiol. 75, 79-105. doi: 10.1085/jgp.75.1.79

Hernandez-Nicaise, M.-L., Nicaise, G., and Malaval, L. (1984). Giant smooth muscle fibers of the ctenophore Mnemiopsis leydii: ultrastructural study of in situ and isolated cells. Biol. Bull. 167, 210-228. doi: 10.2307/1541349

Hertwig, O., and Hertwig, R. (1879). Die Actinien: Anatomisch und Histologisch, Mit Besanderer Berücksichtigung des Nervenmuskelsystems. Jena: G. Fischer.

Heuser, J. E., and Reese, T. S. (1973). Evidence for recycling of synaptic vesicle membrane during transmitter release at the frog neuromuscular junction. $J$. Cell Biol. 57, 315-344. doi: 10.1083/jcb.57.2.315

Heuser, J. E., and Reese, T. S. (1977). "Structure of the synapse," in Handbook of Physiology - Section 1. The Nervous System, Vol. 1, Cellular Biology of Neurons, eds J. M. Brookhart and V. B. Mountcastle (Bethesday, MD: American Physiological Society), 261-294.

Heyland, A., Croll, R., Goodall, S., Kranyak, J., and Wyeth, R. (2014). Trichoplax adhaerens, an Enigmatic Basal Metazoan with potential. Methods Mol. Biol. 1128, 45-61. doi: 10.1007/978-1-62703-974-1_4

Holtmann, M., and Thurm, U. (2001a). Mono-and oligo-vesicular synapses and their connectivity in a Cnidarian sensory epithelium (Coryne tubulosa). J. Comp. Neurol. 432, 537-549. doi: 10.1002/cne.1118

Holtmann, M., and Thurm, U. (2001b). Variations of concentric hair cells in a cnidarian sensory epithelium (Coryne tubulosa). J. Comp. Neurol. 432, 550-563. doi: 10.1002/cne.1119

Hoppa, M. B., Lana, B., Margas, W., Dolphin, A. C., and Ryan, T. A. (2012). $\alpha_{2} \delta$ expression sets presynaptic calcium channel abundance and release probability. Nature 486, 122-125. doi: 10.1038/nature11033

Horridge, G. (1971). "Primitive examples of gravity receptors and their evolution," in Gravity and the Organism, eds S. A. Gordon and M. J. Cohen (Chicago, IL; London: The University of Chicago Press), 203-222.

Horridge, G. A., and Mackay, B. (1964). Neurociliary synapses in Pleurobrachia (Ctenophora). J. Cell Sci. 105, 163-174.

Ikeda, S. R. (2001). Calcium channels-link locally, act globally. Science 294, 318-319. doi: 10.1126/science. 1066160

Ingham, P. W., Nakano, Y., and Seger, C. (2011). Mechanisms and functions of Hedgehog signalling across the metazoa. Nat. Rev. Genet. 12, 393-406. doi: $10.1038 / \mathrm{nrg} 2984$

Jager, M., Chiori, R., Alié, A., Dayraud, C., Quéinnec, E., and Manuel, M. (2011). New insights on ctenophore neural anatomy: immunofluorescence study in Pleurobrachia pileus (Müller, 1776). J. Exp. Zool. B: Mol. Dev. Evol. 316, 171-187. doi: 10.1002/jez.b.21386

Jahn, R., and Fasshauer, D. (2012). Molecular machines governing exocytosis of synaptic vesicles. Nature 490, 201-207. doi: 10.1038/nature11320

Jegla, T. J., Zmasek, C. M., Batalov, S., and Nayak, S. K. (2009). Evolution of the human ion channel set. Comb. Chem. High Throughput Screen. 12, 2-23. doi: $10.2174 / 138620709787047957$

Jékely, G., Paps, J., and Nielsen, C. (2015). The phylogenetic position of ctenophores and the origin(s) of nervous systems. EvoDevo 6:1. doi: 10.1186/2041-9139-6-1

Jeziorski, M. C., Greenberg, R. M., and Anderson, P. A. (2000). The molecular biology of invertebrate voltage-gated $\mathrm{Ca}^{2+}$ channels. J. Exp. Biol. 203, 841-856.

Jeziorski, M. C., Greenberg, R. M., Clark, K. S., and Anderson, P. A. V. (1998). Cloning and functional expression of a voltage-gated calcium channel $\alpha 1$ subunit from jellyfish. J. Biol. Chem. 273, 22792-22799. doi: 10.1074/jbc.273.35.22792

Jospin, M., Jacquemond, V., Mariol, M.-C., Ségalat, L., and Allard, B. (2002). The L-type voltage-dependent $\mathrm{Ca}^{2+}$ channel EGL-19 controls body wall muscle function in Caenorhabditis elegans. J. Cell Biol. 159, 337-348. doi: $10.1083 /$ jcb. 200203055 
Kadurin, I., Alvarez-Laviada, A., Ng, S. F. J., Walker-Gray, R., D’arco, M., Fadel, M. G., et al. (2012). Calcium currents are enhanced by $\alpha_{2} \delta-1$ lacking its membrane anchor. J. Biol. Chem. 287, 33554-33566. doi: 10.1074/jbc.M112.378554

Kaeser, P. S., Deng, L., Wang, Y., Dulubova, I., Liu, X., Rizo, J., et al. (2011). RIM proteins tether $\mathrm{Ca}^{2+}$ channels to presynaptic active zones via a direct PDZ-domain interaction. Cell 144, 282-295. doi: 10.1016/j.cell.2010.12.029

Katsuki, T., and Greenspan, R. J. (2013). Jellyfish nervous systems. Curr. Biol. 23, R592-R594. doi: 10.1016/j.cub.2013.03.057

Kent, W. S. (1880). A Manual of the Infusoria: Including a Description of All Known Flagellate, Ciliate, and Tentaculiferous Protozoa, British and foreign, and an Account of the Organization and the Affinities of the Sponges. London: D. Bogue.

Keough, E. M., and Summers, R. G. (1976). An ultrastructural investigation of the striated subumbrellar musculature of the anthomedusan, Pennaria tiarella. J. Morphol. 149, 507-525. doi: 10.1002/jmor.1051490405

Kerfoot, P., Mackie, G., Meech, R., Roberts, A., and Singla, C. (1985). Neuromuscular transmission in the jellyfish Aglantha digitale. J. Exp. Biol. $116,1-25$.

Khanna, R., Li, Q., Sun, L., Collins, T., and Stanley, E. F. (2006). N type $\mathrm{Ca}^{2+}$ channels and RIM scaffold protein covary at the presynaptic transmitter release face but are components of independent protein complexes. Neuroscience 140, 1201-1208. doi: 10.1016/j.neuroscience.2006.04.053

King, N. (2004). The unicellular ancestry of animal development. Dev. Cell 7, 313-325. doi: 10.1016/j.devcel.2004.08.010

King, N., Westbrook, M. J., Young, S. L., Kuo, A., Abedin, M., Chapman, J., et al. (2008). The genome of the choanoflagellate Monosiga brevicollis and the origin of metazoans. Nature 451, 783-788. doi: 10.1038/nature06617

Kiyonaka, S., Wakamori, M., Miki, T., Uriu, Y., Nonaka, M., Bito, H., et al. (2007). RIM1 confers sustained activity and neurotransmitter vesicle anchoring to presynaptic $\mathrm{Ca}^{2+}$ channels. Nat. Neurosci. 10, 691-701. doi: 10.1038/nn1904

Kreps, T., Purcell, J., and Heidelberg, K. (1997). Escape of the ctenophore Mnemiopsis leidyi from the scyphomedusa predator Chrysaora quinquecirrha. Mar. Biol. 128, 441-446. doi: 10.1007/s002270050110

Kung, C., and Naitoh, Y. (1973). Calcium-induced ciliary reversal in the extracted models of "pawn," a behavioral mutant of paramecium. Science 179, 195-196. doi: 10.1126/science.179.4069.195

Lanner, J. T., Georgiou, D. K., Joshi, A. D., and Hamilton, S. L. (2010). Ryanodine receptors: structure, expression, molecular details, and function in calcium release. Cold Spring Harb. Perspect. Biol. 2:a003996. doi: 10.1101/cshperspect.a003996

Larson, R. J. (1988). Feeding and functional morphology of the lobate ctenophore Mnemiopsis mccradyi. Estuar. Coast. Shelf Sci. 27, 495-502. doi: 10.1016/02727714(88)90080-7

Lawn, I. D., Mackie, G. O., and Silver, G. (1981). Conduction system in a sponge. Science 211, 1169-1171. doi: 10.1126/science.7466387

Leadbeater, B., and Kelly, M. (2001). Evolution of animals-choanoflagellates and sponges. Water Atmosphere 9, 9-11.

Leuckart, R. (1848). Ueber die Morphologie Und Die Verwandtschaftsverhältnisse Der Wirbellosen Thiere: ein Beitrag zur Charakteristik und Classification der Thierischen Formen. Braunschweig: Druck und Verlag von Friedrich Vieweg und Sohn.

Leys, S. P. (2015). Elements of a 'nervous system' in sponges. J. Exp. Biol. 218, 581-591. doi: 10.1242/jeb.110817

Leys, S. P., Cronin, T. W., Degnan, B. M., and Marshall, J. N. (2002). Spectral sensitivity in a sponge larva. J. Comp. Physiol. A 188, 199-202. doi: 10.1007/s00359-002-0293-y

Leys, S. P., and Degnan, B. M. (2001). Cytological basis of photoresponsive behavior in a sponge larva. Biol. Bull. 201, 323-338. doi: 10.2307/1543611

Leys, S. P., and Mackie, G. O. (1997). Electrical recording from a glass sponge. Nature 387, 29-30. doi: 10.1038/387029b0

Leys, S. P., Mackie, G. O., and Meech, R. W. (1999). Impulse conduction in a sponge. J. Exp. Biol. 202, 1139-1150.

Leys, S. P., and Meech, R. W. (2006). Physiology of coordination in sponges. Can. J. Zool. 84, 288-306. doi: 10.1139/z05-171

Liebeskind, B. J., Hillis, D. M., and Zakon, H. H. (2011). Evolution of sodium channels predates the origin of nervous systems in animals. Proc. Natl. Acad. Sci.U.S.A. 108, 9154-9159. doi: 10.1073/pnas. 1106363108
Liebeskind, B. J., Hillis, D. M., and Zakon, H. H. (2015). Convergence of ion channel genome content in early animal evolution. Proc. Natl. Acad. Sci.U.S.A. 112, E846-E851. doi: 10.1073/pnas.1501195112

Lorenz, B., Bohnensack, R., Gamulin, V., Steffen, R., and Müller, W. E. (1996). Regulation of motility of cells from marine sponges by calcium ions. Cell. Signal. 8, 517-524. doi: 10.1016/S0898-6568(96)00108-8

Lory, P., Bidaud, I., and Chemin, J. (2006). T-type calcium channels in differentiation and proliferation. Cell Calcium 40, 135-146. doi: 10.1016/j.ceca.2006.04.017

Lowe, B. (1997). The role of $\mathrm{Ca}^{2+}$ in deflection-induced excitation of motile, mechanoresponsive balancer cilia in the ctenophore statocyst. J. Exp. Biol. 200, 1593-1606.

Lu, J., Dalton, J. F., Stokes, D. R., and Calabrese, R. L. (1997). Functional role of $\mathrm{Ca}^{2+}$ currents in graded and spike-mediated synaptic transmission between leech heart interneurons. J. Neurophysiol. 77, 1779-1794.

Mackie, G. (1979). Is there a conduction system in sponges. Biol. Spongiaires Ed. 291, 145-152.

Mackie, G. (1980). Slow swimming and cyclical "fishing" behavior in Aglantha digitale (Hydromedusae: Trachylina). Can. J. Fish. Aquat. Sci. 37, 1550-1556. doi: 10.1139/f80-200

Mackie, G. O. (1981). Plugged syncytial interconnections in hexactinellid sponges. J. Cell Biol. 91:103a.

Mackie, G. O., and Meech, R. W. (1985). Separate sodium and calcium spikes in the same axon. Nature 313, 791-793. doi: 10.1038/313791a0

Mackie, G., Lawn, I., and De Ceccatty, M. P. (1983). Studies on hexactinellid sponges. II. Excitability, conduction and coordination of responses in Rhabdocalyptus dawsoni (Lambe, 1873). Philos. Trans. R. Soc. Lond. B Biol. Sci. 301, 401-418. doi: 10.1098/rstb.1983.0029

Mackie, G., Mills, C., and Singla, C. (1988). Structure and function of the prehensile tentilla of Euplokamis (Ctenophora, Cydippida). Zoomorphology 107, 319-337. doi: 10.1007/BF00312216

Mackie, G., Mills, C., and Singla, C. (1992). Giant axons and escape swimming in Euplokamis dunlapae (Ctenophora: Cydippida). Biol. Bull. 182, 248-256. doi: $10.2307 / 1542118$

MacKinnon, R. (1995). Pore loops: an emerging theme in ion channel structure. Neuron 14, 889-892. doi: 10.1016/0896-6273(95)90327-5

Maldonado, M., and Bergquist, P. R. (2002). "Phylum Porifera," in Atlas of Marine Invertebrate Larvae, ed C. M. Young (London: Academic Press), 21-50.

Marlow, H., and Arendt, D. (2014). Evolution: Ctenophore Genomes and the Origin of Neurons. Curr. Biol. 24, R757-R761. doi: 10.1016/j.cub.2014. 06.057

Marlow, H. Q., Srivastava, M., Matus, D. Q., Rokhsar, D., and Martindale, M. Q. (2009). Anatomy and development of the nervous system of Nematostella vectensis, an anthozoan cnidarian. Dev. Neurobiol. 69, 235-254. doi: 10.1002/dneu.20698

Marshall, A. (1996). Calcification in hermatypic and ahermatypic corals. Science 271, 637. doi: $10.1126 /$ science.271.5249.637

Martindale, M. Q. (2005). The evolution of metazoan axial properties. Nat. Rev. Genet. 6, 917-927. doi: 10.1038/nrg1725

Martindale, M. Q., Pang, K., and Finnerty, J. R. (2004). Investigating the origins of triploblasty: 'mesodermal' gene expression in a diploblastic animal, the sea anemone Nematostella vectensis (phylum, Cnidaria; class, Anthozoa). Development 131, 2463-2474. doi: 10.1242/dev.01119

Matsuda, A., Yoshimura, K., Sineshchekov, O. A., Hirono, M., and Kamiya, R. (1998). Isolation and characterization of novel Chlamydomonas mutants that display phototaxis but not photophobic response. Cell Motil. Cytoskeleton 41, 353-362.

Maximov, A., and Bezprozvanny, I. (2002). Synaptic targeting of N-type calcium channels in hippocampal neurons. J. Neurosci. 22, 6939-6952.

Meech, R. W. (2015). Electrogenesis in the lower Metazoa and implications for neuronal integration. J. Exp. Biol. 218, 537-550. doi: 10.1242/jeb.111955

Meech, R. W., and Mackie, G. O. (1993). Ionic currents in giant motor axons of the jellyfish, Aglantha digitale. J. Neurophysiol. 69, 884-893.

Mire, P., Nasse, J., and Venable-Thibodeaux, S. (2000). Gap junctional communication in the vibration-sensitive response of sea anemones. Hear. Res. 144, 109-123. doi: 10.1016/S0378-5955(00)00047-2 
Monteith, G. R., Davis, F. M., and Roberts-Thomson, S. J. (2012). Calcium channels and pumps in cancer: changes and consequences. J. Biol. Chem. 287, 31666-31673. doi: 10.1074/jbc.R112.343061

Moran, Y., Barzilai, M. G., Liebeskind, B. J., and Zakon, H. H. (2015). Evolution of voltage-gated ion channels at the emergence of Metazoa. J. Exp. Biol. 218, 515-525. doi: 10.1242/jeb.110270

Moran, Y., and Zakon, H. H. (2014). The evolution of the four subunits of voltagegated calcium channels: ancient roots, increasing complexity, and multiple losses. Genome Biol. Evol. 6, 2210-2217. doi: 10.1093/gbe/evu177

Moroz, L. L., and Kohn, A. B. (2015). Unbiased view of synaptic and neuronal gene complement in ctenophores: are there pan-neuronal and pan-synaptic genes across metazoa? Integr. Comp. Biol. 55, 1028-1049. doi: 10.1093/icb/icv104

Moroz, L. L., and Kohn, A. B. (2016). Independent origins of neurons and synapses: insights from ctenophores. Philos. Trans. R. Soc. Lond. B Biol. Sci. 371:20150041. doi: 10.1098/rstb.2015.0041

Moroz, L. L., Kocot, K. M., Citarella, M. R., Dosung, S., Norekian, T. P., Povolotskaya, I. S., et al. (2014). The ctenophore genome and the evolutionary origins of neural systems. Nature 510, 109-114. doi: 10.1038/nature13400

Moss, A. G., and Tamm, S. L. (1986). Electrophysiological control of ciliary motor responses in the ctenophore Pleurobrachia. J. Comp. Physiol. A 158, 311-330. doi: 10.1007/BF00603615

Moss, A. G., and Tamm, S. L. (1987). A calcium regenerative potential controlling ciliary reversal is propagated along the length of ctenophore comb plates. Proc. Natl. Acad. Sci.U.S.A. 84, 6476-6480. doi: 10.1073/pnas.84.18.6476

Moss, A. G., and Tamm, S. L. (1993). Patterns of electrical activity in comb plates of feeding Pleurobrachia (Ctenophora). Philos. Trans. R. Soc. Lond. B Biol. Sci. 339, 1-16. doi: 10.1098/rstb.1993.0001

Nagel, G., Szellas, T., Huhn, W., Kateriya, S., Adeishvili, N., Berthold, P., et al. (2003). Channelrhodopsin-2, a directly light-gated cation-selective membrane channel. Proc. Natl. Acad. Sci. U.S.A. 100, 13940-13945. doi: $10.1073 /$ pnas. 1936192100

Naitoh, Y. (1968). Ionic control of the reversal response of Cilia in Paramecium caudatum: a calcium hypothesis. J. Gen. Physiol. 51, 85-103. doi: 10.1085/jgp.51.1.85

Nickel, M. (2010). Evolutionary emergence of synaptic nervous systems: what can we learn from the non-synaptic, nerveless Porifera? Invertebrate Biol. 129, 1-16. doi: 10.1111/j.1744-7410.2010.00193.x

Nickel, M., Scheer, C., Hammel, J. U., Herzen, J., and Beckmann, F. (2011). The contractile sponge epithelium sensu lato-body contraction of the demosponge Tethya wilhelma is mediated by the pinacoderm. J. Exp. Biol. 214, 1692-1698. doi: $10.1242 / \mathrm{jeb} .049148$

Nikitin, M. (2015). Bioinformatic prediction of Trichoplax adhaerens regulatory peptides. Gen. Comp. Endocrinol. 212, 145-155. doi: 10.1016/j.ygcen.2014.03.049

Pantin, C. F. A. (1942). The excitation of nematocysts. J. Exp. Biol. 19, 294-310. doi: 10.1038/149109a0

Patel-King, R. S., Benashski, S. E., and King, S. M. (2002). A bipartite $\mathrm{Ca}^{2+}$ regulated nucleoside-diphosphate kinase system within the Chlamydomonas Flagellum. J. Biol. Chem. 277, 34271-34279. doi: 10.1074/jbc.M204137200

Perez-Reyes, E. (2003). Molecular physiology of low-voltage-activated Ttype calcium channels. Physiol. Rev. 83, 117-161. doi: 10.1152/physrev. 00018.2002

Perez-Reyes, E. (2010). Characterization of the gating brake in the I-II loop of Cav 3 T-type calcium channels. Channels 4, 453-458. doi: 10.4161/chan.4.6.12889

Peterson, B. Z., Demaria, C. D., and Yue, D. T. (1999). Calmodulin is the $\mathrm{Ca}^{2+}$ sensor for $\mathrm{Ca}^{2+}$-dependent inactivation of L-type calcium channels. Neuron 22, 549-558. doi: 10.1016/S0896-6273(00)80709-6

Pisani, D., Pett, W., Dohrmann, M., Feuda, R., Rota-Stabelli, O., Philippe, H., et al. (2015). Genomic data do not support comb jellies as the sister group to all other animals. Proc. Natl. Acad. Sci. U.S.A. 112, 15402-15407. doi: $10.1073 /$ pnas. 1518127112

Pozdnyakov, I., and Skarlato, S. (2015). Analysis of the dinoflagellate Prorocentrum minimum transcriptome: identifying the members of the voltage-gated cation channel superfamily. Cell Tissue Biol. 9, 483-492. doi: 10.1134/S1990519X15060085

Price, R. B., and Anderson, P. A. (2006). Chemosensory pathways in the capitate tentacles of the hydroid Cladonema. Invertebrate Neurosci. 6, 23-32. doi: 10.1007/s10158-005-0015-6
Prosser, C. L. (1967). Ionic analyses and effects of ions on contractions of sponge tissues. Z. Vergleich. Physiol. 54, 109-120. doi: 10.1007/BF00298024

Przysiezniak, J., and Spencer, A. N. (1992). Voltage-activated calcium currents in identified neurons from a hydrozoan jellyfish, Polyorchis penicillatus. J. Neurosci. 12, 2065-2078.

Putnam, N. H., Srivastava, M., Hellsten, U., Dirks, B., Chapman, J., Salamov, A., et al. (2007). Sea anemone genome reveals ancestral eumetazoan gene repertoire and genomic organization. Science 317, 86-94. doi: 10.1126/science. 1139158

Qi, H., Moran, M. M., Navarro, B., Chong, J. A., Krapivinsky, G., Krapivinsky, L., et al. (2007). All four CatSper ion channel proteins are required for male fertility and sperm cell hyperactivated motility. Proc. Natl. Acad. Sci. U.S.A. 104, 1219-1223. doi: 10.1073/pnas.0610286104

Quarmby, L. (2009). Ciliary ion channels: location, location, location. Curr. Biol. 19, R158-R160. doi: 10.1016/j.cub.2008.12.038

Rassat, J., and Ruthmann, A. (1979). Trichoplax adhaerens FE Schulze (Placozoa) in the scanning electron microscope. Zoomorphology 93, 59-72. doi: 10.1007/BF02568675

Ren, D., Xu, H., Eberl, D. F., Chopra, M., and Hall, L. M. (1998). A mutation affecting dihydropyridine-sensitive current levels and activation kinetics in Drosophila muscle and mammalian heart calcium channels. J. Neurosci. 18, 2335-2341.

Rettig, J., Sheng, Z.-H., Kim, D. K., Hodson, C. D., Snutch, T. P., and Catterall, W. A. (1996). Isoform-specific interaction of the alpha1A subunits of brain $\mathrm{Ca}^{2+}$ channels with the presynaptic proteins syntaxin and SNAP-25. Proc. Natl. Acad. Sci.U.S.A. 93, 7363-7368. doi: 10.1073/pnas.93.14.7363

Reuter, H. (1979). Properties of two inward membrane currents in the heart. Annu. Rev. Physiol. 41, 413-424. doi: 10.1146/annurev.ph.41.030179.002213

Riesgo, A., Farrar, N., Windsor, P. J., Giribet, G., and Leys, S. P. (2014). The analysis of eight transcriptomes from all poriferan classes reveals surprising genetic complexity in sponges. Mol. Biol. Evol. 31:msu057. doi: 10.1093/molbev/msu057

Rivera, A. S., Ozturk, N., Fahey, B., Plachetzki, D. C., Degnan, B. M., Sancar, A., et al. (2012). Blue-light-receptive cryptochrome is expressed in a sponge eye lacking neurons and opsin. J. Exp. Biol. 215, 1278-1286. doi: $10.1242 /$ jeb.067140

Roberts, A., and Mackie, G. (1980). The giant axon escape system of a hydrozoan medusa, Aglantha digitale. J. Exp. Biol. 84, 303-318.

Roberts, A., and Pachter, L. (2013). Streaming fragment assignment for realtime analysis of sequencing experiments. Nat. Methods 10, 71-73. doi: 10.1038/nmeth.2251

Ryan, J. F., and Chiodin, M. (2015). Where is my mind? How sponges and placozoans may have lost neural cell types. Philos. Trans. R. Soc. Lond. B Biol. Sci. 370:20150059. doi: 10.1098/rstb.2015.0059

Ryan, J. F., Pang, K., Mullikin, J. C., Martindale, M. Q., and Baxevanis, A. D. (2010). The homeodomain complement of the ctenophore Mnemiopsis leidyi suggests that Ctenophora and Porifera diverged prior to the ParaHoxozoa. EvoDevo 1:9. doi: 10.1186/2041-9139-1-9

Ryan, J. F., Pang, K., Schnitzler, C. E., Nguyen, A.-D., Moreland, R. T., Simmons, D. K., et al. (2013). The genome of the ctenophore Mnemiopsis leidyi and Its implications for cell type evolution. Science 342:1242592. doi: 10.1126/science. 1242592

Ryan, T. J., and Grant, S. G. N. (2009). The origin and evolution of synapses. Nat. Rev. Neurosci. 10, 701-712. doi: 10.1038/nrn2717

Sakarya, O., Armstrong, K. A., Adamska, M., Adamski, M., Wang, I.-F., Tidor, B., et al. (2007). A post-synaptic scaffold at the origin of the animal kingdom. PLoS ONE 2:e506. doi: 10.1371/journal.pone.0000506

Sakarya, O., Conaco, C., Eğecioğlu, Ö., Solla, S. A., Oakley, T. H., and Kosik, K. S. (2010). Evolutionary expansion and specialization of the PDZ domains. Mol. Biol. Evol. 27, 1058-1069. doi: 10.1093/molbev/msp311

Sanderson, M. J., Delmotte, P., Bai, Y., and Perez-Zogbhi, J. F. (2008). Regulation of airway smooth muscle cell contractility by $\mathrm{Ca}^{2+}$ signaling and sensitivity. Proc. Am. Thorac. Soc. 5, 23-31. doi: 10.1513/pats.200704-050VS

Satir, P., and Christensen, S. T. (2007). Overview of structure and function of mammalian cilia. Annu. Rev. Physiol. 69, 377-400. doi: 10.1146/annurev.physiol.69.040705.141236

Satterlie, R. A. (2011). Do jellyfish have central nervous systems? J. Exp. Biol. 214, 1215-1223. doi: $10.1242 / \mathrm{jeb} .043687$ 
Schierwater, B. (2005). My favorite animal, Trichoplax adhaerens. BioEssays 27, 1294-1302. doi: 10.1002/bies.20320

Schierwater, B., Eitel, M., Jakob, W., Osigus, H.-J., Hadrys, H., Dellaporta, S. L., et al. (2009). Concatenated analysis sheds light on early metazoan evolution and fuels a modern "urmetazoon" hypothesis. PLoS Biol. 7:e1000020. doi: 10.1371/journal.pbio. 1000020

Schuchert, P. (1993). Trichoplax adhaerens (Phylum Placozoa) has cells that react with antibodies against the neuropeptide RFamide. Acta Zool. 74, 115-117. doi: 10.1111/j.1463-6395.1993.tb01227.x

Schulze, F. E. (1883). Trichoplax adhaerens, nov. gen., nov. spec. Zool. Anz. 6, 92.

Schulze, F. E. (1892). Über "Trichoplax adhaerens," von Hrn Franz Eilhard Schulze. Berlin: G. Reimer.

Senatore, A., Guan, W., Boone, A. N., and Spafford, J. D. (2014). T-type channels become highly permeable to sodium ions using an alternative extracellular turret region (S5-P) outside the selectivity filter. J. Biol. Chem. 289, 11952-11969. doi: 10.1074/jbc.M114.551473

Senatore, A., Zhorov, B. S., and Spafford, J. D. (2012). Ca 3 T-type calcium channels. Wiley Interdiscipl. Rev. Membr. Transp. Signal. 1, 467-491. doi: $10.1002 /$ wmts.41

Sheng, Z.-H., Rettig, J., Takahashi, M., and Catterall, W. A. (1994). Identification of a syntaxin-binding site on N-type calcium channels. Neuron 13, 1303-1313. doi: 10.1016/0896-6273(94)90417-0

Shinzato, C., Shoguchi, E., Kawashima, T., Hamada, M., Hisata, K., Tanaka, M., et al. (2011). Using the Acropora digitifera genome to understand coral responses to environmental change. Nature 476, 320-323. doi: 10.1038/nature10249

Simms, B. A., and Zamponi, G. W. (2014). Neuronal voltage-gated calcium channels: structure, function, and dysfunction. Neuron 82, 24-45. doi: 10.1016/j.neuron.2014.03.016

Simpson, T. L. (2012). The Cell Biology of Sponges. Berlin: Springer Science \& Business Media.

Singla, C. (1978). Fine structure of the neuromuscular system of Polyorchis penicillatus (Hydromedusae, Cnidaria). Cell Tissue Res. 193, 163-174. doi: $10.1007 / \mathrm{BF} 00221609$

Singla, V., and Reiter, J. F. (2006). The primary cilium as the cell's antenna: signaling at a sensory organelle. Science 313, 629-633. doi: $10.1126 /$ science. 1124534

Skaer, R. (1973). The secretion and development of nematocysts in a siphonophore. J. Cell Sci. 13, 371-393.

Sleigh, M. A. (1974). Metachronism of cilia of metazoa. Cilia Flagella 11, 287-304.

Smith, C. L., Pivovarova, N., and Reese, T. S. (2015). Coordinated feeding behavior in Trichoplax, an animal without synapses. PLoS ONE 10:e0136098. doi: 10.1371/journal.pone.0136098

Smith, C. L., Varoqueaux, F., Kittelmann, M., Azzam, R. N., Cooper, B., Winters, C. A., et al. (2014). Novel cell types, neurosecretory cells, and body plan of the early-diverging metazoan Trichoplax adhaerens. Curr. Biol. 24, 1565-1572. doi: 10.1016/j.cub.2014.05.046

Somlyo, A. P., and Somlyo, A. V. (2003). $\mathrm{Ca}^{2+}$ sensitivity of smooth muscle and nonmuscle myosin II: modulated by G proteins, kinases, and myosin phosphatase. Physiol. Rev. 83, 1325-1358. doi: 10.1152/physrev.00023.2003

Spafford, J. D., Dunn, T., Smit, A. B., Syed, N. I., and Zamponi, G. W. (2006). In vitro characterization of L-type calcium channels and their contribution to firing behavior in invertebrate respiratory neurons. J. Neurophysiol. 95, 42-52. doi: $10.1152 /$ jn. 00658.2005

Spafford, J. D., Munno, D. W., Van Nierop, P., Feng, Z.-P., Jarvis, S. E., Gallin, W. J., et al. (2003). Calcium channel structural determinants of synaptic transmission between identified invertebrate neurons. J. Biol. Chem. 278, 4258-4267. doi: 10.1074/jbc.M211076200

Spafford, J., Grigoriev, N., and Spencer, A. (1996). Pharmacological properties of voltage-gated $\mathrm{Na}^{+}$currents in motor neurones from a hydrozoan jellyfish Polyorchis penicillatus. J. Exp. Biol. 199, 941-948.

Spencer, A. (1979). Neurobiology of Polyorchis. II. Structure of effector systems. J. Neurobiol. 10, 95-117. doi: 10.1002/neu.480100202

Spencer, A., and Satterlie, R. A. (1981). The action potential and contraction in subumbrellar swimming muscle of Polyorchis penicillatus (Hydromedusae). J. Comp. Physiol. A Neuroethol. Sens. Neural Behav. Physiol. 144, 401-407. doi: 10.1007/BF00612572
Spencer, A. N., Przysiezniak, J., Acosta-Urquidi, J., and Basarsky, T. A. (1989). Presynaptic spike broadening reduces junctional potential amplitude. Nature 340, 636-638. doi: 10.1038/340636a0

Srivastava, M., Begovic, E., Chapman, J., Putnam, N. H., Hellsten, U., Kawashima, T., et al. (2008). The Trichoplax genome and the nature of placozoans. Nature 454, 955-960. doi: 10.1038/nature07191

Srivastava, M., Simakov, O., Chapman, J., Fahey, B., Gauthier, M. E. A., Mitros, T., et al. (2010). The Amphimedon queenslandica genome and the evolution of animal complexity. Nature 466, 720-726. doi: 10.1038/nature09201

Stanley, E. F. (2016). The nanophysiology of fast transmitter release. Trends Neurosci. 39, 183-197. doi: 10.1016/j.tins.2016.01.005

Steinmetz, P. R., Kraus, J. E., Larroux, C., Hammel, J. U., Amon-Hassenzahl, A., Houliston, E., et al. (2012). Independent evolution of striated muscles in cnidarians and bilaterians. Nature 487, 231-234. doi: 10.1038/nature 11180

Stocker, M. (2004). $\mathrm{Ca}^{2+}$-activated $\mathrm{K}^{+}$channels: molecular determinants and function of the SK family. Nat. Rev. Neurosci. 5, 758-770. doi: 10.1038/nrn1516

Swanberg, N. (1974). The feeding behavior of Beroe ovata. Mar. Biol. 24, 69-76. doi: 10.1007/BF00402849

Syed, T., and Schierwater, B. (2002). The evolution of the Placozoa: a new morphological model. Senckenb. Lethaea 82, 315-324. doi: 10.1007/BF03043791

Taiakina, V., Boone, A. N., Fux, J., Senatore, A., Weber-Adrian, D., Guillemette, J. G., et al. (2013). The calmodulin-binding, short linear motif, NSCaTE is conserved in L-type channel ancestors of vertebrate $\mathrm{Ca}_{\mathrm{V}} 1.2$ and $\mathrm{Ca}_{\mathrm{V}} 1.3$ channels. PLoS ONE 8:e61765. doi: 10.1371/journal.pone.0061765

Tamm, S. (1980). Cilia and ctenophores. Oceanus 23, 50-59.

Tamm, S. (1982). "Ctenophora," in Electrical Conduction and Behaviour in Simple Invertebrates, ed G. A. B. Shelton (New York, NY: Clarendon Press; Oxford University Press), 266-358.

Tamm, S. (1994). $\mathrm{Ca}^{2+}$ channels and signalling in cilia and flagella. Trends Cell Biol. 4, 305-310. doi: 10.1016/0962-8924(94)90226-7

Tamm, S. L. (1983). Motility and mechanosensitivity of macrocilia in the ctenophore Beroë. Nature 305, 430-433. doi: 10.1038/305430a0

Tamm, S. L. (1988a). Calcium activation of macrocilia in the ctenophore Beroë. J. Comp. Physiol. A 163, 23-31. doi: 10.1007/BF00611993

Tamm, S. L. (1988b). Iontophoretic localization of Ca-sensitive sites controlling activation of ciliary beating in macrocilia of Beroë: the ciliary rete. Cell Motil. Cytoskeleton 11, 126-138. doi: 10.1002/cm.970110206

Tamm, S. L. (2014a). Cilia and the life of ctenophores. Invertebrate Biol. 133, 1-46. doi: $10.1111 /$ ivb. 12042

Tamm, S. L. (2014b). Formation of the statolith in the Ctenophore Mnemiopsis leidyi. Biol. Bull. 227, 7-18. doi: 10.1086/BBLv227n1p7

Tamm, S. L. (2015). Functional consequences of the asymmetric architecture of the ctenophore statocyst. Biol. Bull. 229, 173-184. doi: 10.1086/BBLv229n2p173

Tamm, S. L., and Moss, A. G. (1985). Unilateral ciliary reversal and motor responses during prey capture by the ctenophore Pleurobrachia. J. Exp. Biol. 114, 443-461.

Tamm, S. L., and Tamm, S. (1981). Ciliary reversal without rotation of axonemal structures in ctenophore comb plates. J. Cell Biol. 89, 495-509. doi: 10.1083/jcb.89.3.495

Tamm, S. L., and Tamm, S. (1985). Visualization of changes in ciliary tip configuration caused by sliding displacement of microtubules in macrocilia of the ctenophore Beroe. J. Cell Sci. 79, 161-179.

Tamm, S. L., and Tamm, S. (1988). Development of macrociliary cells in Beroe. II. Formation of macrocilia. J. Cell Sci. 89, 81-95.

Tamm, S. L., and Terasaki, M. (1994). Visualization of calcium transients controlling orientation of ciliary beat. J. Cell Biol. 125, 1127-1135. doi: 10.1083/jcb.125.5.1127

Tamm, S., and Tamm, S. L. (1989). Extracellular ciliary axonemes associated with the surface of smooth muscle cells of ctenophores. J. Cell Sci. 94, 713-724.

Tamm, S., and Tamm, S. L. (1995). A giant nerve net with multi-effector synapses underlying epithelial adhesive strips in the mouth of Beroë (Ctenophora). J. Neurocytol. 24, 711-723. doi: 10.1007/BF01179820

Tanabe, T., Beam, K. G., Adams, B. A., Niidome, T., and Numa, S. (1990). Regions of the skeletal muscle dihydropyridine receptor critical for excitationcontraction coupling. Nature 346, 567-569. doi: 10.1038/346567a0 
Tanabe, T., Mikami, A., Niidome, T., Numa, S., Adams, B. A., and Beam, K. G. (1993). Structure and function of voltage-dependent calcium channels from muscle. Ann. N Y. Acad. Sci. 707, 81-86. doi: 10.1111/j.17496632.1993.tb38044.x

Tanbutté, É., Allemand, D., Mueller, E., and Jaubert, J. (1996). A compartmental approach to the mechanism of calcification in hermatypic corals. J. Exp. Biol. 199, 1029-1041.

Taylor, J. T., Zeng, X.-B., Pottle, J. E., Lee, K., Wang, A. R., Yi, S. G., et al. (2008). Calcium signaling and T-type calcium channels in cancer cell cycling. World J. Gastroenterol. 14, 4984-4991. doi: 10.3748/wjg.14.4984

Thurm, U., Brinkmann, M., Golz, R., Holtmann, M., Oliver, D., and Sieger, T. (2004). Mechanoreception and synaptic transmission of hydrozoan nematocytes. Hydrobiologia 530, 97-105. doi: 10.1007/s10750-004-2679-z

Thurm, U., Brinkmann, M., Holtmann, M., Lawonn, P., Oliver, D., and Sieger, T. (1998). "Modulation of the output of a mechanosensory cell by chemosensory and synaptic inputs," in From Structure to Information in Sensory Systems, eds C. Taddei-Ferretti and C. Musio (Singapore: World Scientific Publishers), 237-253.

Tompkins-Macdonald, G. J., Gallin, W. J., Sakarya, O., Degnan, B., Leys, S. P., and Boland, L. M. (2009). Expression of a poriferan potassium channel: insights into the evolution of ion channels in metazoans. J. Exp. Biol. 212, 761-767. doi: 10.1242/jeb.026971

Tsien, R. (1983). Calcium channels in excitable cell membranes. Annu. Rev. Physiol. 45, 341-358. doi: 10.1146/annurev.ph.45.030183.002013

Ueda, T., Koya, S., and Maruyama, Y. K. (1999). Dynamic patterns in the locomotion and feeding behaviors by the placozoan Trichoplax adhaerens. Biosystems 54, 65-70. doi: 10.1016/S0303-2647(99)00066-0

Valentine, M. S., Rajendran, A., Yano, J., Weeraratne, S. D., Beisson, J., Cohen, J., et al. (2012). Paramecium BBS genes are key to presence of channels in Cilia. Cilia 1:16. doi: 10.1186/2046-2530-1-16

Vergara, C., Latorre, R., Marrion, N. V., and Adelman, J. P. (1998). Calciumactivated potassium channels. Curr. Opini. Neurobiol. 8, 321-329. doi: 10.1016/S0959-4388(98)80056-1

Walton, K. D., Croce, J. C., Glenn, T. D., Wu, S.-Y., and Mcclay, D. R. (2006). Genomics and expression profiles of the Hedgehog and Notch signaling pathways in sea urchin development. Dev. Biol. 300, 153-164. doi: 10.1016/j.ydbio.2006.08.064

Wargo, M. J., and Smith, E. F. (2003). Asymmetry of the central apparatus defines the location of active microtubule sliding in Chlamydomonas flagella. Proc. Natl. Acad. Sci. U.S.A. 100, 137-142. doi: 10.1073/pnas.0135800100

Weber, A. M., Wong, F. K., Tufford, A. R., Schlichter, L. C., Matveev, V., and Stanley, E. F. (2010). N-type $\mathrm{Ca}^{2+}$ channels carry the largest current: implications for nanodomains and transmitter release. Nat. Neurosci. 13, 1348-1350. doi: 10.1038/nn.2657

Weiss, N., and Zamponi, G. W. (2013). Control of low-threshold exocytosis by T-type calcium channels. Biochim. Biophys. Acta 1828, 1579-1586. doi: 10.1016/j.bbamem.2012.07.031

Weiss, N., Hameed, S., Fernández-Fernández, J. M., Fablet, K., Karmazinova, M., Poillot, C., et al. (2012). A Ca $3.2 /$ syntaxin-1A signaling complex controls T-type channel activity and low-threshold exocytosis. J. Biol. Chem. 287, 2810-2818. doi: 10.1074/jbc.M111.290882

Wells, G. D., Tang, Q.-Y., Heler, R., Tompkins-Macdonald, G. J., Pritchard, E. N., Leys, S. P., et al. (2012). A unique alkaline $\mathrm{pH}$-regulated and fatty acid-activated tandem pore domain potassium channel $\left(\mathrm{K}_{2 P}\right)$ from a marine sponge. J. Exp. Biol. 215, 2435-2444. doi: 10.1242/jeb.066233

Westfall, J. A. (2004). Neural pathways and innervation of cnidocytes in tentacles of sea anemones. Hydrobiologia 530, 117-121. doi: 10.1007/s10750-004-2678-0

Whelan, N. V., Kocot, K. M., Moroz, L. L., and Halanych, K. M. (2015). Error, signal, and the placement of Ctenophora sister to all other animals. Proc. Natl. Acad. Sci.U.S.A. 112, 5773-5778. doi: 10.1073/pnas.1503453112

Wong, F. K., and Stanley, E. F. (2010). Rab3a interacting molecule (RIM) and the tethering of pre-synaptic transmitter release site-associated Cav2. 2 calcium channels. J. Neurochem. 112, 463-473. doi: 10.1111/j.1471-4159.2009.06466.x

Wray, G. A. (2015). Molecular clocks and the early evolution of metazoan nervous systems. Philos. Trans. R. Soc. Lond. B Biol. Sci. 370:20150046. doi: 10.1098/rstb.2015.0046

Wu, J., Yan, Z., Li, Z., Qian, X., Lu, S., Dong, M., et al. (2016). Structure of the voltage-gated calcium channel $\mathrm{Ca}_{\mathrm{v}} 1.1$ at $3.6 \AA$ A resolution. Nature 537, 191-196. doi: 10.1038/nature19321

Wu, J., Yan, Z., Li, Z., Yan, C., Lu, S., Dong, M., et al. (2015). Structure of the voltage-gated calcium channel $\mathrm{Ca}_{\mathrm{v}} 1.1$ complex. Science 350:aad2395. doi: $10.1126 /$ science.aad2395

Yang, P., Diener, D. R., Rosenbaum, J. L., and Sale, W. S. (2001). Localization of calmodulin and dynein light chain LC8 in flagellar radial spokes. J. Cell Biol. 153, 1315-1326. doi: 10.1083/jcb.153.6.1315

Yarom, Y., Sugimori, M., and Llinás, R. (1985). Ionic currents and firing patterns of mammalian vagal motoneurons in vitro. Neuroscience 16, 719-737. doi: 10.1016/0306-4522(85)90090-9

Yasuda, T., Chen, L., Barr, W., Mcrory, J. E., Lewis, R. J., Adams, D. J., et al. (2004). Auxiliary subunit regulation of high-voltage activated calcium channels expressed in mammalian cells. Eur. J. Neurosci. 20, 1-13. doi: 10.1111/j.14609568.2004.03434.x

Yu, F. H., and Catterall, W. A. (2004). The VGL-chanome: a protein superfamily specialized for electrical signaling and ionic homeostasis. Sci. Signal. 2004:re15. doi: 10.1126/stke.2532004re15

Zhang, T., Liu, Z., Song, W., Du, Y., and Dong, K. (2011). Molecular characterization and functional expression of the DSC1 channel. Insect Biochem. Mol. Biol. 41, 451-458. doi: 10.1016/j.ibmb.2011.04.010

Zhou, W., Chung, I., Liu, Z., Goldin, A. L., and Dong, K. (2004). A voltage-gated calcium-selective channel encoded by a sodium channel-like gene. Neuron 42, 101-112. doi: 10.1016/S0896-6273(04)00148-5

Zoccola, D., Tambutté, E., Sénégas-Balas, F., Michiels, J.-F., Failla, J.-P., Jaubert, J., et al. (1999). Cloning of a calcium channel $\alpha_{1}$ subunit from the reefbuilding coral, Stylophora pistillata. Gene 227, 157-167. doi: 10.1016/S03781119(98)00602-7

Conflict of Interest Statement: The authors declare that the research was conducted in the absence of any commercial or financial relationships that could be construed as a potential conflict of interest.

Copyright (C) 2016 Senatore, Raiss and Le. This is an open-access article distributed under the terms of the Creative Commons Attribution License (CC BY). The use, distribution or reproduction in other forums is permitted, provided the original author(s) or licensor are credited and that the original publication in this journal is cited, in accordance with accepted academic practice. No use, distribution or reproduction is permitted which does not comply with these terms. 